INDICADORES DE GESTIÓN DE LA LÍNEA DE ATENCIÓN AL CIUDADANO, CAMPAÑA SIC

DANIEL WOODCOCK GUERRERO

UNIVERSIDAD SANTO TOMÁS

FACULTAD DE INGENIERÍA ELECTRÓNICA

BOGOTÁ

2015 


\title{
INDICADORES DE GESTIÓN DE LA LÍNEA DE ATENCIÓN AL CIUDADANO, CAMPAÑA SIC
}

\section{DANIEL WOODCOCK GUERRERO}

Proyecto presentado para optar al título de Ingeniero Electrónico

\author{
Tutor
}

Jorge Alfredo López Jiménez

Jefe inmediato

Daniel Alejandro González Ángel

\section{UNIVERSIDAD SANTO TOMÁS}

FACULTAD DE INGENIERÍA ELECTRÓNICA

BOGOTÁ

2015 
Firma del estudiante

Firma del tutor

Firma del jefe inmediato

Bogotá, 9 de Febrero del 2015 


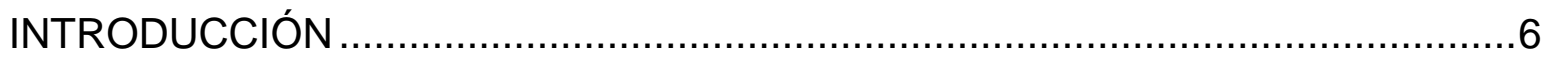

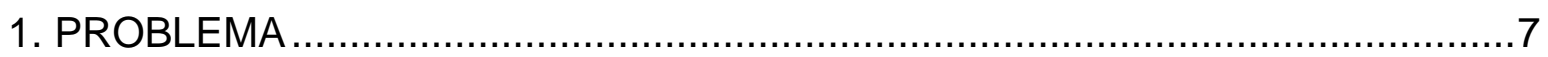

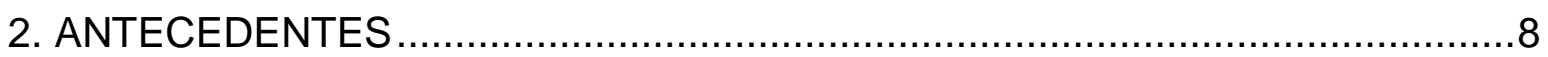

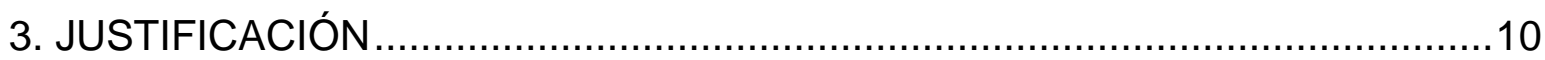

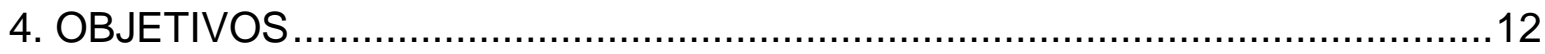

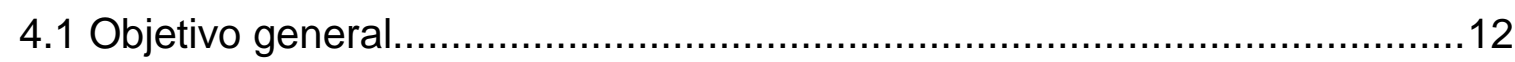

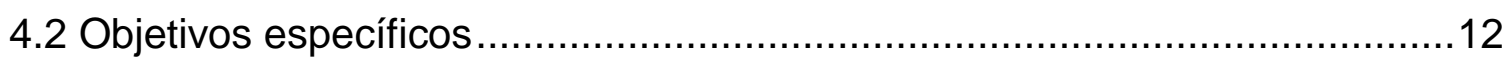

5. FACTIBILIDAD

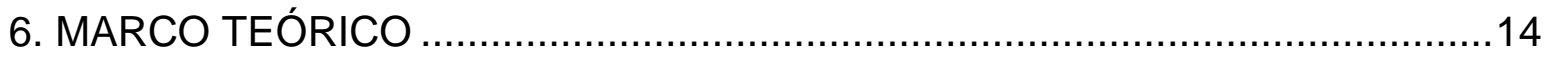

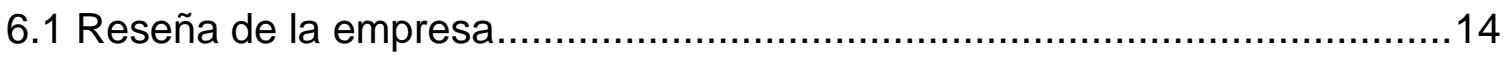

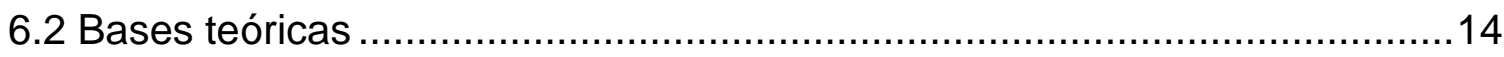

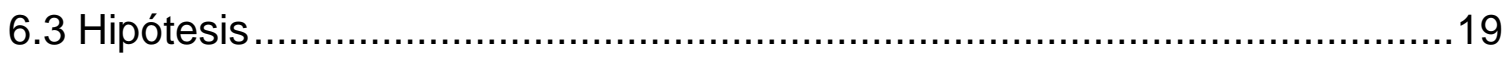

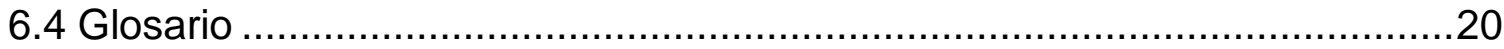

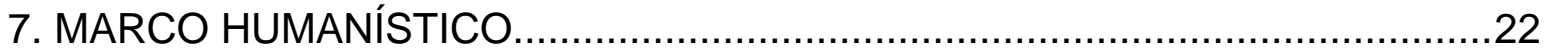

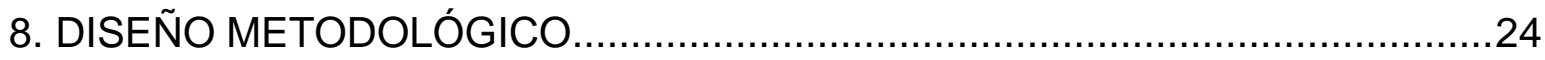

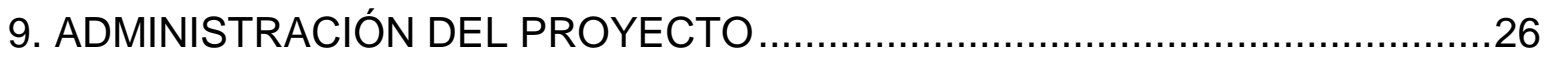

10. DISEÑO DEL APLICATIVO Y RESULTADOS OBTENIDOS..........................30 
11. CONCLUSIONES

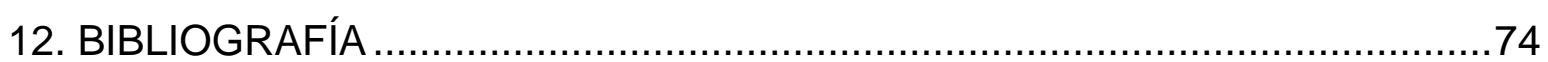

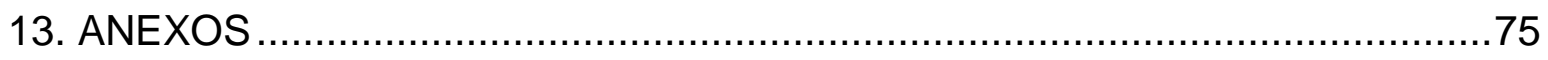




\section{INTRODUCCIÓN}

En el siguiente trabajo, se da a conocer cómo se realizó y diseñó el aplicativo web: "INDICADORES DE GESTIÓN DE LA LÍNEA DE ATENCIÓN AL CIUDADANO, CAMPAÑA SIC", el cual es el proyecto realizado durante la pasantía desempeñada en EMTELCO S. A. Para esto, inicialmente se identificó las situaciones susceptibles a mejorar en la empresa, en las cuales un ingeniero electrónico puede intervenir cómo factor de cambio para solucionar los inconvenientes presentados. Al realizar el análisis de las diferentes situaciones susceptibles a mejorar, se evidenció la problemática que se presentaba en la campaña SIC al dar a conocer los indicadores de gestión del estado de la línea.

Se presenta el aplicativo web como solución a la problemática, el cual permite un conocimiento oportuno, confiable y automático de los indicadores de gestión de la campaña SIC, al cual pueden acceder todos los agentes desde su puesto de trabajo sin necesidad que el supervisor interrumpa sus actividades para poder genéralos.

El diseño del aplicativo se realizó dando un adecuado uso a las diferentes tecnologías de la información, recursos tecnológicos y herramientas que la empresa posee, evitando costos adicionales durante la elaboración y entrada en operación del aplicativo. 


\section{PROBLEMA}

La Superintendencia de Industria y Comercio, tiene institucionalizada la línea de atención al ciudadano 5920400, 018000910165 y el sitio web http://www.atencionvirtual.com/website/sicchat/, operado por EMTELCO S.A, para lo cual ha establecido metas que debe cumplir la operación de la línea, EMTELCO, organiza a sus clientes utilizando la metodología de campañas, las cuales están controladas, por asesores de atención al ciudadano y el supervisor que se encargan de gestionar los requerimientos de los clientes.

Para medir y controlar el estado de la Campaña se utilizan los siguientes indicadores de gestión: Llamadas entrantes, llamadas atendidas, llamadas abandonadas, porcentaje de abandono, porcentaje de eficacia, Average Handling Time (AHT), Nivel De Servicio (NDS) y Average Speed of Answer (ASA). Los cuales no son dados a conocer de manera oportuna a los asesores de atención, generando una problemática de gestión, por la cual no se pueden tomar acciones de mejora en la calidad del servicio.

Los Indicadores de Gestión manejados en EMTELCO S.A., son procesados manualmente y no están exentos de error por la intervención del ser humano en su captura, creando así una problemática en el monitoreo y control que debe realizar el supervisor, quien no está disponible el cien por ciento de su tiempo para este tipo de operación en virtud de las demás actividades inherentes a su cargo. Para solucionar este problema, se hace necesario crear una herramienta informática, que permita automatizar la captura, procesamiento y generación de una base de datos, originada en la fuente ciudadana y requerida para la producción y publicación de los Indicadores de Gestión de la Campaña, que deben ser transparentes y socialmente responsables. 


\section{ANTECEDENTES}

Como se evidencia en los primeros meses la práctica laboral realizada en EMTELCO S.A., la metodología de campañas empleada por la empresa, requiere que los supervisores informen a los agentes de atención los indicadores de calidad de servicio con una frecuencia de 2 veces por hora. Debido a las circunstancias operativas, el supervisor puede o no tardar más tiempo en informar los indicadores de calidad. Este retraso en la comunicación de estos indicadores no les permite a los agentes contar con el estado actual de las líneas de la campaña.

Según lo comentado por el supervisor actual de la campaña ${ }^{1}$, en los primeros días de implementación de la campaña SIC, el supervisor daba a conocer el estado actual de la línea voceando la información a los agentes, lo cual generaba inconvenientes en las llamadas que estaban atendiendo los agentes en ese momento, ya que en muchas ocasiones, se veía interrumpida la llamada por el aviso; dado esto, el supervisor decidió informar los indicadores de gestión a los agentes, escribiéndolos en una hoja de papel y que estos vayan de puesto en puesto para que cada asesor se entere del estado de la línea; esto generó un alto gasto de papel, ya que, se pasaba el reporte cada hora y la operación de la campaña es de 8 horas al día, por lo cual, diariamente se gastaban varias hojas de papel y con el paso del tiempo, dado que es una tarea que acarrea bastante tiempo, se dejó de realizar.

Posteriormente se procedió, y es la forma actual cómo se muestran los indicadores, a la adquisición de un tablero y marcadores; por lo cual el supervisor debe, si sus actividades lo permiten: generar el reporte de los indicadores de gestión, borrar los anteriores y escribir los nuevos en el tablero e informar a los agentes que el tablero se encuentra actualizado.

\footnotetext{
${ }^{1}$ Cristian Rojas Torres Bernal, actual supervisor de la campaña SIC
} 
Las aplicaciones Web para Internet e Intranet presentan una serie de ventajas y beneficios competitivos mucho más amplios con respecto al software de escritorio, la utilización de la web logra aprovechar y acoplar los recursos de una empresa en forma más práctica que el software tradicional, un ejemplo destacable en la utilización de sitios web es la enciclopedia británica donde los usuarios pueden consultar en línea contenidos elaborados por equipos de expertos².

Por lo cual un aplicativo web, dado los recursos tecnológicos que posee la empresa, sirve para dar a conocer los indicadores de gestión de la campaña, sin interrumpir la actividad del supervisor y evitar fallas en la atención al usuario, brindando información actual, sencilla y oportuna, utilizando la comunicación trasversal entre usuario, agente, supervisor y la SIC.

\footnotetext{
${ }^{2}$ PEÑA, Alejandro. Tecnologías de la información: Su alineamiento al negocio de las organizaciones [en línea]. Instituto Politecnico Nacional. [citado 12 feb,. 2015]. Disponible en Internet: <URL:

http://www.hacienda.go.cr/cifh/sidovih/spaw2/uploads/images/file/Tecnologias\%20de\%20la\%20informaci on.pdf>
} 


\section{JUSTIFICACIÓN}

En la evaluación de los resultados del primer año de ejecución del contrato con la SIC, "línea de atención al ciudadano", se detectó que la información de los indicadores de gestión no se realiza de forma oportuna y que los resultados son cuestionables en la medida que los datos procesados se hacen de forma manual y la evaluación de los resultados hay mucha interacción del factor humano, por esto, se ha planteado una acción de mejora que ayude a obtener un conocimiento oportuno y en tiempo real de los indicadores de operación que permita a los asesores de la campaña y al supervisor, tomar decisiones efectivas e inmediatas en el servicio de la línea, regulando el tránsito de la línea, incrementando el nivel de servicio y logrando el objetivo de la línea de atención al ciudadano.

El conocimiento oportuno y en tiempo real de los indicadores de operación, permite a los asesores de la campaña y al supervisor, tomar decisiones efectivas e inmediatas en el servicio de la línea, regulando el tránsito de la línea, incrementando el nivel de servicio y logrando el objetivo de la línea de atención al ciudadano.

Las formas implementadas en la campaña SIC para dar a conocer los indicadores de gestión, no brindan una solución definitiva a la necesidad de comunicar a los integrantes de la campaña esta información de manera oportuna, el supervisor genera los indicadores de gestión de manera periódica y transcritos en una hoja para circularlos en el grupo de agentes adscritos a la campaña SIC, o en ocasiones los escribe en un tablero. Significa esto cambio de actividades en su rutina diaria y adicionar tiempo a sus actividades para realizar esta tarea.

Para dar una solución definitiva e innovadora, se diseñó un aplicativo web, que ofrece información on line de la operatividad de la línea de atención al ciudadano campaña SIC, en el cual, con la utilización del aplicativo web, el supervisor 
obtendrá de manera automática, confiable y oportuna los indicadores de gestión y podrá tomar acciones y socializarlos en la organización de forma transversal. 


\section{OBJETIVOS}

\section{Objetivo general:}

Crear una herramienta de gestión para la recolección información que permita la toma de decisiones para el mejoramiento de los procesos monitoreados para la línea de atención al ciudadano de la Superintendencia de Industria y Comercio.

\subsection{Objetivos específicos:}

1. Diseñar un aplicativo web que interactúe con el software AVAYA CMS, capturando la información sobre el tráfico de la línea de atención al ciudadano de forma directa sin intervención de los asesores o el supervisor.

2. Generar los indicadores de operación de la campaña SIC de forma automática.

3. Socializar al supervisor y a los asesores los indicadores de gestión de la campaña en determinados intervalos de tiempo.

4. Potenciar el aplicativo web como una herramienta de gestión para la toma de decisiones. 


\section{FACTIBILIDAD}

La implementación del aplicativo web, contribuye a generar ahorro de tiempo y maximizar la efectividad de la operación del Contact Center, focalizando las actividades de atención y servicio al cliente, evitando las operaciones que en la actualidad se realizan de forma manual y así evitar los errores de apreciación y trasmisión que hoy quitan estabilidad al proceso cumpliendo así con la misión de EMTELCO S.A. y sus factores de éxito.

La elaboración y puesta en marcha del aplicativo es posible, en la medida en que se utilice software libre idóneo para evitar la generación de mayores costos al proyecto en el proceso de elaboración y operación, esta decisión ya fue consultada con gerencia de decisión ejecutiva y el área de seguridad informática de la empresa, que aprobaron el desarrollo del aplicativo como solución viable a la problemática actual del contrato. 


\section{MARCO TEÓRICO}

\section{Reseña de la empresa:}

Emtelco S.A., nació en 1992 como una empresa de telecomunicaciones para prestar servicios de conectividad y equipos de comunicaciones. Posteriormente, en el 2003 incursionó en la prestación de servicios de Contact Center y en 2009 amplió su portafolio con el diseño de soluciones Business Process Outsourcing (BPO) para la tercerización de los procesos de relacionamiento de las empresas con sus clientes: Ventas, Servicio al Cliente, Gestión de Cartera, Soporte Técnico, Gestión de Datos y Gestión de PQR ${ }^{3}$.

Misión: En Emtelco S.A., enfocamos nuestra misión en el que hacemos y para quien lo hacemos, por lo que nuestra misión es:

"Sabemos el arte de darle valor a cada contacto y cómo generar relaciones memorables y duraderas" ${ }^{4}$.

\section{Bases teóricas:}

\section{Indicadores de gestión}

Uno de los factores determinantes para que todo proceso, llámese logístico o de producción, se lleve a cabo con éxito, es implementar un sistema adecuado de indicadores para medir la gestión de los mismos, con el fin de que se puedan implementar indicadores en posiciones estratégicas que reflejen un resultado

32 EMTELCO S.A. Información corporativa [en línea]. [Medellin, Colombia]: EMTELCO S.A., [citado 04 feb,. 2015]. Disponible en internet: <URL:

http://www.emtelco.com.co/index.php?option=com k2\&view=item\&layout=item\&id=37\&ltemid=31\&l ang $=$ es $>$ 
óptimo en el mediano y largo plazo, mediante un buen sistema de información que permita medir las diferentes etapas del proceso. Todo se puede medir y por tanto todo se puede controlar, allí radica el éxito de cualquier operación, no podemos olvidar: "lo que no se mide, no se puede administrar". El adecuado uso y aplicación de estos indicadores y los programas de productividad y mejoramiento continuo en los procesos logísticos de las empresas, serán una base de generación de ventajas competitivas sostenibles y por ende de su posicionamiento frente a la competencia nacional e internacional ${ }^{5}$.

\section{Propósitos y beneficios de los indicadores de gestión}

Podría decirse que el objetivo de los sistemas de medición es aportar a la empresa un camino correcto para que ésta logre cumplir con las metas establecidas. Todo sistema de medición debe satisfacer los siguientes objetivos: Comunicar la estrategia y las metas, Identificar problemas y oportunidades, diagnosticar problemas, entender procesos, definir responsabilidades, mejorar el control de la empresa, identificar iniciativas y acciones necesarias, medir comportamientos, facilitar la delegación en las personas, integrar la compensación con la actuación ${ }^{6}$.

\footnotetext{
${ }^{5}$ Ing. MORA G., Luis Aníbal, Indicadores de gestión logísticos [en línea]. [Medellín, Colombia]: Webpicking, jun. 2014 [citado 11 feb,. 2015]. Disponible en internet: <URL: http://datateca.unad.edu.co/contenidos/242005/Archivos 2014 2/unidad tres/INDICADORES DE GESTION LOGISTICO.pdf>

${ }^{6}$ PEREZ, Gonzalo. ¿Por qué Medir y para qué? [en línea]. deGerencia, mar. 2004 [citado 04 feb,. 2015]. Disponible en Internet: <URL:

http://www.degerencia.com/articulo/por que medir y para que>
} 


\section{Indicadores de gestión en un Contact Center:}

El Contact Center de servicio al cliente se desarrolla en base a indicadores de desempeño. Estos indicadores entregan una noción acerca de la eficiencia del proceso de servicio al cliente, incluyendo la efectividad con la que los representantes de servicio al cliente están realizando sus labores así como la calidad del servicio que están recibiendo los clientes. Muchos indicadores de desempeño son tan antiguos como la industria del Contact Center en sí y aún siguen siendo ampliamente utilizados hoy en día. En la medida que el Contact Center evoluciona con el tiempo, se van desarrollando e implementando nuevos indicadores de desempeño. Aunque aún los indicadores estándar como velocidad promedio de respuesta (ASA), tiempo promedio de relación con el cliente (AHT), tiempo de espera, tasa de abandono y el tiempo promedio de cierre son ampliamente aceptados, éstos no son necesariamente relevantes más allá del mundo de las transacciones telefónicas. A medida que surgen nuevos canales de comunicaciones con el cliente como los medios sociales y mientras la definición de lo que es servicio eficiente al cliente evoluciona, los nuevos indicadores de desempeño están captando la atención de la industria. El hecho de adoptar estos indicadores más nuevos también implica el poder de transformar el foco del Contact Center hacia resultados que mejorarán drásticamente los niveles de servicio al cliente ${ }^{7}$.

\section{Definición de aplicación web}

Una aplicación web es cualquier aplicación que es accedida vía web por una red como internet o una intranet. En general, el término también se utiliza para designar aquellos programas informáticos que son ejecutados en el entorno del

\footnotetext{
${ }^{7}$ STOKFORD, Paul; STAPLES, Joe. Los indicadores del Contact Center que si Importan [en línea]. [Indianápolis, USA]: Interactive Intelligence, 2013 [citado 04 feb,. 2015]. Disponible en Internet: $<U R L$ : http://www.inin.com/LatinAmerica-es/Resources/Los-indicadores-del-Contact-Center-queS\%C3\%AD-importan.pdf>.
} 
navegador o codificado con algún lenguaje soportado por el navegador; confiándose en el navegador web para que reproduzca la aplicación. Una de las ventajas de las aplicaciones web cargadas desde internet, es la facilidad de mantener y actualizar dichas aplicaciones sin la necesidad de distribuir e instalar un software en, potencialmente, miles de clientes. También la posibilidad de ser ejecutadas en múltiples plataformas ${ }^{8}$.

\section{Ventajas de los aplicativos web}

La aparición de aplicaciones y sitios Web proporciona la explotación de otros mercados y servicios antes impensables como el comercio electrónico, la enseñanza virtual, etc., y esto conlleva un importante crecimiento en el desarrollo del software sobre dicha tecnología. Ahora bien, desde el punto de vista de la ingeniería del software es importante dotar de los mecanismos adecuados, para que la realización de este tipo de aplicaciones satisfaga las necesidades tanto de los usuarios como de los clientes que contratan el desarrollo de este tipo de aplicaciones ${ }^{9}$.

\section{Desarrollo de aplicativos web}

El desarrollo de aplicaciones web involucra decisiones no triviales de diseño e implementación que inevitablemente influyen en todo el proceso de desarrollo, afectando la división de tareas. Los problemas involucrados, como el diseño del

\footnotetext{
${ }^{8}$ ALEGSA, Leandro. Definición de aplicación web [en línea]. [Santa Fe, Argentina]: ALEGSA, ago. 2010 [citado 04 feb,. 2015]. Disponible en Internet: <URL: http://www.alegsa.com.ar/Dic/aplicacion\%20web.php>

${ }^{9}$ CÁCERES, Paloma y MARCOS, Esperanza. Procesos Ágiles para el desarrollo de aplicaciones web. Madrid: Universidad Rey Juan Carlos. Departamento de Ciencias Experimentales e Ingeniería. Taller de Web Engineering de las Jornadas de Ingeniería del Software y Bases de Datos de 2001 (2001).
} 
modelo del dominio y la construcción de la interfaz de usuario, tienen requerimientos disjuntos que deben ser tratados por separado. El alcance de la aplicación y el tipo de usuarios a los que estará dirigida son consideraciones tan importantes como las tecnologías elegidas para realizar la implementación. Así como las tecnologías pueden limitar la funcionalidad de la aplicación, decisiones de diseño equivocadas también pueden reducir su capacidad de extensión y reusabilidad. Es por ello que el uso de una metodología de diseño y de tecnologías que se adapten naturalmente a ésta, son de vital importancia para el desarrollo de aplicaciones complejas ${ }^{10}$

${ }^{10}$ SILVA, Darío; MERCERAT, Bárbara. Construyendo aplicaciones web con una metodología de diseño orientada a objetos [en línea]. [Bucaramanga, Colombia]: ene. 2002 [citado 11 feb,. 2015]. Disponible en Internet:

<URL: http://www.unab.edu.co/editorialunab/revistas/rcc/pdfs/r22_art5_c.pdf> 


\subsection{Hipótesis}

El diseño de un aplicativo web para el control de los indicadores de gestión da a conocer el estado de la línea de atención al ciudadano de la SIC, a todos los agentes de la campaña, sin que el supervisor tenga que interrumpir sus actividades de rutina para generar el reporte cada determinado tiempo y escribirlo de forma manual en el tablero, permitirá tomar decisiones efectivas e inmediatas, que permitan suplir las diferentes eventualidades que se presenten en el transcurso de la operación de la campaña y cumplir las metas trazadas con el cliente. 


\subsection{Glosario:}

1. AHT: (Average Handling Time o Tiempo Medio de Llamada): Es el tiempo promedio que se utiliza en la gestión, desde que ingresa la llamada hasta que se realiza la tipificación ${ }^{11}$.

2. AVAYA CMS (Call Management System): Aplicativo operado por los supervisores de las distintas campañas en la empresa, con el cual tienen acceso a subsistemas de reportes en tiempo real, históricos e integrados.

3. ASA: (Average Speed of Answer - Velocidad Media de Respuesta): Es el tiempo promedio en que se responden las llamadas. Se mide desde que ingresa la llamada hasta que el asesor la contesta ${ }^{12}$.

4. Llamadas abandonadas: Son las llamadas que no se logran atender porque el ciudadano cuelga, producto de la espera en el teléfono ${ }^{13}$.

5. Llamadas atendidas: Son todas las Ilamadas a las cuales se logra brindar atención ${ }^{14}$.

6. Llamadas entrantes: Son todas las llamadas realizadas por los ciudadanos a las líneas de atención ${ }^{15}$.

7. NDS: (Nivel de servicio): Este indicador cuantifica el porcentaje de llamadas atendidas antes de un umbral determinado de tiempo.

Para el caso de la campaña SIC, aplica la regla 80 en 20, lo cual indica que la meta del NDS es $80 \%$ contestando las llamadas antes de 20 segundos $^{16}$.

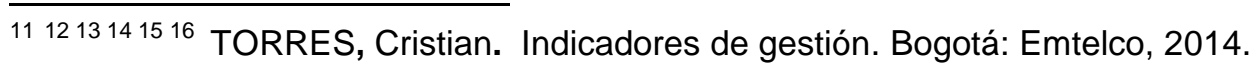




$$
\% N D S=\frac{\text { Total de llamadas contestadas antes de 20segundos }}{\text { Total de llamadas entrantes }} \times 100
$$

8. Porcentaje de abandono: Es un indicador que mide el porcentaje de llamadas abandonadas en la gestión. se calcula con la siguiente formula ${ }^{17}$ :

$$
\% \text { abandono }=\frac{\text { Total de llamadas abandonadas }}{\text { Todal de llamadas entrantes }} \times 100
$$

9. Porcentaje de eficacia: Este indicador mide el porcentaje de llamadas contestadas. se calcula con la siguiente formula ${ }^{18}$ :

$$
\% \text { eficacia }=\frac{\text { Total de llamadas contestadas (No importa tiempo) }}{\text { Todal de llamadas entrantes }} \times 100
$$

10. SIC: Superintendencia de Industria y Comercio.

11.XAMPP: Distribución de Apache completamente gratuita. $X$ (para cualquiera de los diferentes sistemas operativos), A (Apache), M (MySQL), P (PHP), P (Perl).

1718 TORRES, Cristian. Indicadores de gestión. Bogotá: Emtelco, 2014. 


\section{MARCO HUMANÍSTICO}

El desarrollo de un aplicativo web, para la visualización de indicadores de gestión de la línea de atención al ciudadano de la campaña SIC, liderado por EMTELCO S.A., permite evidenciar aspectos claves de la formación que adquiere un Ingeniero Electrónico egresado de la Universidad Santo Tomás, destacándose como un profesional humanista, integral, ético, crítico con capacidad de solucionar problemas, innovar, modelar, diseñar, desarrollar, integrar, gestionar y emprender en los campos de la electrónica, el control, la automatización, la robótica, la instrumentación y las tecnologías de la información y las comunicaciones, orientado hacia la optimización y uso eficiente de los recursos en un mundo globalizado, con responsabilidad ambiental, compromiso social y cultura investigativa ${ }^{19}$.

En la elaboración de este proyecto se evidencian los aspectos que caracterizan a un profesional humanista, siendo critico al reconocer las falencias que presentaba la empresa en el proceso de generación de indicadores de gestión, lo cual interfiere en las labores que debe realizar el supervisor de la campaña. Para dar solución a esta problemática, se realizó la intervención del ser humano como gestor del cambio, buscando nuevas formas de comprender la recolección, análisis e interpretación de los indicadores de gestión.

Con la implementación de esta solución, se evidencia la capacidad creativa de un profesional humanista al desarrollar un aplicativo web, que innova la forma de realizar un proceso convencional a un proceso que sistematiza las funciones que realizaba el supervisor.

\footnotetext{
${ }^{19}$ Universidad Santo Tomás, Perfil profesional [en línea]. [Bogotá, Colombia]: Universidad Santo Tomás, [citado 24 feb,. 2015]. Disponible en internet: <URL: http://electronica.usta.edu.co/index.php/homefacultad-electronica/perfil-profesional>
} 
El deseo de mejora y bienestar en la operación de la campaña SIC, evidencia el sentido ético de un profesional humanista, ya que el aplicativo web permite que los integrantes de la campaña puedan tomar en conjunto decisiones sobre el estado de la línea, lo cual se ve directamente reflejado en el servicio brindado a los usuarios de la línea de atención al ciudadano.

El aplicativo web modelado y diseñado en el transcurso de la practica laboral, tiene como objetivo dar solución a los inconvenientes que se presentan al momento de dar a conocer los indicadores de gestión de la campaña, lo cual se ha logrado al dar un adecuado uso a las diferentes tecnologías de la información y recursos tecnológicos que la empresa posee, evitando así el uso innecesario de materiales elaborados de recursos naturales, evidenciando así el compromiso ambiental.

El aplicativo web INDICADORES DE GESTIÓN DE LA LÍNEA DE ATENCIÓN AL CIUDADANO, CAMPAÑA SIC, benefició tanto a los analistas de la campaña, como a todos los agentes, ya que les permite tener acceso fácil e inmediato a la información sobre el estado de la línea y así tomar en conjunto decisiones que busquen cumplir las metas trazadas con el cliente; evidenciando así el compromiso social de un egresado tomasino, ya que sus resultados se verán directamente reflejados en el servicio brindado a los usuarios de la línea de atención al ciudadano. 


\section{DISEÑO METODOLÓGICO}

Para realizar la investigación, se indagó sobre la importancia de las variables de estudio. Seguidamente se midió la importancia de la relación entre los agentes y los indicadores de gestión.

Población: La población la constituyen los 43 agentes y el supervisor, de la línea de atención al ciudadano de la Superintendencia de Industria y Comercio.

Muestra: La muestra está conformada por 20 agentes y el supervisor de la campaña SIC.

Técnicas de recolección de datos: Toda la información que se mostrara en el aplicativo web, será tomada del software AVAYA CMS del supervisor, con el cual se realizará una programación previa, para que este genere la información necesaria cada determinado tiempo en un archivo de texto plano, con este archivo se alimentará una base de datos en el servidor apache y, con la programación del aplicativo, se creará la comunicación con la base de datos, para que esta pueda ser visualizada de una manera ordenada por cada agente de la campaña y el supervisor en un explorador web de su respectivo computador.

Posteriormente, para determinar si el aplicativo cumple con sus objetivos, se construirá un cuestionario, en el cual, se pueda indagar a la población muestra sobre las experiencias adquiridas al interactuar con el aplicativo web y sobre las posibles mejoras que esta pueda tener, de igual manera, se indagará al supervisor de la campaña, si el aplicativo web ha permitido tener mayor control y gestión de la línea, al tomar decisiones con base a los indicadores que mostrara la aplicación. 
Técnicas de análisis: Se analizará si el tiempo de respuesta del supervisor y de los agentes de la campaña en caso de presentarse una eventualidad en la línea que influya directamente en los indicadores de la campaña, fue más oportuna con la aplicación web, debido a que la información de la situación de la campaña se actualizara de forma automática y constante y tanto el supervisor como todos los agentes de la campaña tendrán acceso al aplicativo. Esto se realizará comparando los indicadores de gestión de la campaña antes poner en funcionamiento la aplicación, con los indicadores de la línea cuando la aplicación entre en operación. 


\section{ADMINISTRACIÓN DEL PROYECTO}

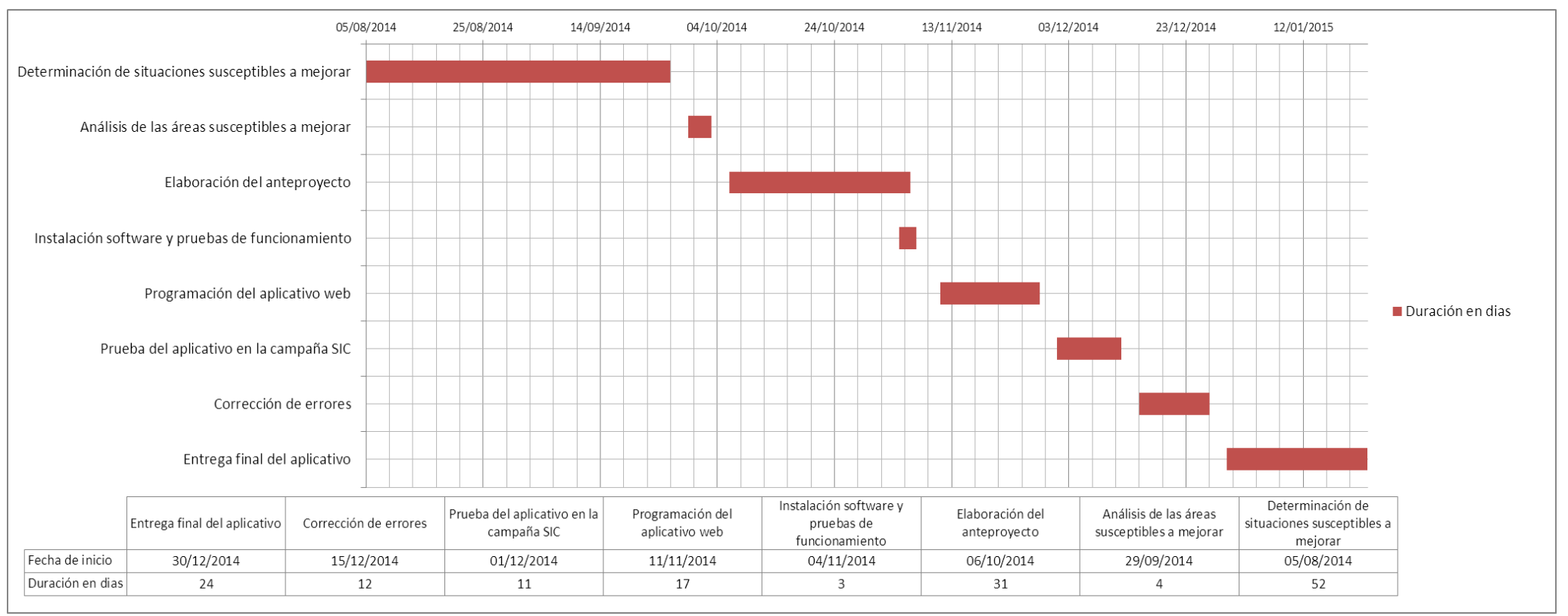

Figura 1. Cronograma de actividades(Anexo 1)

Determinación de las situaciones susceptibles a mejorar: Para poder plantear el problema y darle una solución, se realizó investigación en las diferentes áreas de la empresa, en las cuales me puedo desempeñar, y de esta forma se determinó cuáles son las situaciones susceptibles a mejorar.

Esta actividad se llevó a cabo con la ayuda del tutor designado en la universidad y jefe inmediato en la empresa.

Análisis de las áreas susceptibles a mejorar: Al tener ya identificadas las situaciones en las cuales se puede realizar un mejoramiento en su ejecución, se realizó un análisis de cada una de ellas, determinando las ventajas que conllevaría 
atacar cada situación, tanto para la empresa como para mi futuro como ingeniero, determinando así, mejorar la forma en que la campaña SIC da a conocer a sus agentes los indicadores de gestión de la línea.

Esta actividad se llevó a cabo con la ayuda del tutor designado en la universidad y jefe inmediato en la empresa.

Elaboración del anteproyecto: Se procede a la realización del documento que soporte el proyecto. Con la ayuda del supervisor de la campaña, se realizó el planteamiento del problema, se indagó sobre los antecedentes, se elaboró la justificación, objetivos y factibilidad del proyecto.

Para conocer más sobre la importancia de los indicadores de gestión, se realizó una investigación en diferentes portales y presentaciones elaboradas por el supervisor, para así determinar tanto la importancia de la empresa por conocerlos, como la importancia que los agentes de las campañas tengan conocimientos de la situación de la línea.

Junto al tutor designado por la universidad, se evaluó la mejor forma de realizar el proyecto, determinado así, realizar un aplicativo web. Por lo cual se investigó la forma de realizar el aplicativo, según las herramientas con las que se cuenta.

Se elaboró el cronograma de actividades realizadas, junto a un estimado del tiempo en días, que llevará la ejecución del resto del proyecto.

Instalación software necesario y pruebas de funcionamiento: Se determinó, que la forma más factible para la elaboración del aplicativo web, es realizar la programación en PHP y soportarla en un servidor Apache. 
Se instaló en la máquina que será el servidor el paquete XAMPP, que es una distribución de Apache completamente gratuita que contiene MySQL, PHP y Perl.

Se crea una nueva entrada, en el firewall de Windows del servidor, para de esta manera, poder visualizar los aplicativos de prueba creados en otra máquina cualquiera que esté en la intranet.

Programación del aplicativo web: Se realizará la programación del aplicativo en lenguaje PHP, de tal forma que se logre leer y mostrar el reporte de la línea, generado por el AVAYA CMS del supervisor.

Los agentes podrán acceder al aplicativo en cualquier momento, con el cual podrán tener conocimiento oportuno y en tiempo real de los indicadores de operación, para que junto al supervisor, puedan tomar las medidas necesarias para brindar un buen servicio al ciudadano y cumplir las metas planteadas por el cliente.

Prueba del aplicativo en la campaña SIC: Al terminar la programación del aplicativo, se indicará al supervisor y a 20 agentes de la campaña SIC, la forma de ingresar al aplicativo, y posteriormente realizar una retroalimentación, para poder determinar los aspectos a mejorar.

Corrección de errores: Después de realizada la retroalimentación con los agentes y supervisor de la campaña, se realizarán las correcciones necesarias, para que el aplicativo cumpla con los objetivos planteados. 
Entrega final del aplicativo: Al realizar las correcciones, finalmente se procederá a poner en funcionamiento el aplicativo en la campaña. 


\section{DISEÑO DEL APLICATIVO Y RESULTADOS OBTENIDOS}

Instalación y prueba de softwares: Para proceder con el diseño del aplicativo, primero se instalaron los softwares necesarios y se realizaron pruebas para comprobar el correcto funcionamiento:

1. Instalación paquete XAMPP, que es una distribución de Apache completamente gratuita que contiene MySQL, PHP y Perl. ${ }^{20}$

Se comprueba el correcto funcionamiento del aplicativo:

Accedemos al panel de control del paquete dándole doble click al acceso directo creado en el escritorio:

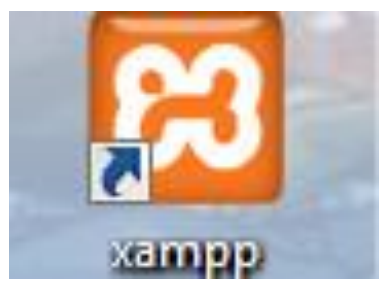

Figura 1. Acceso directo paquete XAMPP

\footnotetext{
${ }^{20}$ Ver anexo 2: Instalación paquete XAMPP
} 


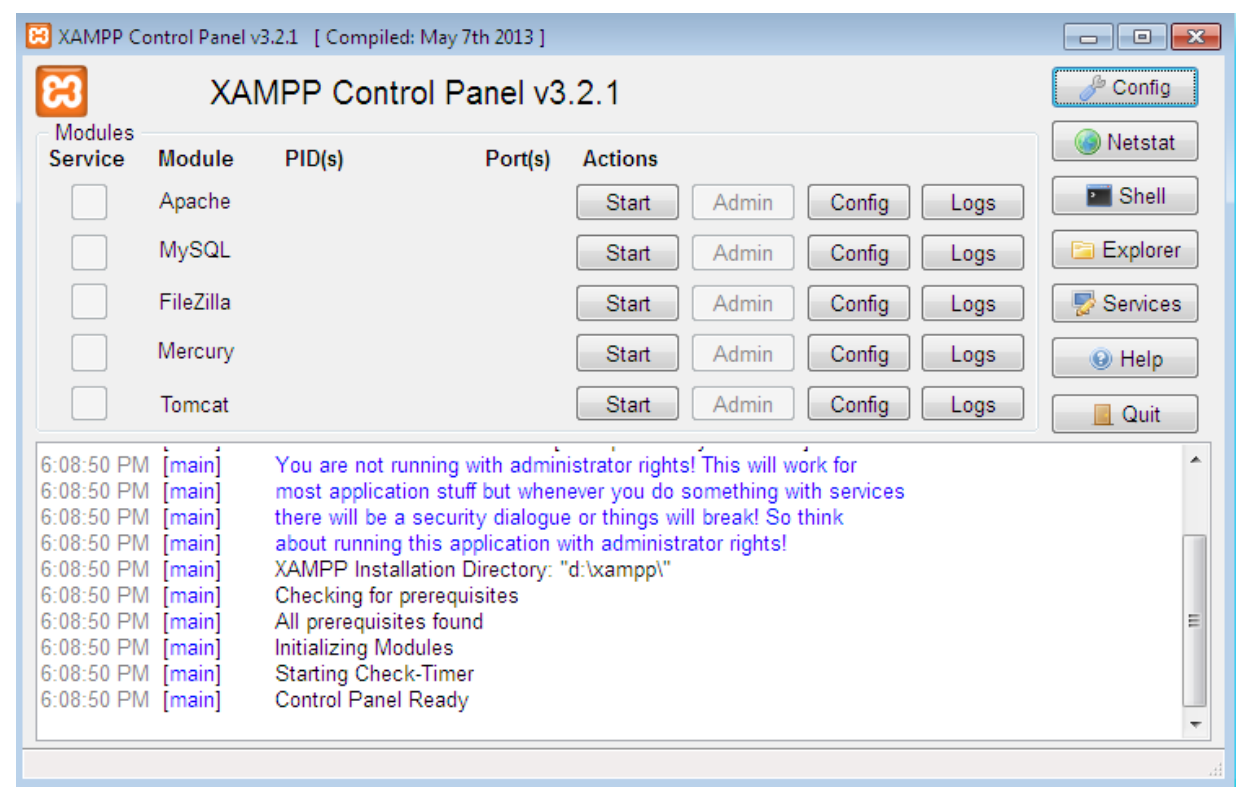

Figura 2. Panel de control paquete XAMPP

Una vez en el panel de control, ejecutamos el módulo apache, con el cual se ejecutar el servidor que soportara el aplicativo.

\begin{tabular}{|c|c|c|c|c|c|c|c|c|c|}
\hline \multicolumn{8}{|c|}{ 国 XAMPP Control Panel v3.2.1 [ Compiled: May 7th 2013 ] } & 口回 & \\
\hline 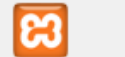 & \multicolumn{7}{|c|}{ XAMPP Control Panel v3.2.1 } & \multicolumn{2}{|l|}{ \& Config } \\
\hline $\begin{array}{l}\text { Modules } \\
\text { Service }\end{array}$ & Module & PID(s) & Port(s) & Actions & & & & \multicolumn{2}{|l|}{ (9) Netstat } \\
\hline 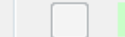 & Apache & 5980 & 80,443 & Stop & Admin & Config & Logs & \multicolumn{2}{|l|}{ Shell } \\
\hline$\square$ & MySQL & & & Start & Admin & Config & Logs & \multicolumn{2}{|c|}{ Explorer } \\
\hline$\square$ & FileZilla & & & Start & Admin & Config & Logs & \multicolumn{2}{|c|}{ Fervices } \\
\hline 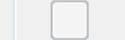 & Mercury & & & Start & Admin & Config & Logs & \multicolumn{2}{|l|}{ (9) Help } \\
\hline$\square$ & Tomcat & & & Start & Admin & Config & Logs & \multicolumn{2}{|l|}{ Q Quit } \\
\hline \multicolumn{2}{|c|}{$\begin{array}{l}\text { 6:08:50 PM [main] } \\
\text { 6:08:50 PM [main] } \\
\text { 6:08:50 PM [main] } \\
\text { 6:08:50 PM [main] } \\
\text { 6:08:50 PM [main] } \\
\text { 6:08:50 PM [main] } \\
\text { 6:08:50 PM [main] } \\
\text { 6:08:50 PM [main] } \\
\text { 6:10:10 PM [Apache] } \\
\text { 6:10:16 PM [Apache] }\end{array}$} & \multicolumn{6}{|c|}{$\begin{array}{l}\text { there will be a security dialogue or things will break! So think } \\
\text { about running this application with administrator rights! } \\
\text { XAMPP Installation Directory: "d: lxamppl" } \\
\text { Checking for prerequisites } \\
\text { All prerequisites found } \\
\text { Initializing Modules } \\
\text { Starting Check-Timer } \\
\text { Control Panel Ready } \\
\text { Attempting to start Apache service... } \\
\text { Status change detected: running }\end{array}$} & & $\equiv$ \\
\hline
\end{tabular}

Figura 3. Panel de control paquete XAMPP 
Accedemos al host local para verificar que el servidor se esté ejecutando, al cual se accede escribiendo localhost en el navegador

\begin{tabular}{|c|c|}
\hline XAMPP 1.8 .3 & Daniel 0 回 $x$ \\
\hline$\leftarrow \rightarrow$ C $\square$ localhost/xampp/ & $\xi \stackrel{3}{\equiv}$ \\
\hline :I: Aplicaciones or Outlook.com - & \\
\hline
\end{tabular}

\section{疍 XAMPP for Windows}

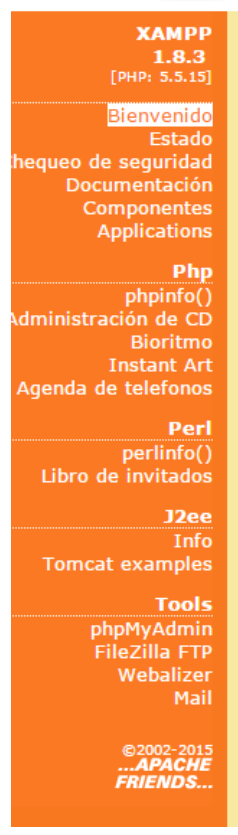

Bienvenido a XАMPP para Windows!

Felicidades:

XAMPP se instaló con exito en su ordenador!

Ahora se puede empezar a trabajar. :) Primero por favor pulse encima de »Estado« en la parte izquierda. De esta manera tendrá una visión de que es lo que funciona ya. Algunas funciones estarán desactivadas. Es intencionado. Son funciones, que no funcionan en todas partes o eventualmente podrían ocasionar problemas.

Atención: XAMPP fue modificado a partir de la versión 1.4.X a una administración de paquete único. Existen los siguientes paquetes/Addons:

- XAMPP paquete básico

- Xampp Perl addon

- XAMPP Tomcat addon

: XAMPP Cocoon addon

- XAMPP Python addon (developer version)

Yen un futuro:

- XAMPP Utility addon (Accesorio pero aún inactivo)

- XAMPP Server addon (otros servidores aún inactivos)

- XAMPP Other addon (otras cosas útiles aún inactivas)

Por favor "instalad" los paquetes adicionales, que aún necesiteis, simplemente a continuación. Despues de subirlos con éxito, por favor siempre accionar "setup_xampp.bat" , para inicializar nuevamente XAMPP. A bueno, las versiones Instalador de los Addons individuales funcionan sólo si el paquete básico XAMPP tambien fue montado a partir de una versión instalador.

Para el soporte OpenSSL utilice por favor el certificado de chequeo con la URL https://127.0.0.1 ó https://localhost

Os deseamos mucha diversión, Kay Vogelgesang + Kai 'Oswald' Seidler

Install applications on XAMPP using BitNami

Apache Friends and BitNami are cooperating to make dozens of open source applications available on XAMPP, for free. BitNami-packaged applications include Wordpress, Drupal, Joomla! and dozens of others and can be deployed with one-click installers. Visit the BitNami XAMPP page for details on the currently available apps.

\section{(4) 这}

Figura 4. Acceso al localhost

Creamos un pequeño aplicativo de prueba:

En el directorio donde se instaló el paquete XAMPP, accedemos a la ruta XAMPP\htdocs, en la cual creamos el archivo Prueba.php con el siguiente código.

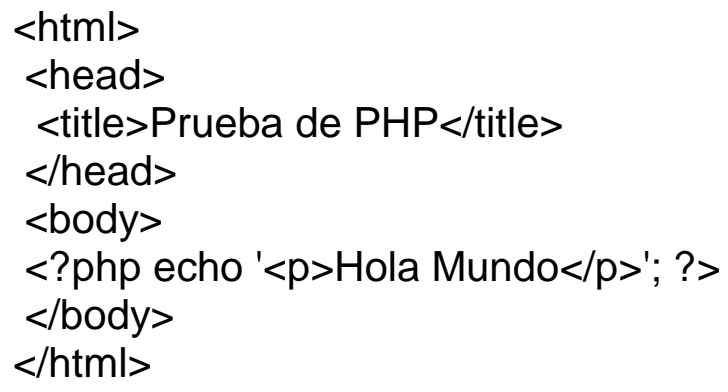


Al cual accedemos desde el navegador escribiendo el nombre con el que fue creado: http://localhost/Prueba.php

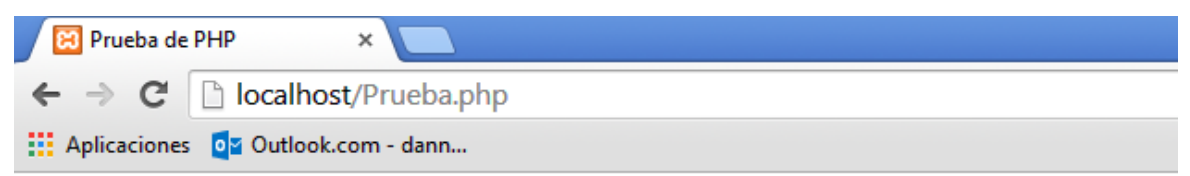

Hola Mundo

Figura 5. Aplicativo web de prueba

Verificamos si podemos acceder al aplicativo desde cualquier otra máquina perteneciente a la intranet, para lo cual es necesario conocer la dirección IP de la máquina donde se está ejecutando el servidor, en este caso la dirección es: 192.168.1.4, por lo cual podemos acceder al aplicativo en la intranet con la dirección: http://192.168.1.4/Prueba.php

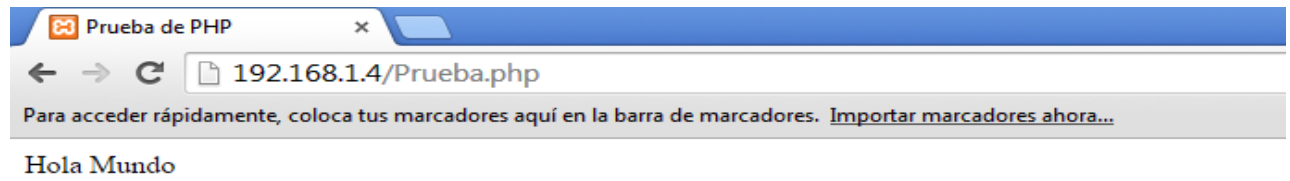

Figura 6. Aplicativo web de prueba desde la intranet

2. Instalamos Notepad ++, el cual es un software libre, el cual permite editar código fuente de programas que soporta varios lenguajes, entre ellos php y html, que son con los cuales se diseñará el aplicativo ${ }^{21}$.

Se comprueba el funcionamiento del aplicativo.

\footnotetext{
${ }^{21}$ Ver anexo 3: Instalación Notepad++
} 


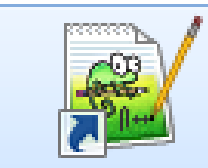

Notepadtof

Figura 7. Acceso directo al software

Creamos un archivo nuevo y pegamos el código Hola mundo de prueba

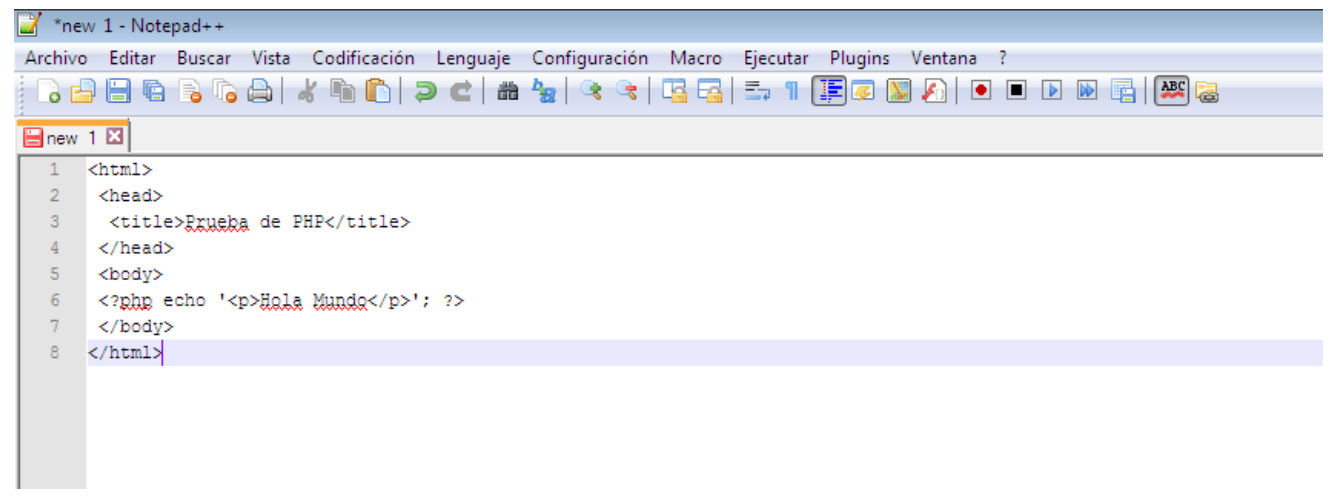

Figura 8. Ventana Notepad ++

Seleccionamos el lenguaje en el cual se está realizando la programación:

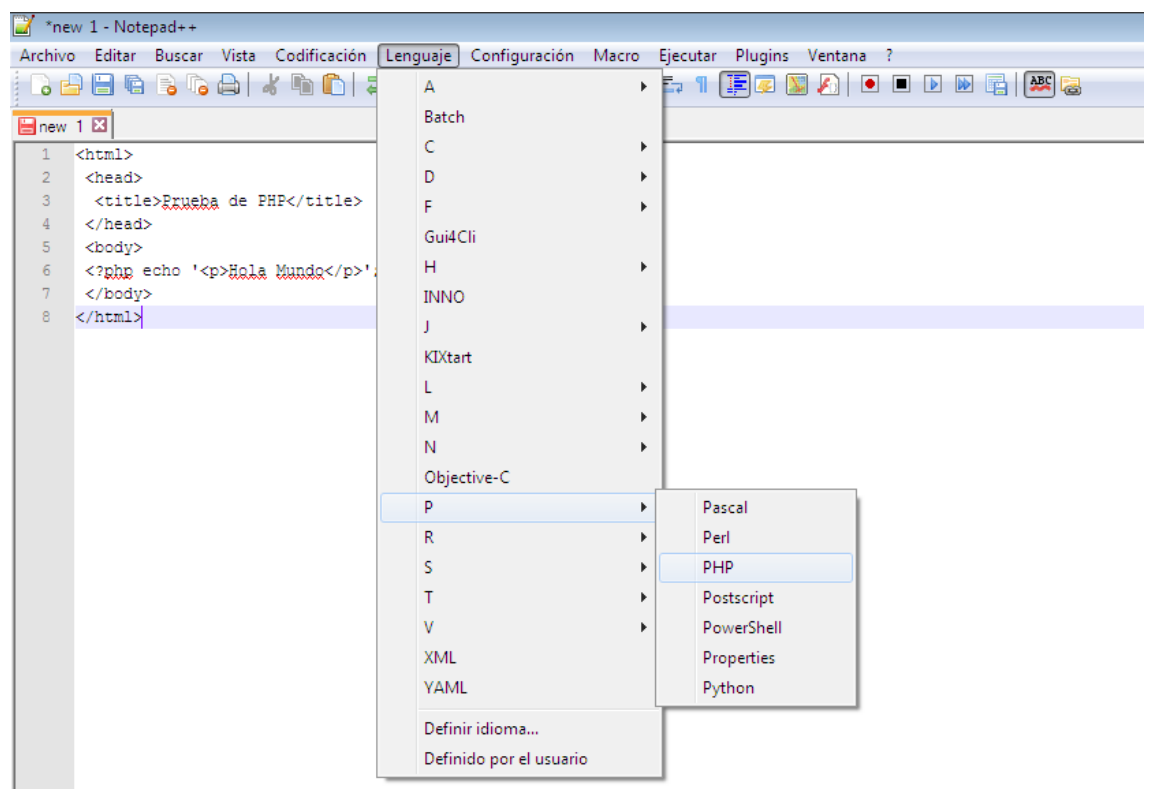

Figura 9. Selección de lenguaje de programación 


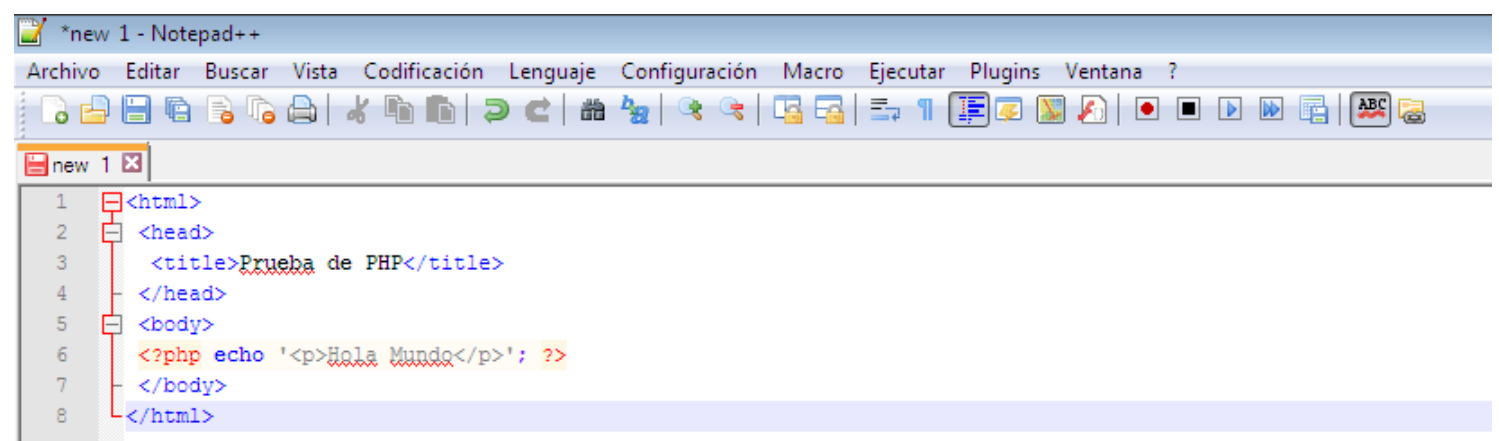

Figura 10. Ventana Notepad++

Guardamos el archivo, el cual ya tendrá la extensión .php

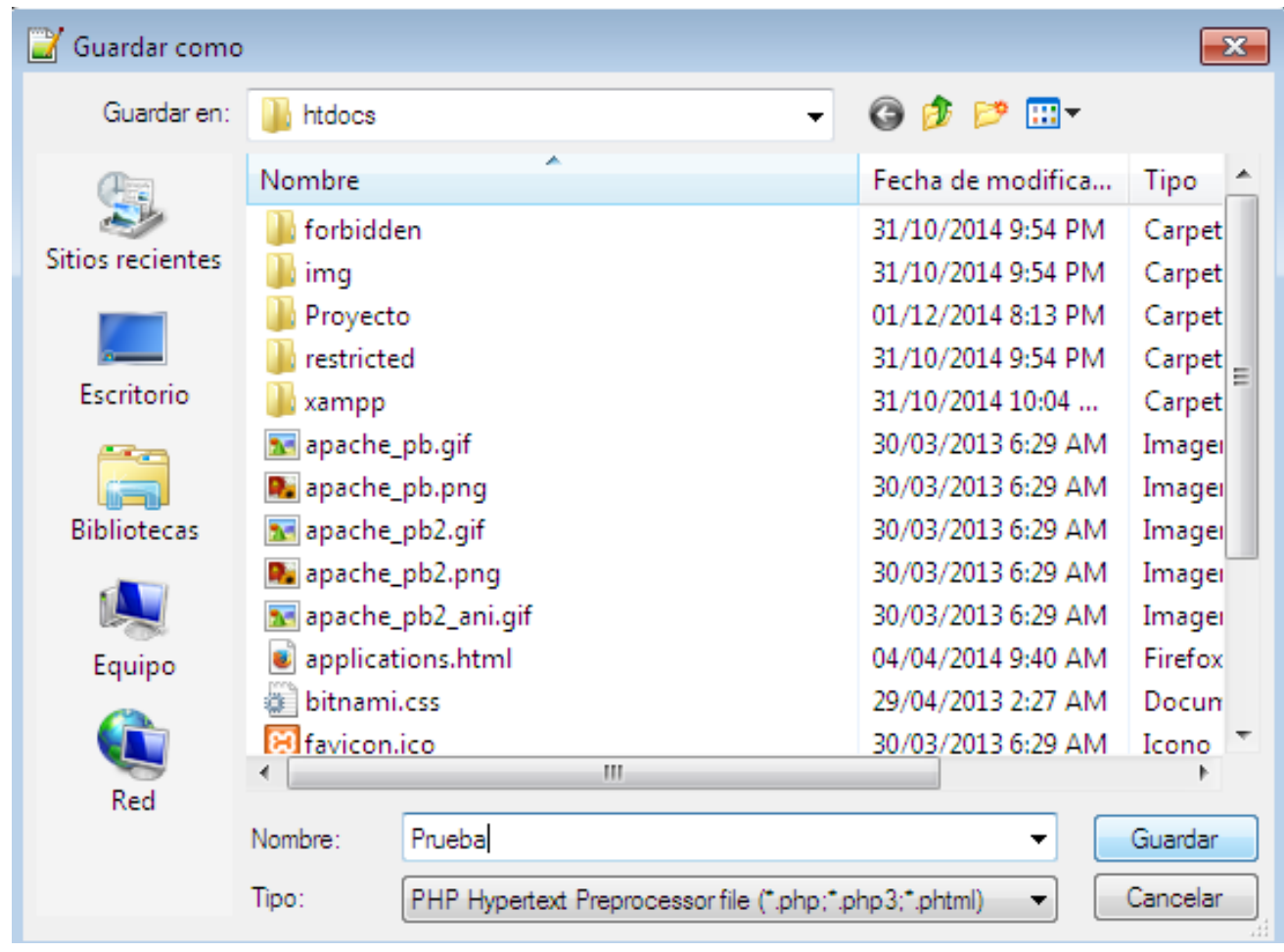

Figura 11. Guardando archivo de prueba 
Diseño del aplicativo: Para iniciar con el aplicativo, inicialmente se debe sistematizar la generación manual de los indicadores de gestión ${ }^{22}$, aprovechando las herramientas que ofrece el software AVAYA CMS, con el cual se puede crear un archivo de ordenes script, con el cual ya no será necesario realizar el procedimiento manual de generación de los indicadores.

Al tener el script creado, se procede a crear una base de datos y tablas en donde se almacenarán los indicadores de gestión generados por el script.

Una vez con la base de datos y el script creados, se crea una tarea automática de Windows, con la cual se almacenarán automáticamente los indicadores de gestión en la base de datos, con un programa en php que alimentará la base de datos.

Al tener ya la información en la base de datos, se crea una consulta, con la cual, se organizará la información de la base de datos en una tabla para que esta pueda ser visualizada de manera clara y organizada en el aplicativo web.

\section{Sistematización de la generación de indicadores de gestión}

Para generar los indicadores de gestión de manera automática, aprovechamos las herramientas que AVAYA CMS ofrece.

Para esto se debe inicialmente, generar los indicadores de gestión de cualquier día en cualquier intervalo de hora. Una vez los resultados estén en pantalla, en la pestaña editar, nos dirigimos a la opción exportar datos de tabla.

\footnotetext{
${ }^{22}$ Ver anexo 4: Generación manual de los indicadores de gestión
} 


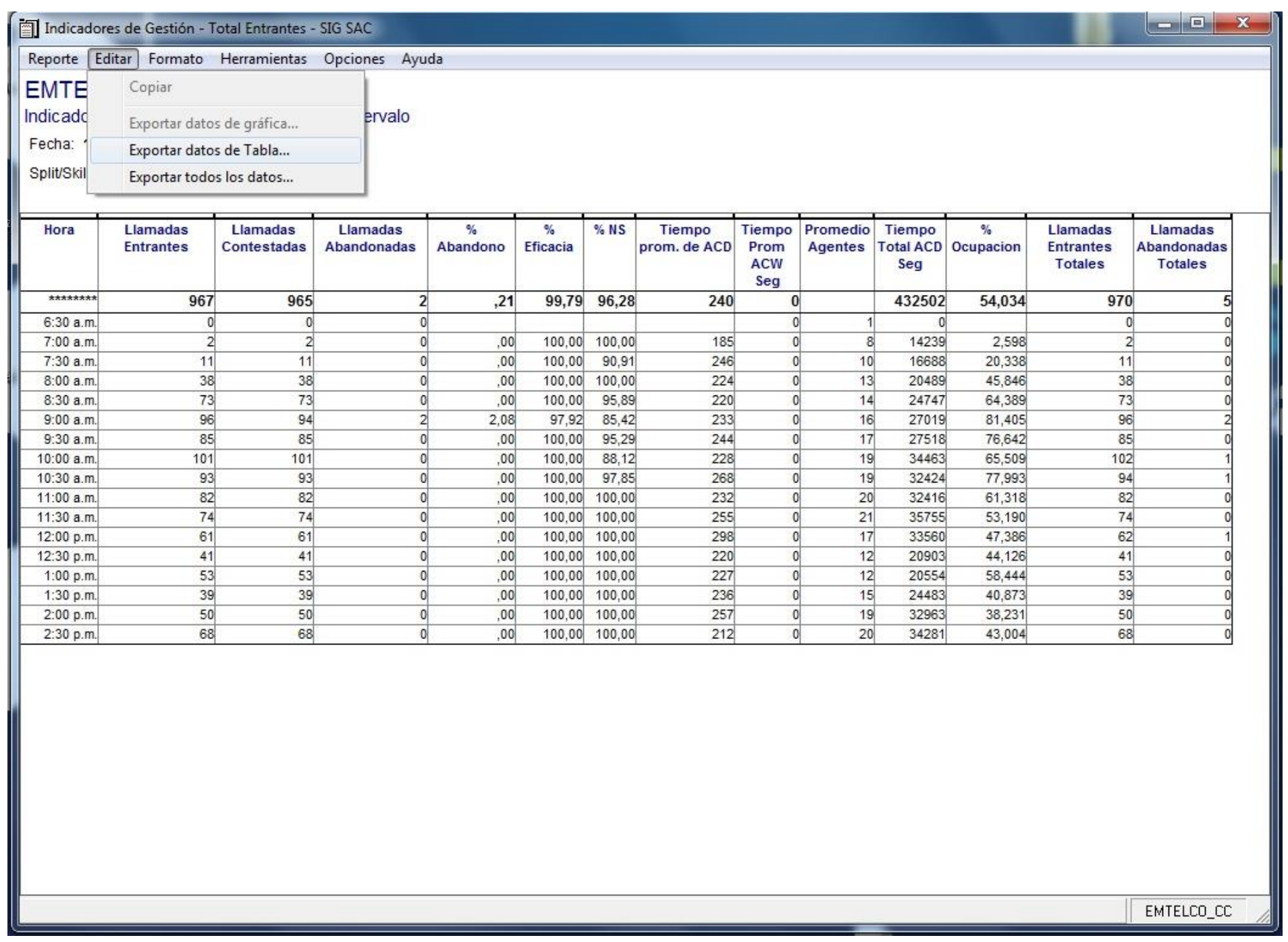

Figura 12. Indicadores de gestión 


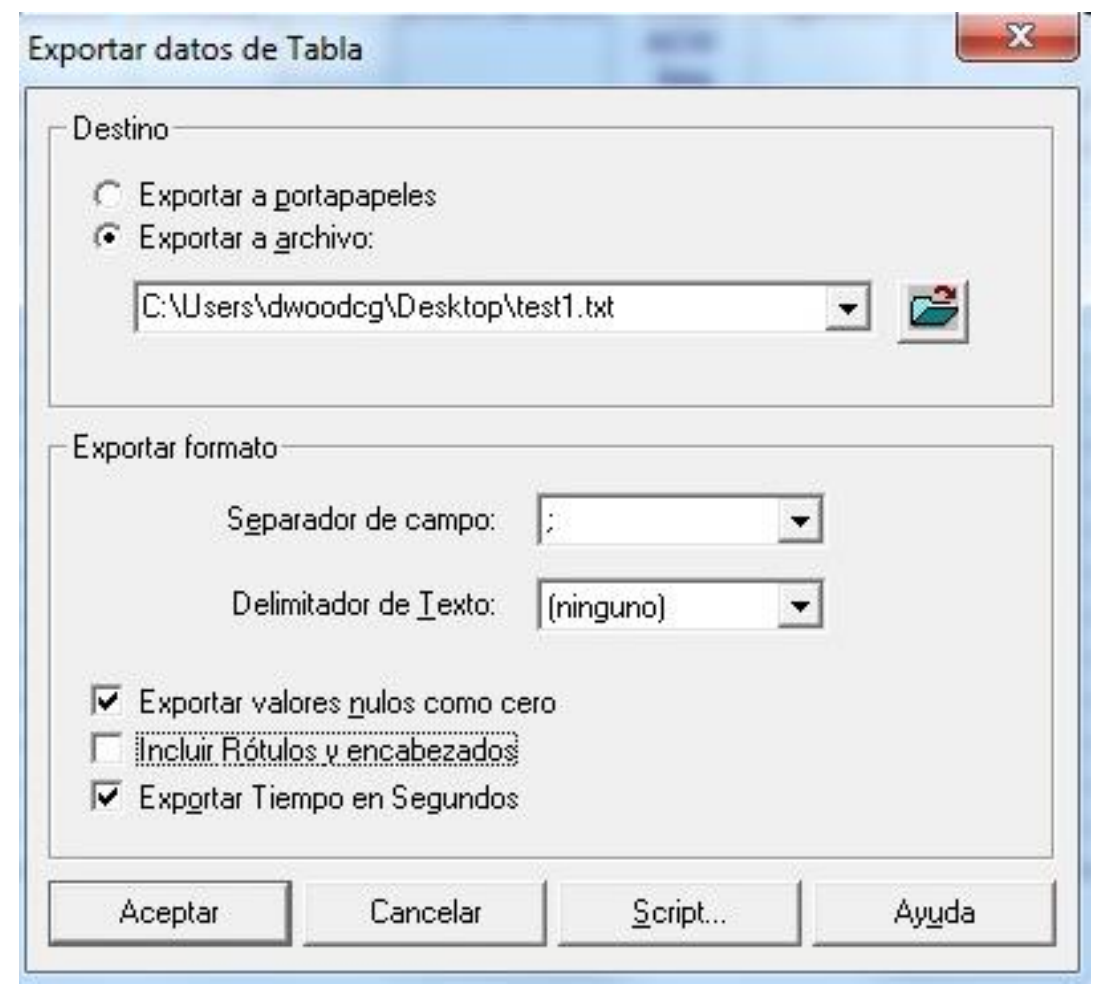

Figura 13. Selección de parámetros

Al seleccionar todos los parámetros, seleccionamos la opción Script, con la cual se podrá crear el archivo de órdenes.

Se da la ubicación donde se quiere que se genere el archivo .script y seleccionamos guardar. 


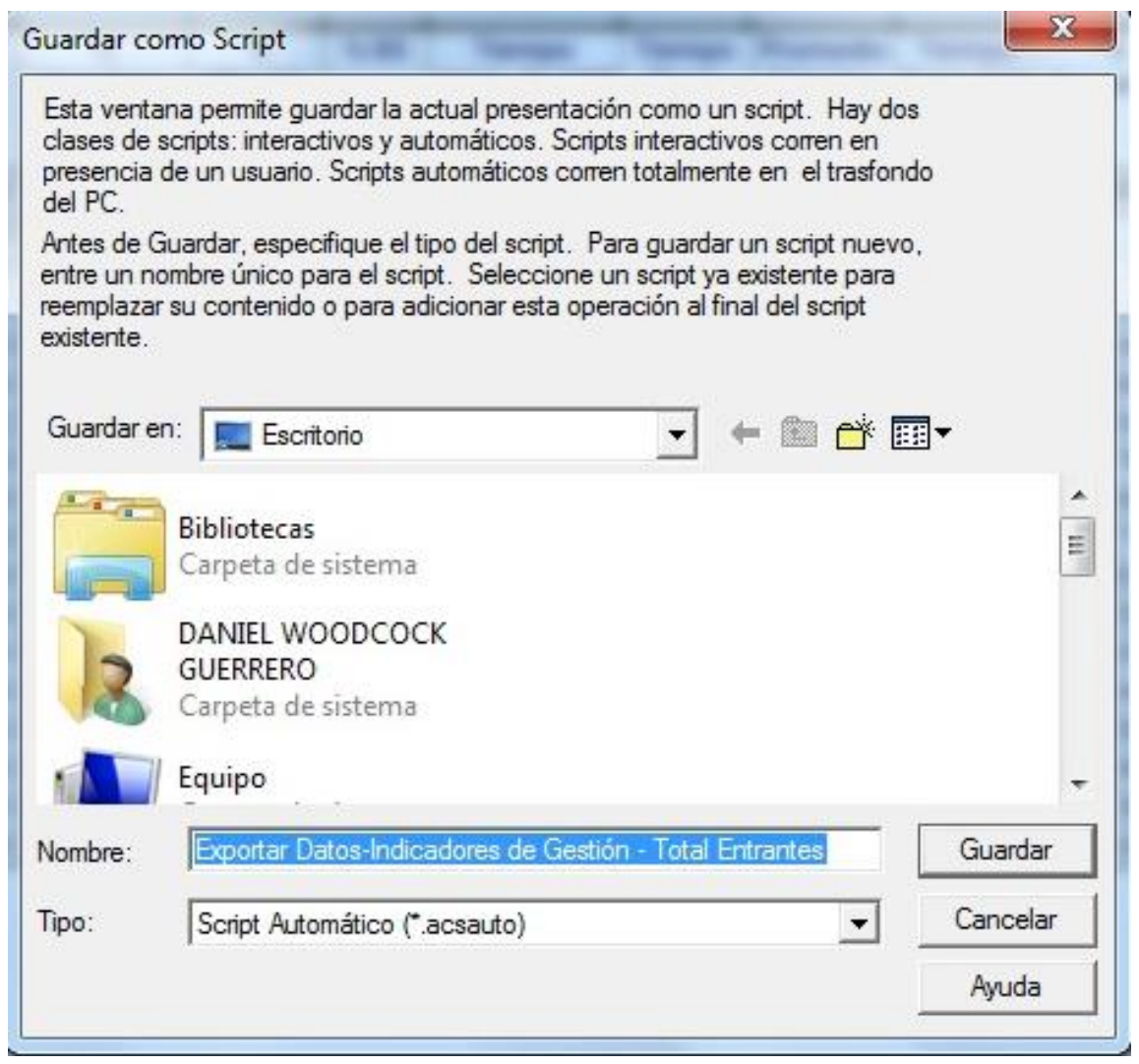

Figura 14. Creación del script

\section{Guardar como Script}

El script automático Exportar Datos-Indicadores de Gestión - Total Entrantes.acsauto ha sido guardado. Usted puede programarlo para ejecutarlo más tarde usando cualquier aplicación de Windows de programación de tiempos.

Figura 15. Creación del script 
Lo cual nos creará el siguiente archivo en la ubicación indicada

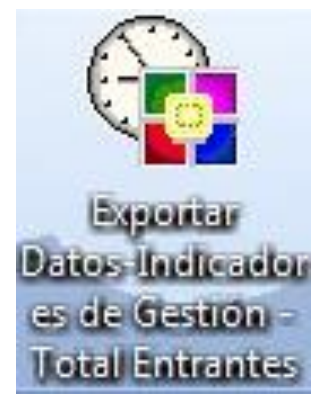

Figura 16. Archivo creado

Al ejecutar el archivo, se crearán automáticamente los indicadores de gestión pero de la fecha inicialmente seleccionara, para lo cual, se debe realizar una modificación en el archivo, para que cada vez que se ejecute, tome la fecha actual.

Creamos la variable hoy, en la cual con la función Date(), se almacenará la fecha actual.

' $L A N G U A G E=E S O$

'SERVERNAME $=10.3 .10 .96$

Dim hoy

hoy=Date()

Public sub Main()

Asignamos al variable hoy a los parámetros "Fecha", seleccionamos el intervalo en el que se desea que se generen los indicadores en el parámetro "Intervalo" y seleccionamos donde queremos que se guarde el archivo en el parámetro "_Output"

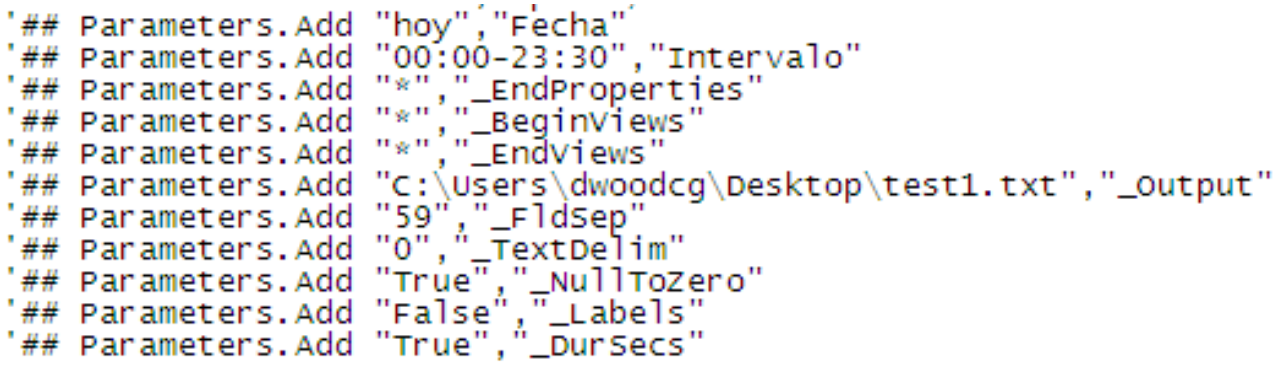




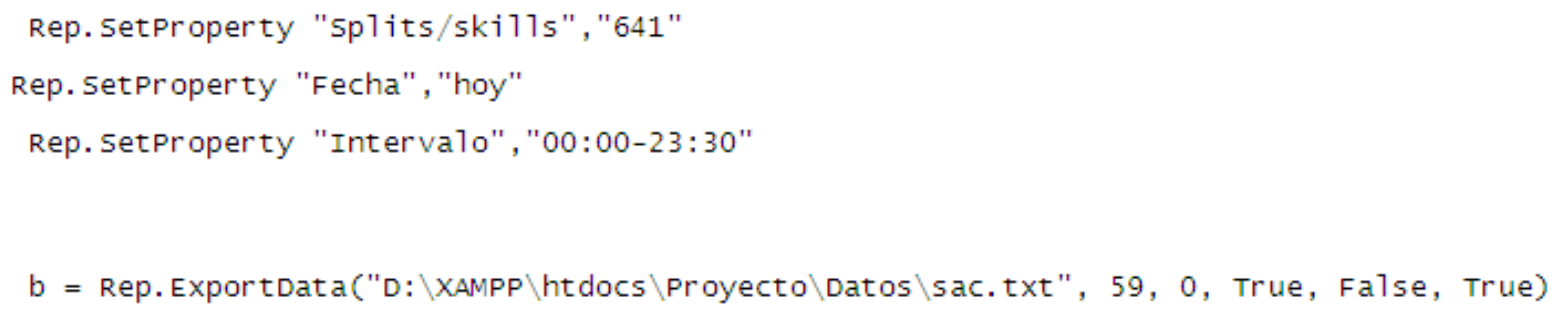

Guardamos y al ejecutar el archivo script, se creará un archivo de texto plano con los indicadores de gestión, con el cual se alimentara la base de datos.

Al ejecutar el archivo, se abre la siguiente pantalla

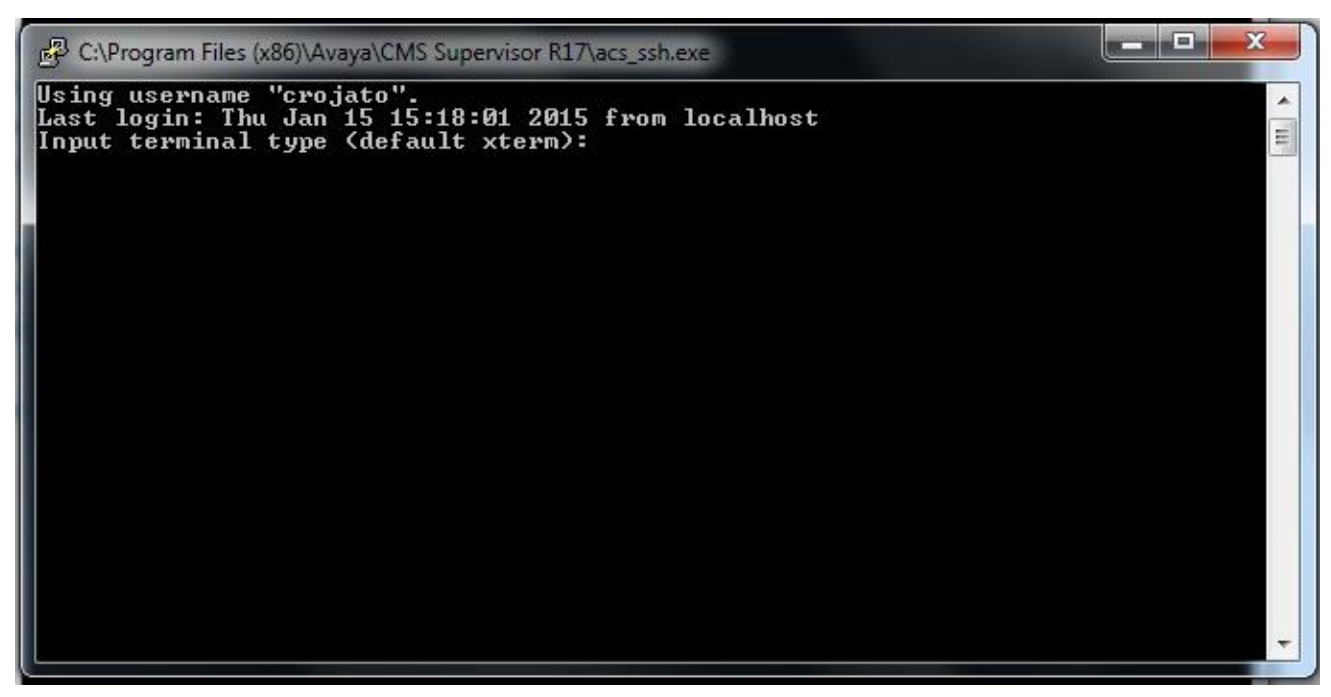

Figura 17. Ejecución archivo Script

Al finalizar el procedimiento, se cerrará la ventana y en el directorio especificado se crea el archivo de texto plano con los indicadores de gestión 


\begin{tabular}{|c|c|c|c|c|c|}
\hline Organizar - & Imprimir & Nueva carpeta & & & \\
\hline Favoritos & \multicolumn{2}{|l|}{ Nombre } & Fecha de modifica... & Tipo & \multirow[t]{5}{*}{ Tamaño } \\
\hline Descargas & D. CMS & & $15 / 01 / 201503: 01 \ldots$ & Carpeta de archivos & \\
\hline E- Escritorio & 13 crud & & 04/01/2014 10:05 ... & Carpeta de archivos & \\
\hline \multirow[t]{2}{*}{ Iitios recientes } & 13. Datos & & $26 / 11 / 201409 ; 40 \mathrm{a} \ldots$ & Carpeta de archivos & \\
\hline & 13. Informes & & $06 / 01 / 2015$ 10:41 a... & Carpeta de archivos & \\
\hline \multirow{6}{*}{$\begin{array}{l}\text { Bibliotecas } \\
\text { Documentos } \\
\text { Imágenes } \\
\text { Música } \\
\text { Videos }\end{array}$} & a cargabasemeta & & $29 / 12 / 201402: 33 \ldots$ & Archivo PHP & $1 \mathrm{~KB}$ \\
\hline & - cargabasesac & & $30 / 12 / 201404: 29 \ldots$ & Archivo PHP & $2 \mathrm{~KB}$ \\
\hline & a cargabasetotal & & $29 / 12 / 201402: 38 \ldots$ & Archivo PHP & $2 \mathrm{~KB}$ \\
\hline & E conexion & & 27/11/2014 11:49 a... & Archivo PHP & $1 \mathrm{~KB}$ \\
\hline & - crearbdsac & & $11 / 12 / 201410: 36 \mathrm{a} \ldots$ & Archivo PHP & $2 \mathrm{~KB}$ \\
\hline & 르 datosgrafica & & $01 / 01 / 201505: 24 \ldots$ & Archivo PHP & $2 \mathrm{~KB}$ \\
\hline \multirow{2}{*}{$\begin{array}{l}\text { Equipo } \\
\text { OS (C:) }\end{array}$} & - eliminasac & & $30 / 12 / 201404: 15 \ldots$ & Archivo PHP & $3 \mathrm{~KB}$ \\
\hline & - eliminatd & & $30 / 12 / 201404: 27 \ldots$ & Archivo PHP & $1 \mathrm{~KB}$ \\
\hline \multirow[t]{2}{*}{$\hookrightarrow$ Disco local (D:) } & E eliminatotal & & $29 / 12 / 201402: 10 \ldots$ & Archivo PHP & $1 \mathrm{~KB}$ \\
\hline & a grafico & & 05/01/2015 01:38 ... & Archivo PHP & $2 \mathrm{~KB}$ \\
\hline \multirow[t]{8}{*}{ Ex Red } & 을 grafico2 & & 05/01/2015 01:38 ... & Archivo PHP & $2 \mathrm{~KB}$ \\
\hline & - grafico3 & & $05 / 01 / 201501: 38 \ldots$ & Archivo PHP & $2 \mathrm{~KB}$ \\
\hline & - grafico4 & & $05 / 01 / 201504: 11 \ldots$ & Archivo PHP & $2 \mathrm{~KB}$ \\
\hline & E index & & $06 / 01 / 201505: 00 \ldots$ & Archivo PHP & $6 \mathrm{~KB}$ \\
\hline & a index 2 & & $30 / 12 / 2014$ 09:56 а... & Archivo PHP & $1 \mathrm{~KB}$ \\
\hline & - indext & & $30 / 12 / 2014$ 09:08 a... & Archivo PHP & $1 \mathrm{~KB}$ \\
\hline & meta & & $29 / 12 / 201402: 34 \ldots$ & Documento de tex... & $1 \mathrm{~KB}$ \\
\hline & sac & & $15 / 01 / 201503: 36 \ldots$ & Documento de tex... & $2 \mathrm{~KB}$ \\
\hline
\end{tabular}

Figura 18. Archivo de texto plano creado

\title{
En el cual cada campo se encuentra separado por punto y coma y está delimitado de ninguna forma.
}

\author{
testl.txt: Bloc de notas \\ Archivo Edición Formato Ver Ayuda \\ $15 / 01 / 2015$ \\ SIG SAC \\ *******; $967 ; 965 ; 2 ;, 21 ; 99,79 ; 96,28 ; 240,152328491 ; 0 ; 0 ; 432502,000000000 ; 54,034 ; 970 ; 5$ \\ $6: 30$ a.m. $; 0 ; 0 ; 0 ; 0 ; 0 ; 0 ; 0 ; 0 ; 1 ;, 000000000 ; 0 ; 0 ; 0$ \\ $7: 00$ a.m. ;2;2;0; ,00;100,00;100,00;185,000000000;0;8;14239,000000000; 2, 598; $2 ; 0$ \\ $7: 30$ a.m.;11;11;0; ,00;100,00; 90,$91 ; 246,181823730 ; 0 ; 10 ; 16688,000000000 ; 20,338 ; 11 ; 0$ \\ $8: 00$ a.m. $; 38 ; 38 ; 0 ;, 00 ; 100,00 ; 100,00 ; 224,421051025 ; 0 ; 13 ; 20489,000000000 ; 45,846 ; 38 ; 0$ \\ $8: 30$ a.m. $; 73 ; 73 ; 0 ;, 00 ; 100,00 ; 95,89 ; 219,753417969 ; 0 ; 14 ; 24747,000000000 ; 64,389 ; 73 ; 0$ \\ $9: 00$ a.m. ; $96 ; 94 ; 2 ; 2,08 ; 97,92 ; 85,42 ; 232,712768555 ; 0 ; 16 ; 27019,000000000 ; 81,405 ; 96 ; 2$ \\ $9: 30$ a.m. $; 85 ; 85 ; 0 ;, 00 ; 100,00 ; 95,29 ; 243,670593262 ; 0 ; 17 ; 27518,000000000 ; 76,642 ; 85 ; 0$ \\ $10: 00$ a.m. $; 101 ; 101 ; 0 ;, 00 ; 100,00 ; 88,12 ; 227,594055176 ; 0 ; 19 ; 34463,000000000 ; 65,509 ; 102 ; 1$ \\ $10: 30$ a.m.;93;93;0; ,00; 100,$00 ; 97,85 ; 268,086029053 ; 0 ; 19 ; 32424,000000000 ; 77,993 ; 94 ; 1$ \\ $11: 00$ a.m.; $82 ; 82 ; 0 ;, 00 ; 100,00 ; 100,00 ; 232,353652954 ; 0 ; 20 ; 32416,000000000 ; 61,318 ; 82 ; 0$ \\ $11: 30$ a.m. ; 74;74;0; ,00;100,00;100,00;254,554046631;0; $21 ; 35755,000000000 ; 53,190 ; 74 ; 0$ \\ $12: 00$ p.m. $; 61 ; 61 ; 0 ;, 00 ; 100,00 ; 100,00 ; 297,508209229 ; 0 ; 17 ; 33560,000000000 ; 47,386 ; 62 ; 1$ \\ $12: 30$ p.m. ;41;41;0; ,00;100,00;100,00;220,414627075;0;12;20903,000000000;44,126;41;0 \\ $1: 00$ p.m. ; 53;53;0; $00 ; 100,00 ; 100,00 ; 227,075469971 ; 0 ; 12 ; 20554,000000000 ; 58,444 ; 53 ; 0$ \\ $1: 30$ p.m. ; 39; 39;0; ,00;100,00;100,00;236,025634766;0;15;24483,000000000;40,873;39;0 \\ $2: 00$ p.m. ; 50; 50;0; ,00;100,00;100,00;257,140014648;0;19;32963,000000000; 38,231;50;0 \\ $2: 30$ p.m. ;68;68;0;,00;100,00;100,00;212,073532104;0;20;34281,000000000;43,004;68;0
}

Figura 19. Indicadores de gestión 


\section{Creación base de datos y tablas}

Se creará una base de datos llamada Indicadoresdegestion, en la cual, se crearán 3 tablas:

- Tabla indicadores de gestión por intervalo de tiempo (Tabla sac)

\begin{tabular}{|c|c|c|}
\hline Parámetro & Nombre en tabla & Tipo \\
\hline Hora & Hora & time('hn:nn:ss AM/PM' ,time) NOT NULL \\
\hline Llamadas entrantes & Llam_in & float NOT NULL \\
\hline Llamadas contestadas & Llam_con & float NOT NULL \\
\hline Llamadas abandonadas & Llam_aban & float NOT NULL \\
\hline $\begin{array}{c}\text { Porcentaje de abandono } \\
\text { Porcentaje de eficacia }\end{array}$ & Por_Abandono & float NOT NULL \\
\hline $\begin{array}{c}\text { Porcentaje de nivel de } \\
\text { servicio }\end{array}$ & Por_eficacia & float NOT NULL \\
\hline AHT & AHT & float NOT NULL \\
\hline ACW & ACW & float NOT NULL \\
\hline $\begin{array}{c}\text { Promedio agentes } \\
\text { totales }\end{array}$ & Pro_Agentes & float NOT NULL \\
\hline Tiempo ACD & T_ACD & float NOT NULL \\
\hline $\begin{array}{c}\text { Porcentaje de ocupación } \\
\text { Llamadas entrantes }\end{array}$ & Por_ocupacion & float NOT NULL \\
\hline Llam_int & Llam_abant & \\
\hline
\end{tabular}

Tabla 1. Parámetros tabla sac 
- Tabla indicadores de gestión acumulados del día (Tabla indicadores)

\begin{tabular}{|c|c|c|}
\hline Parámetro & Nombre en tabla & Tipo \\
\hline Hora & Hora & time('hn:nn:ss AM/PM' ,time) NOT NULL \\
\hline Llamadas entrantes & Llam_in & float NOT NULL \\
\hline Llamadas contestadas & Llam_con & float NOT NULL \\
\hline Llamadas abandonadas & Llam_aban & float NOT NULL \\
\hline $\begin{array}{c}\text { Porcentaje de abandono } \\
\text { Porcentaje de eficacia }\end{array}$ & Por_Abandono & float NOT NULL \\
\hline $\begin{array}{c}\text { Porcentaje de nivel de } \\
\text { servicio }\end{array}$ & Por_eficacia & float NOT NULL \\
\hline AHT & Por_NS & float NOT NULL \\
\hline ACW & ACW & float NOT NULL \\
\hline $\begin{array}{c}\text { Plamadas abandonadas } \\
\text { totales }\end{array}$ & Llam_abant & float NOT NULL \\
\hline tiempo ACD & Pro_Agentes & float NOT NULL \\
\hline $\begin{array}{c}\text { Porcentaje de ocupación } \\
\text { Llamadas entrantes }\end{array}$ & Por_ocupacion & float NOT NULL \\
\hline
\end{tabular}

Tabla 2. Parámetros tabla indicadores 
- Tabla meta indicadores de gestión (Tabla indicadores)

\begin{tabular}{|c|c|c|}
\hline Parámetro & Nombre en tabla & Tipo \\
\hline Porcentaje de abandono & Por_Abandono & float NOT NULL \\
\hline Porcentaje de eficacia & Por_eficacia & float NOT NULL \\
\hline $\begin{array}{c}\text { Porcentaje de nivel de } \\
\text { servicio }\end{array}$ & Por_NS & float NOT NULL \\
\hline AHT & AHT & \\
\hline
\end{tabular}

Tabla 3. Parámetros tabla indicadores

Ya con los parámetros de cada tabla, procedemos a crear la base de datos "Indicadoresdegestion"

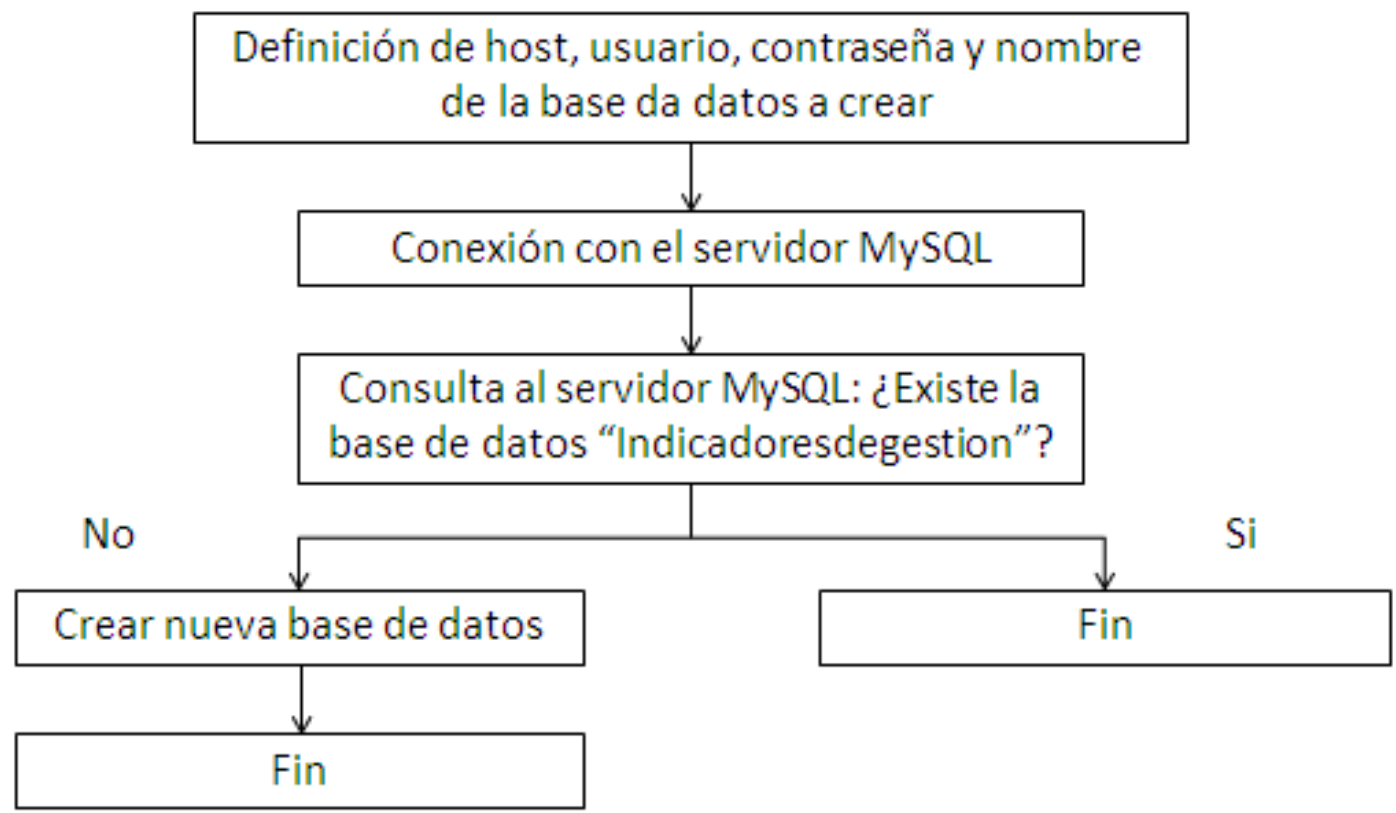

Figura 20. Creación base de datos 
Ahora creamos la tabla "sac", con los parámetros deseados

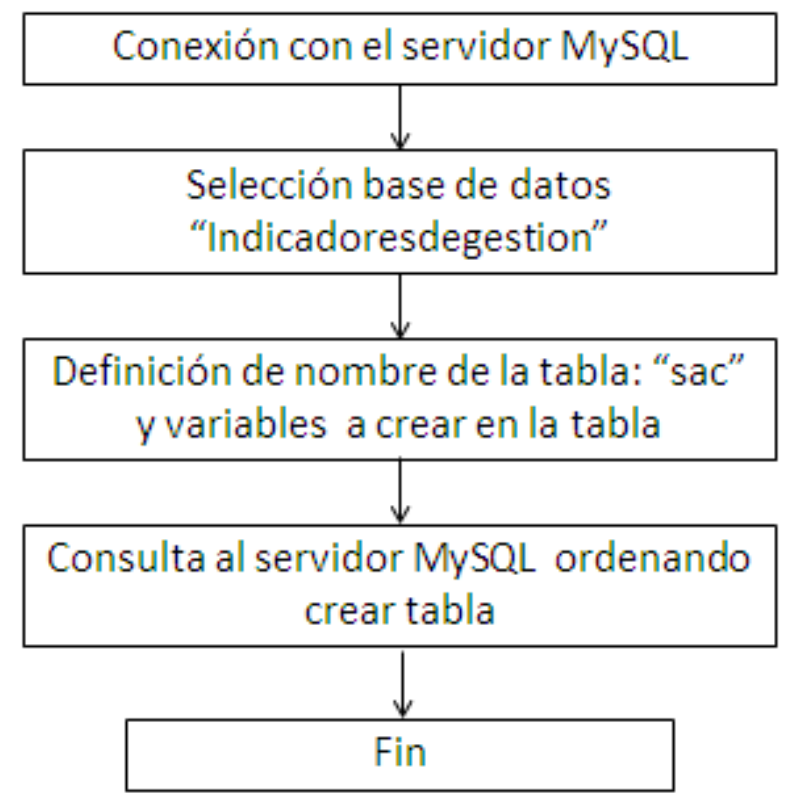

Figura 21. Creación tabla sac

Guardamos el archivo con el nombre crarbdsac.php y lo ejecutamos en el navegador web

192.168.1.3/Proyecto/crea $\times \square$

$\leftarrow \rightarrow$ C $\mathbb{1} \square$ 192.168.1.3/Proyecto/crearbdsac.php

Para acceder rápidamente, coloca tus marcadores aquí en la barra de marcadores. Importar marcadores ahora...

Base de datos creada exitosamente

Figura 22. C Creación base de datos 
Se procede a crear la tabla "indicadores", con los parámetros deseados

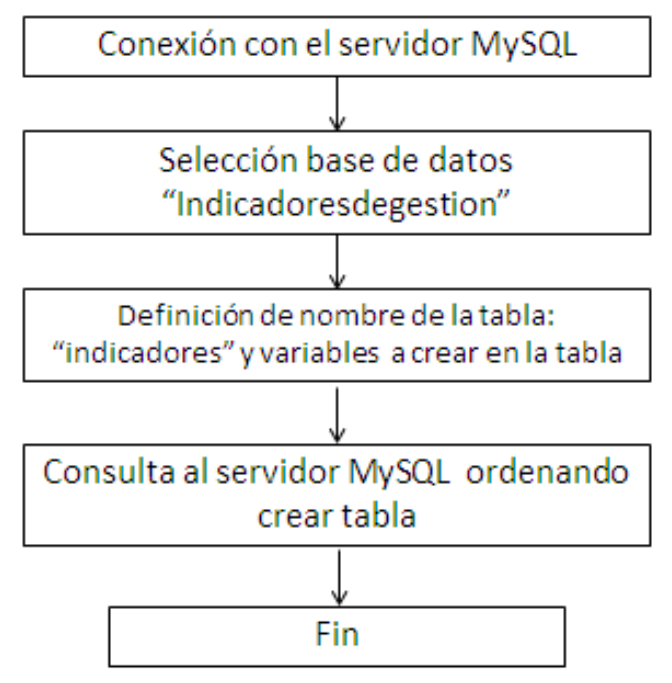

Figura 23. Creación tabla indicadores

Guardamos el archivo con el nombre crearbdtotal.php y lo ejecutamos en el navegador web

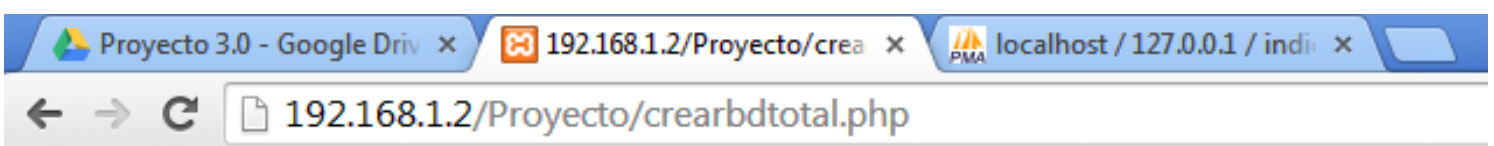

Base de datos creada exitosamente

Figura 24. Creación tabla 
Se procede a crear la tabla "meta", con los parámetros deseados

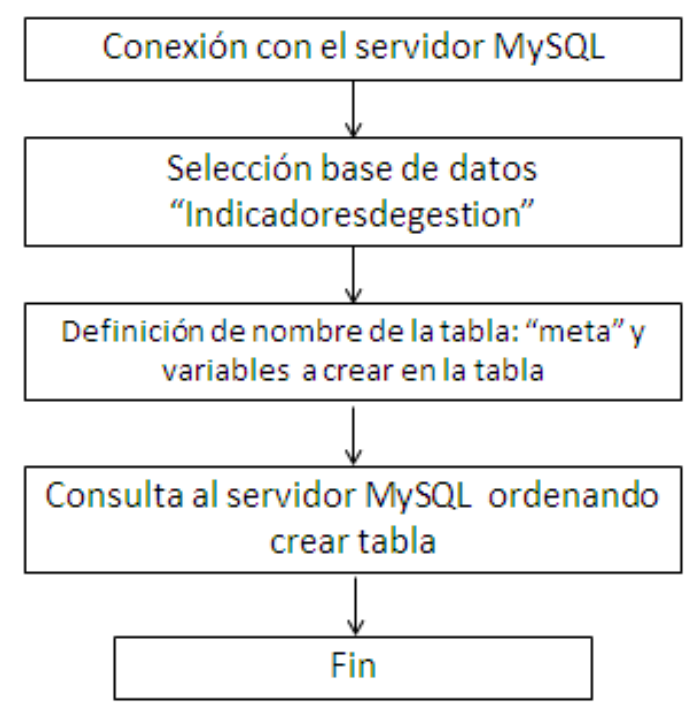

Figura 25. C C C $\quad$ reación tabla meta

Guardamos el archivo con el nombre crearbdmeta.php y lo ejecutamos en el navegador web

\begin{tabular}{|c|}
\hline \\
\hline \\
\hline L Proyecto 3.0 - Google Driv $\times$ 192.168.1.2/Proyecto/crea $\times$ PAd localhost/127.0.0.1/indi $\times \square$ \\
\hline
\end{tabular}

Base de datos creada exitosamente

Figura 26. Creación tabla 
Verificamos en el administrador si las tablas se crearon correctamente accediendo a la ruta: http://localhost/phpmyadmin/

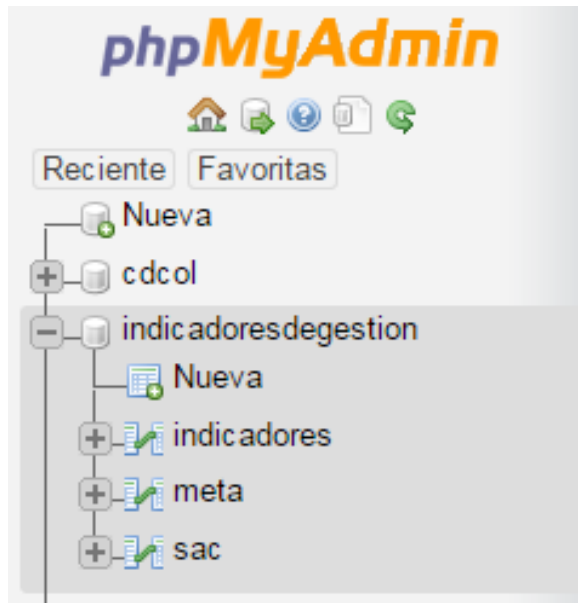

Figura 27. Base de datos y tablas creadas

\section{막 Servidor 127 0.0.1 „0 Base de datos: indicadoresdegestion}

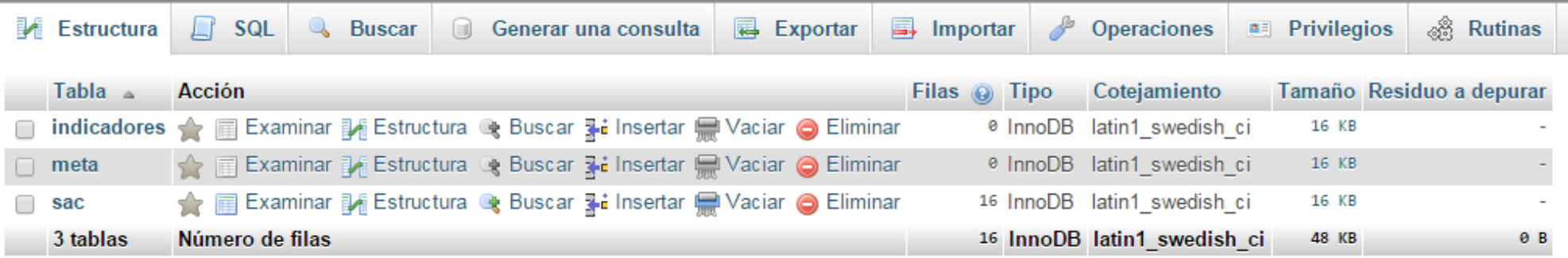

Figura 28. Tablas creadas 


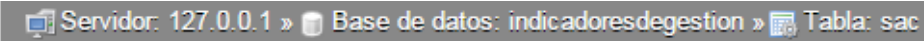

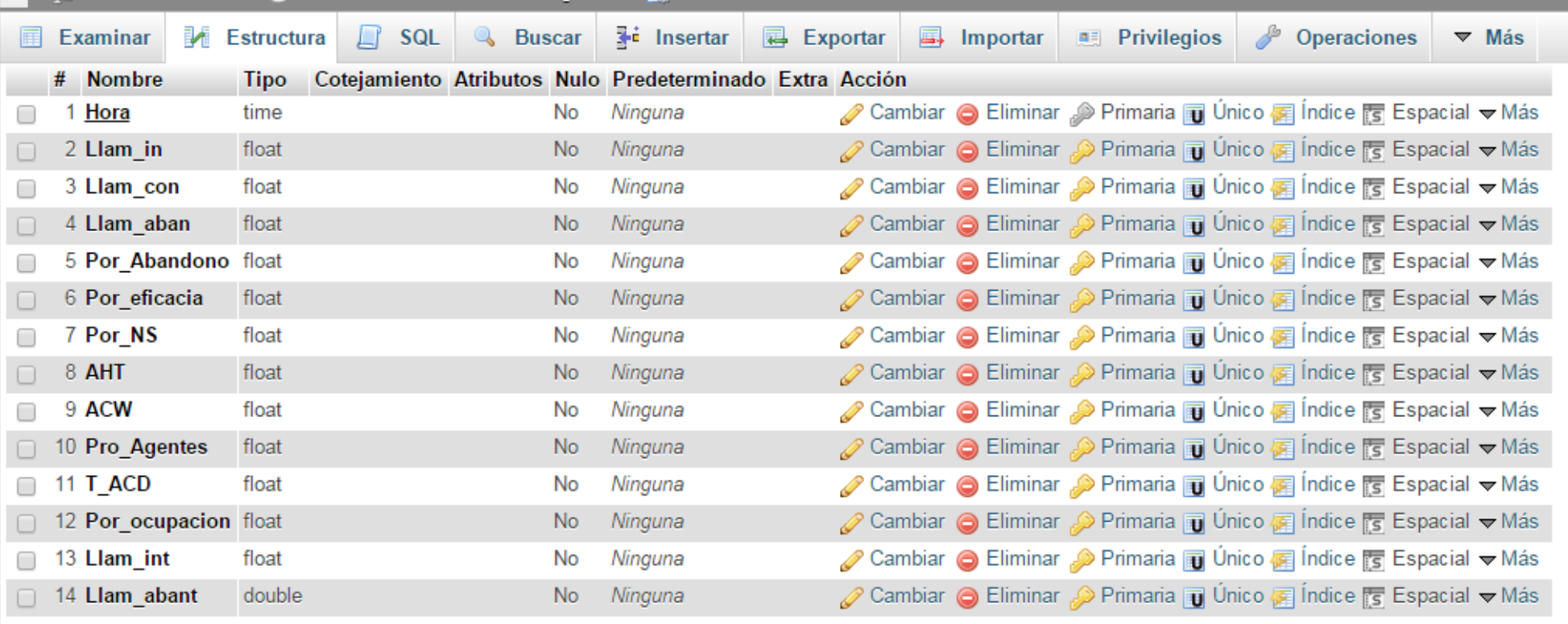

Figura 29. Tabla sac

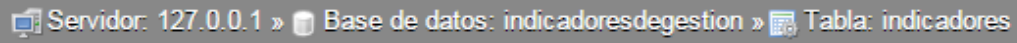

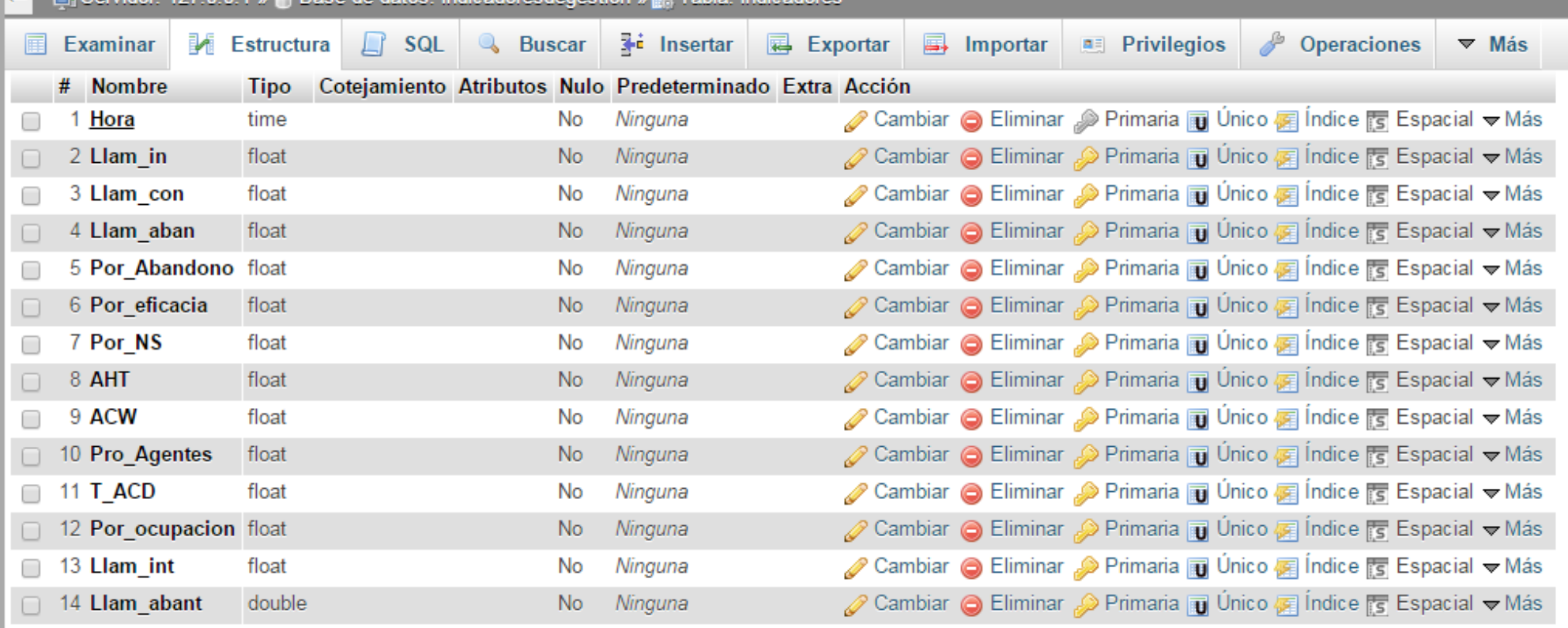

Figura 30. Tabla indicadores 


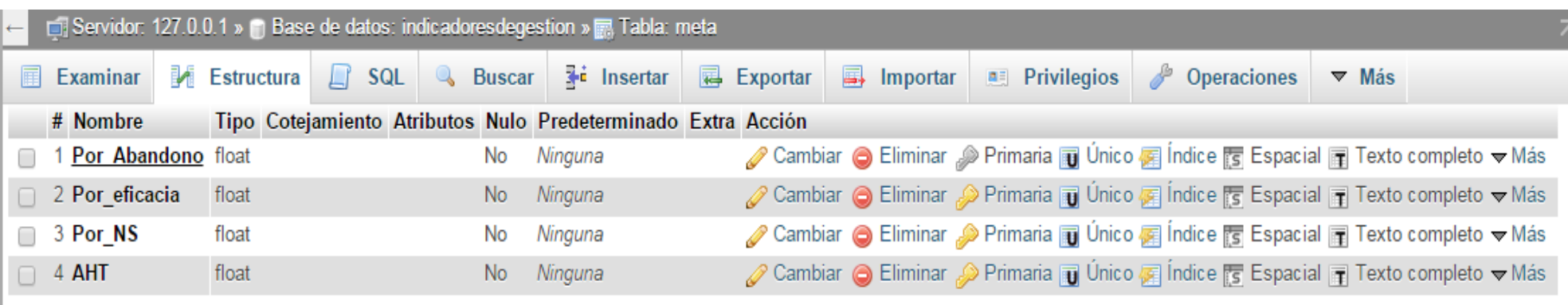

Figura 31. Tabla meta 


\section{Almacenamiento automático de la información en las tablas de la base de datos}

Para almacenar los indicadores de gestión que están en el archivo de texto plano, primero es necesario eliminar el encabezado del archivo, para esto, se crea un programa en php que elimine las dos primeras líneas del archivo.

Las líneas que se desea eliminar tiene la siguiente estructura:

$02 / 01 / 2015$

SIG SAC

Por lo cual se busca " $/$ " para saber si las líneas ya fueron eliminadas del archivo y se procede a eliminar las dos primeras líneas y se guarda el nuevo archivo sobrescribiendo el anterior

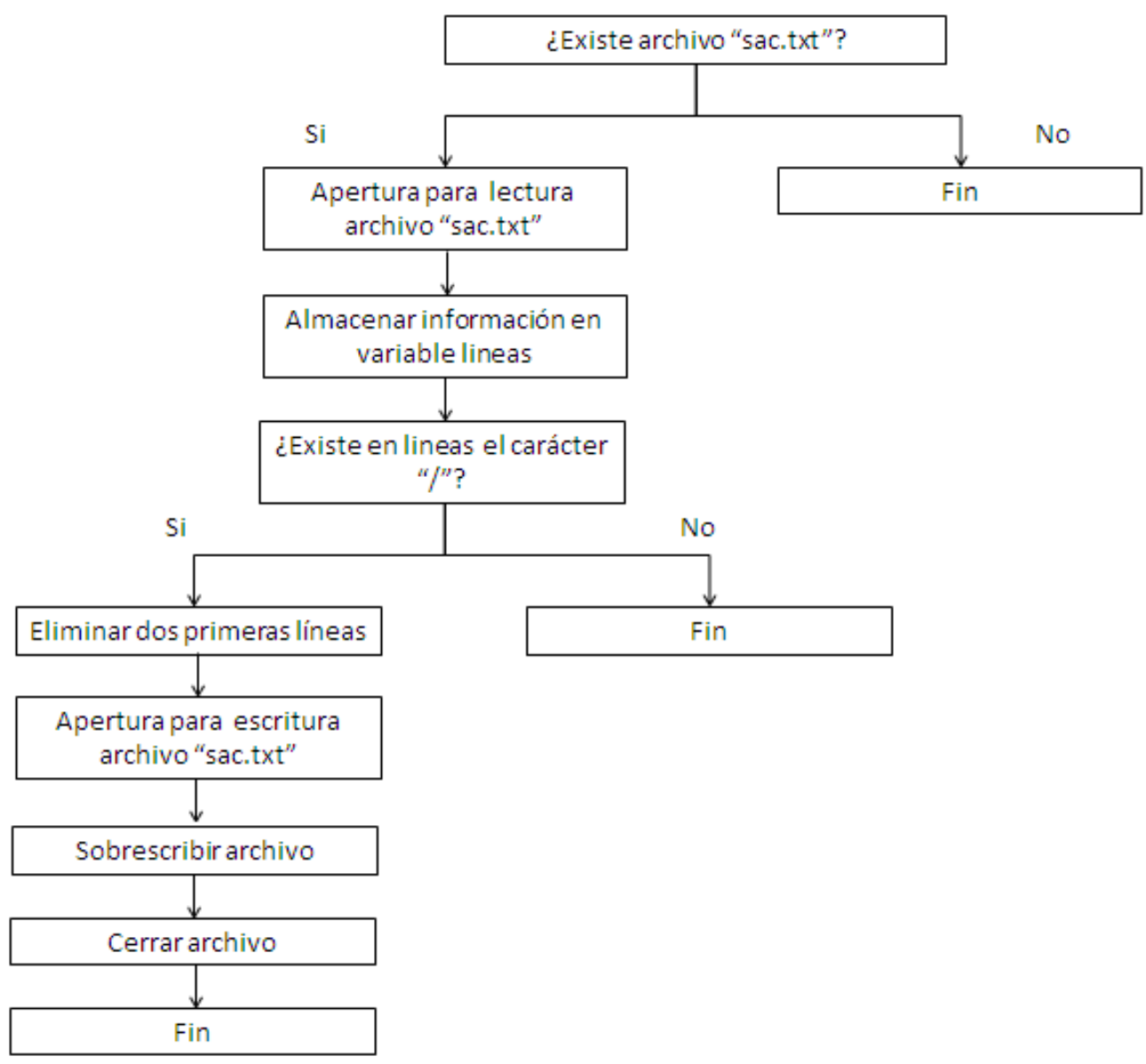

Figura 32. Eliminación de las 2 primeras líneas 
Guardamos el archivo con el nombre eliminasac.php y lo ejecutamos en el navegador con la dirección http://192.168.1.4/Proyecto/eliminasac.php

Al revisar el archivo, se verifica que las 2 primeras líneas fueron eliminadas

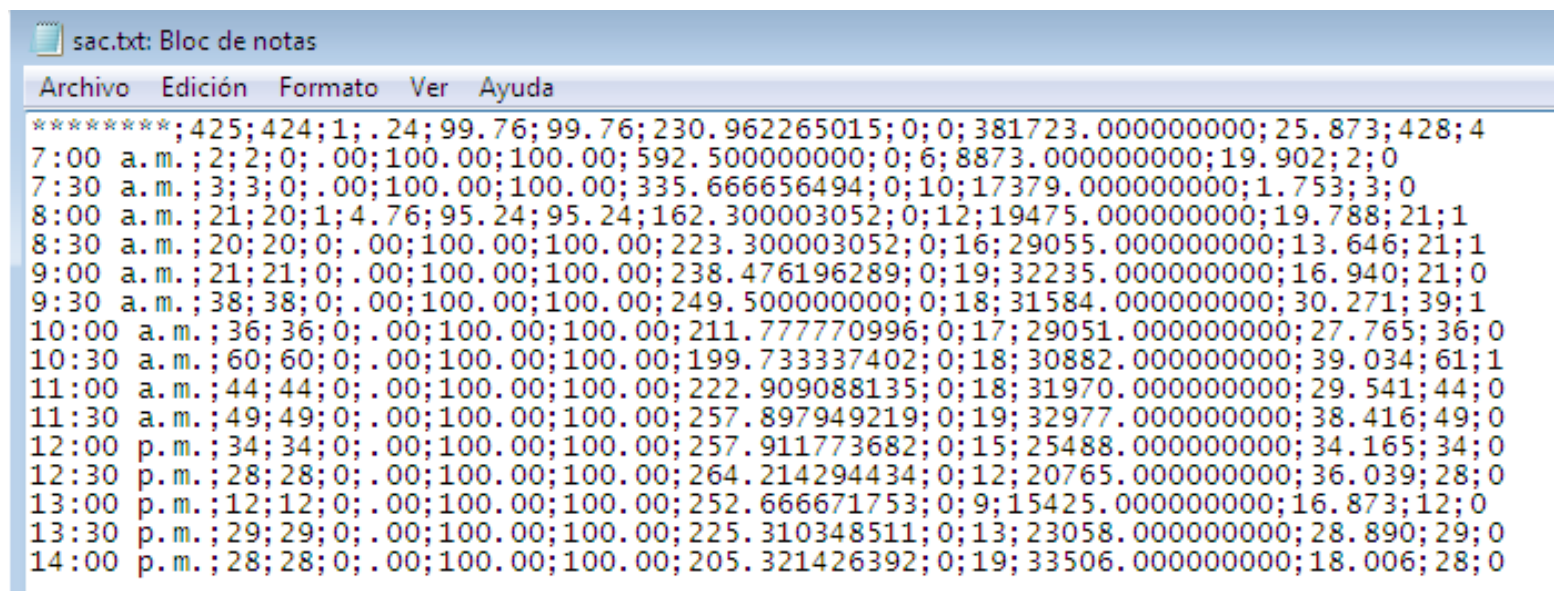

Figura 33. Nuevo archivo sac.txt

En la primera línea del nuevo archivo de texto, se encuentra la información de los indicadores de gestión totales del día, por lo cual se creará un nuevo archivo de texto con esa línea eliminándola del archivo sac.txt

Para realizar este procedimiento, primero se crea un programa en php, el cual creé un nuevo archivo de texto con solo la primera línea del archivo sac.txt. se guarda el programa con el nombre eliminatotal.php y se ejecuta en el navegador con la ruta: http://192.168.1.2/Proyecto/eliminatotal.php 


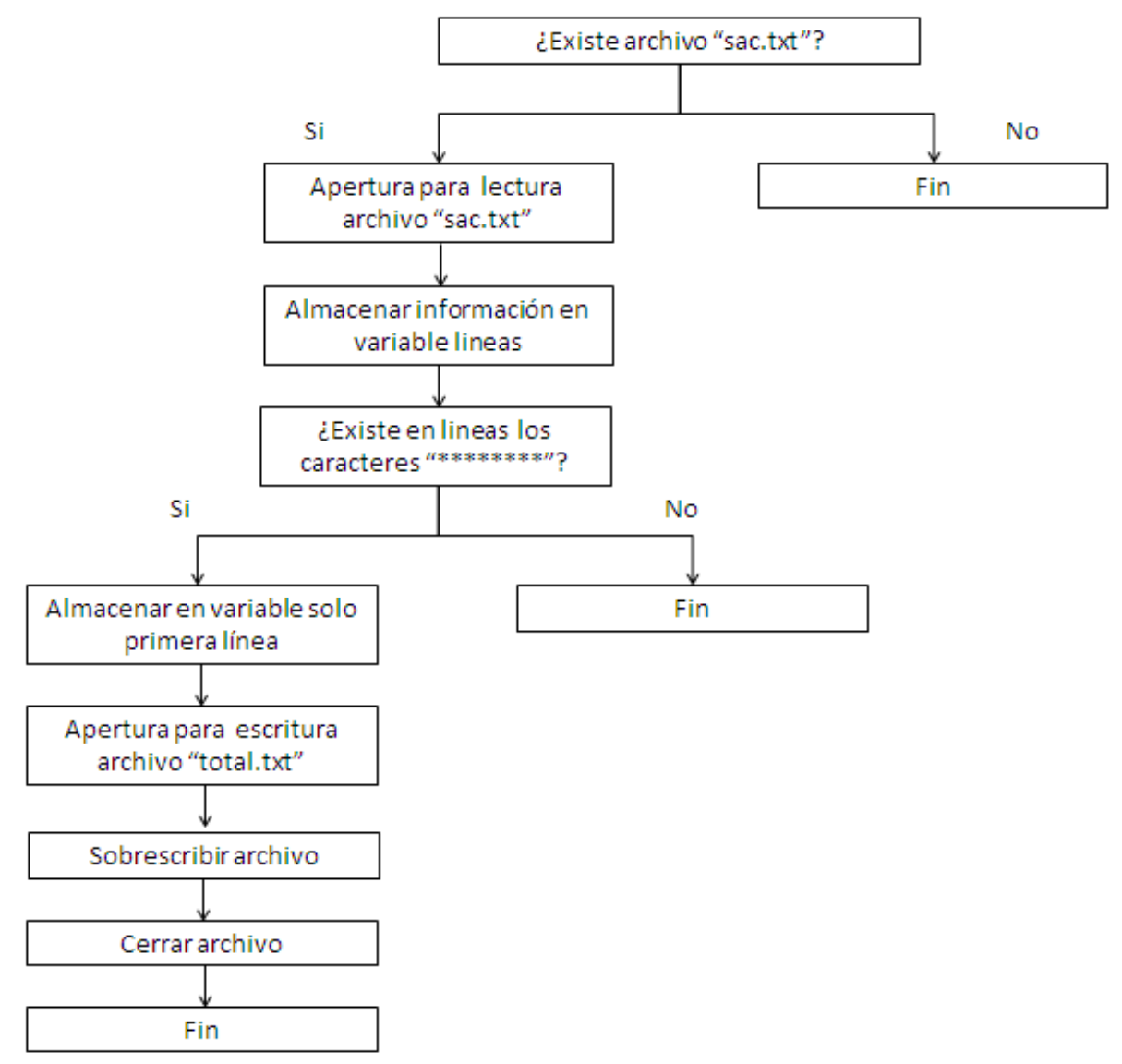

Figura 34. Creación archivo total.txt

Al ejecutar el programa, se crea un nuevo archivo de texto con el nombre "total.txt", en el cual solo se encuentra la información de los indicadores de gestión acumulados del día.

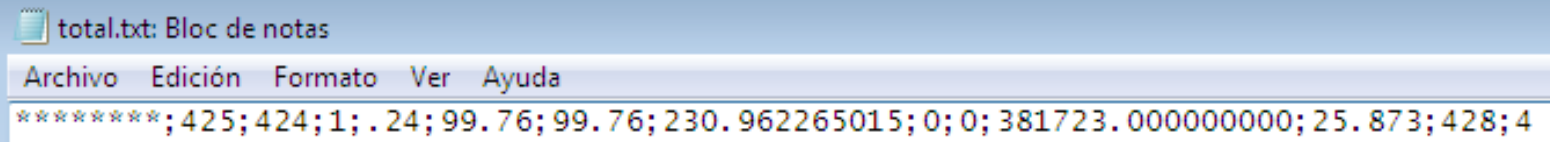

Figura 35. Archivo total.txt 
Ahora es necesario eliminar la primera línea del archivo sac.txt, para lo cual se crea un programa el cual eliminara esta línea.

Se abre el archivo sac.txt, se guarda a información en una variable y se busca “********”, los cuales indican que la línea corresponde a los indicadores de gestión acumulados del día.

Se elimina la línea y se guarda la información en un archivo de texto llamado sact.txt.

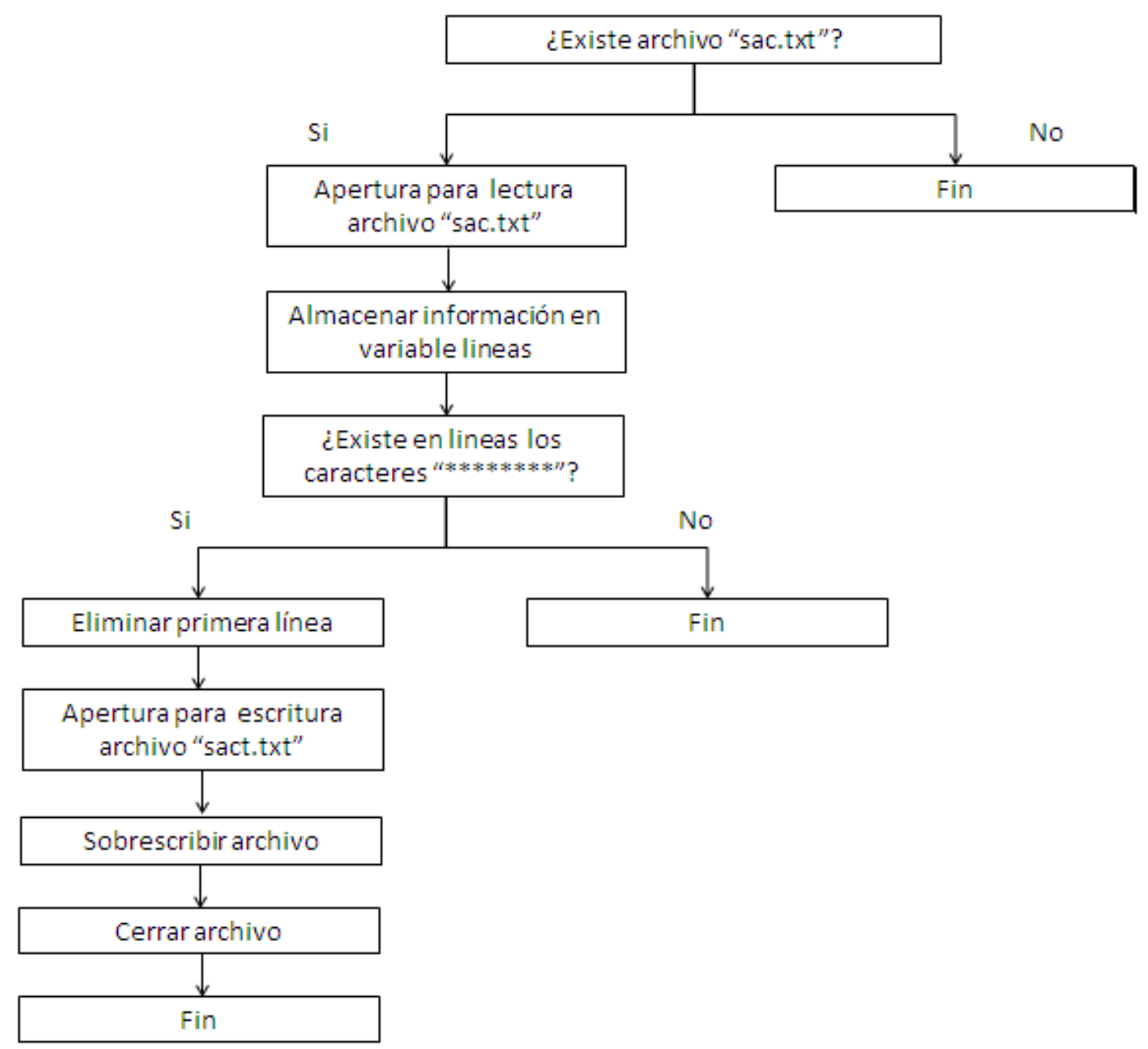

Figura 36. Eliminación primera línea 
Se guarda el programa con el nombre eliminatd.php y se ejecuta en el navegador con la dirección http://192.168.1.2/Proyecto/eliminatd.php

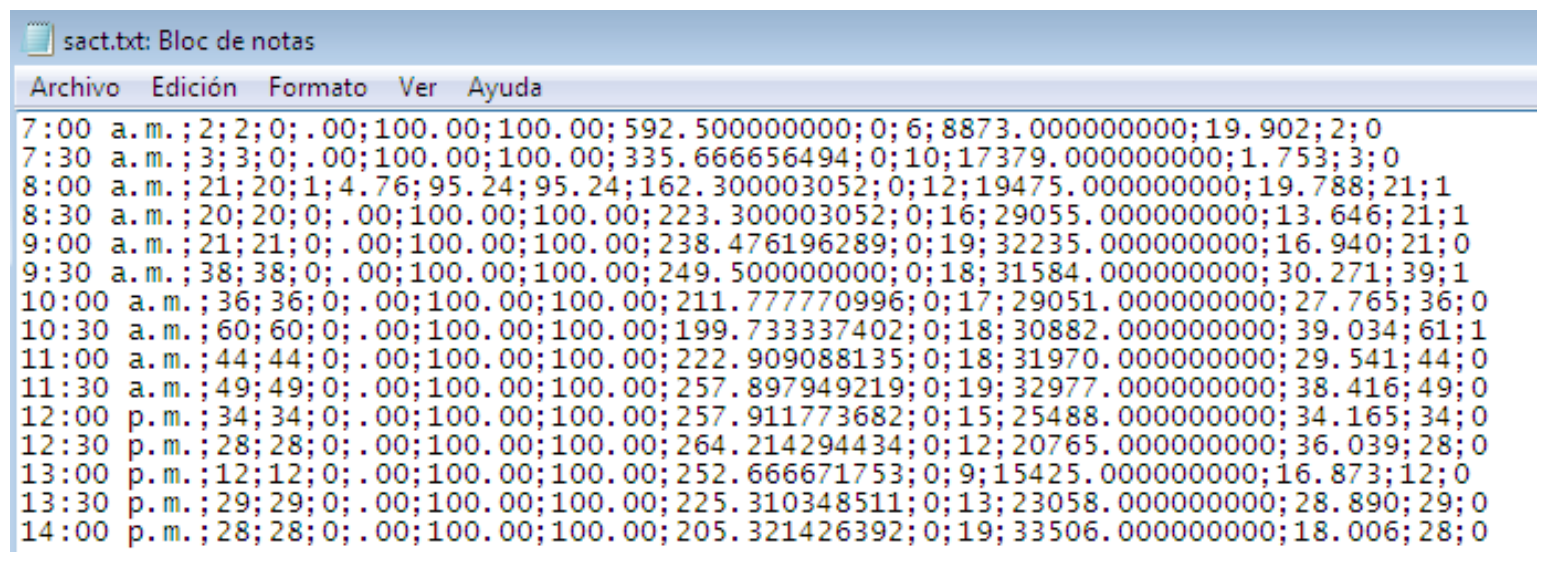

Figura 37. Archivo de texto sact.txt

Con los nuevos archivos de texto, se procede a almacenar la información en las tablas de la base de datos.

Se establece la conexión con la base de datos y se abre el archivo sact.txt y se almacena en la variable filas

Listamos la información almacenada en la variable value, diciendo que cada valor termina en cada punto y coma e insertamos esta información en la tabla sac.

Este procedimiento lo debe realizar desde la columna hora, que es la primera columna de la base de datos, hasta la columna Llam_abant que es la última de la tabla, con lo cual se guardara la información en otro fila de la tabla. 


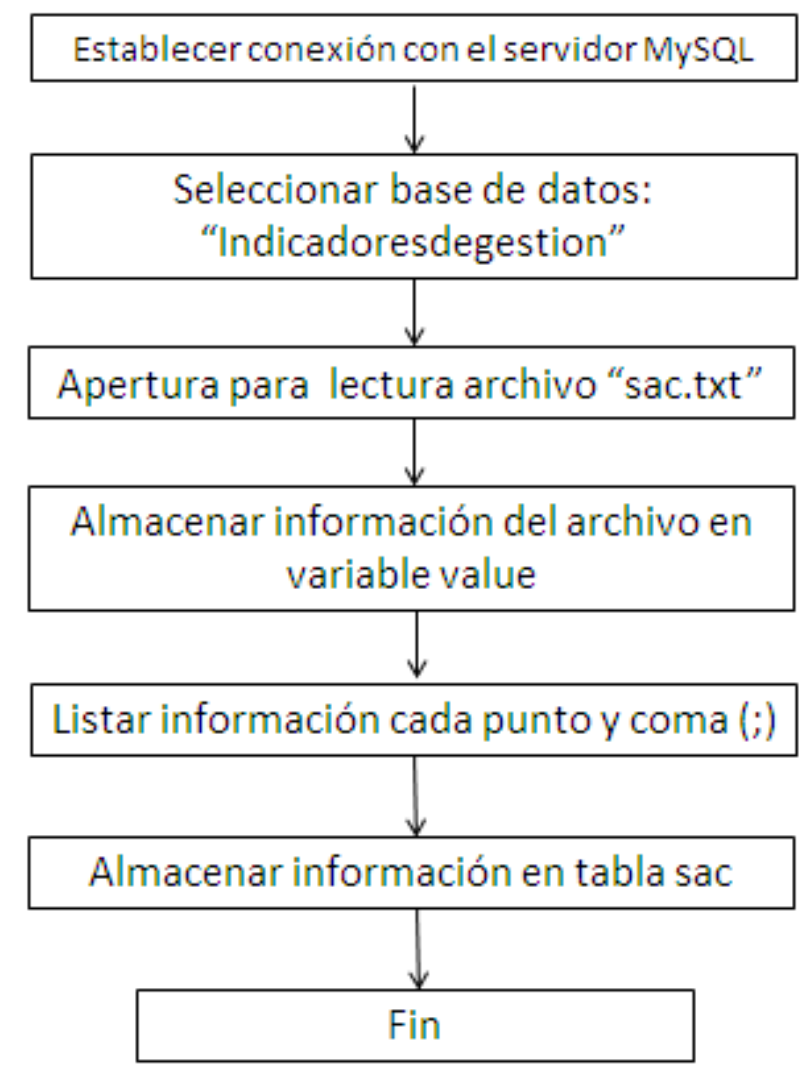

Figura 38. Proceso de almacenamiento de la información

Se guarda el programa con el nombre cargabasesac.php y se ejecuta en el navegador web con la dirección: http://192.168.1.4/Proyecto/cargabasesac.php

Se verifica en el administrador si la información se almaceno correctamente en la base de datos 


\section{묵 Servidor: 127 0.0.1 „ Base de datos: indicadoresdegestion »}

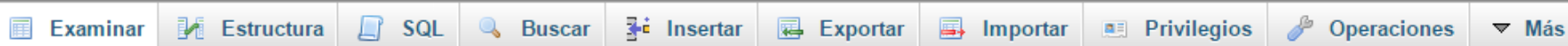
Ordenar según la clave: Ninguna

\begin{tabular}{|c|c|c|c|c|c|c|c|c|c|c|c|c|}
\hline $\begin{array}{l}+ \text { Opciones } \\
\leftarrow \top \rightarrow\end{array}$ & Hora & Llam_in & Llam_con & Llam_aban & Por_Abandono & Por_eficacia & Por_NS & AHT & ACW & Pro_Agentes & T_ACD & Por_ocup \\
\hline$\square$ Editar ̧ㅜ $\square$ Copiar $\odot$ Borrar & 07:00:00 & 2 & 2 & 0 & 0 & 100 & 100 & 592.5 & 0 & 6 & 8873 & \\
\hline 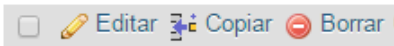 & 07:30:00 & 3 & 3 & 0 & 0 & 100 & 100 & 335.667 & 0 & 10 & 17379 & \\
\hline$\square$ Editar 가 & 08:00:00 & 21 & 20 & 1 & 4.76 & 95.24 & 95.24 & 162.3 & 0 & 12 & 19475 & \\
\hline$\square$ Editar ż: Copiar $\odot$ Borrar & 08:30:00 & 20 & 20 & 0 & 0 & 100 & 100 & 223.3 & 0 & 16 & 29055 & \\
\hline 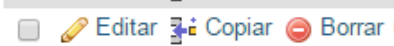 & 09:00:00 & 21 & 21 & 0 & 0 & 100 & 100 & 238.476 & 0 & 19 & 32235 & \\
\hline 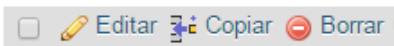 & $09: 30: 00$ & 38 & 38 & 0 & 0 & 100 & 100 & 249.5 & 0 & 18 & 31584 & \\
\hline$\square$ Editar 굴 Copiar $\odot$ Borrar & $10: 00: 00$ & 36 & 36 & 0 & 0 & 100 & 100 & 211.778 & 0 & 17 & 29051 & \\
\hline$\square$ Editar žk Copiar $\odot$ Borrar & $10: 30: 00$ & 60 & 60 & 0 & 0 & 100 & 100 & 199.733 & 0 & 18 & 30882 & \\
\hline 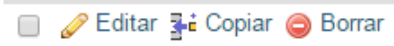 & $11: 00: 00$ & 44 & 44 & 0 & 0 & 100 & 100 & 222.909 & 0 & 18 & 31970 & \\
\hline$\square$ Editar żk Copiar $\odot$ Borrar & $11: 30: 00$ & 49 & 49 & 0 & 0 & 100 & 100 & 257.898 & 0 & 19 & 32977 & \\
\hline 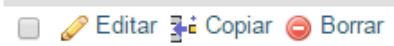 & $12: 00: 00$ & 34 & 34 & 0 & 0 & 100 & 100 & 257.912 & 0 & 15 & 25488 & \\
\hline$\square$ Editar 하. Copiar (-) Borrar & $12: 30: 00$ & 28 & 28 & 0 & 0 & 100 & 100 & 264.214 & 0 & 12 & 20765 & \\
\hline$\square$ Editar żł Copiar $\odot$ Borrar & $13: 00: 00$ & 12 & 12 & 0 & 0 & 100 & 100 & 252.667 & 0 & 9 & 15425 & \\
\hline 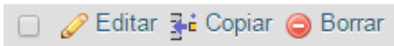 & $13: 30: 00$ & 29 & 29 & 0 & 0 & 100 & 100 & 225.31 & 0 & 13 & 23058 & \\
\hline$\square$ Editar 楼 Copiar $\odot$ Borrar & $14: 00: 00$ & 28 & 28 & 0 & 0 & 100 & 100 & 205.321 & 0 & 19 & 33506 & \\
\hline
\end{tabular}

Figura 39. Proceso de almacenamiento de la información

Se realiza el mismo procedimiento para almacenar la información en la tabla indicadores, en la cual se almacenará los indicadores de gestión acumulados del día.

http://192.168.1.2/Proyecto/cargabasetotal.php

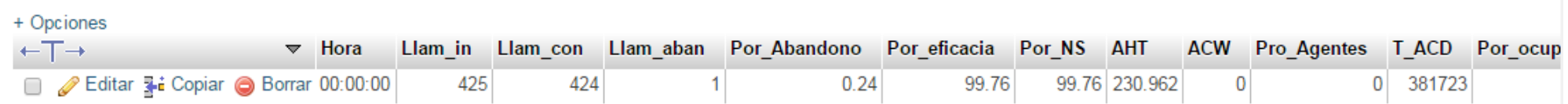

Figura 40. Tabla indicadores 
Se crea un index principal para realizar estos procedimientos index2.php:

- eliminasac.php

- indext.php:

- eliminatotal.php

- cargabasetotal.php

- eliminatd.php

- cargabasesac.php

Se guarda el index principal con el nombre index2.php, el cual se puede ejecutar en el navegador y realizará todos los procedimientos anteriormente realizados, se ejecuta con la ruta http://192.168.1.2/Proyecto/index2.php

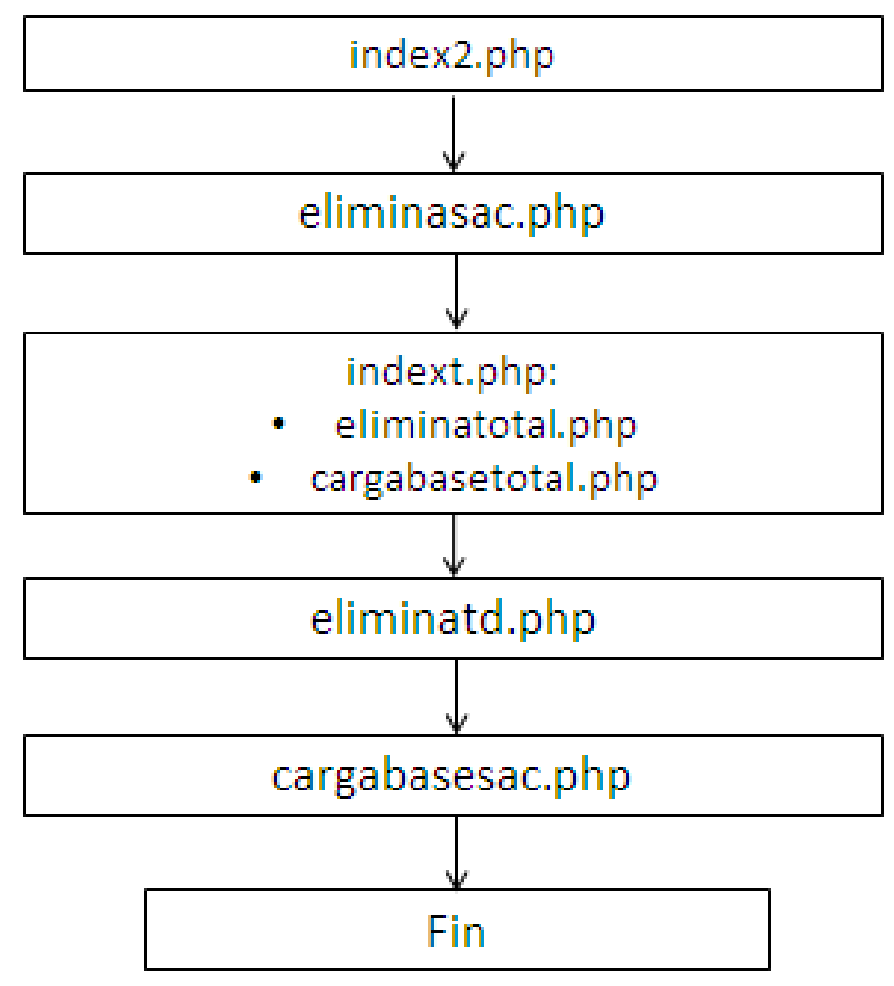

Figura $41 . \quad$ index2.php 


\section{Programación tarea automática}

Para que el almacenamiento en las tabas de la base de datos sea automático, se creará una tarea automática en el programador de tareas de Windows.

Antes de crear la tarea, se debe crear un archivo de procesamiento por lotes .bat, para que sea ejecutado en la tarea, en el cual se ordenara ejecutar el script creado con AVAYA CMS

Este archivo se crea en block de notas, en el cual se escribe la ruta de donde se encuentra el script a ejecutar y se guarda con la extensión .bat

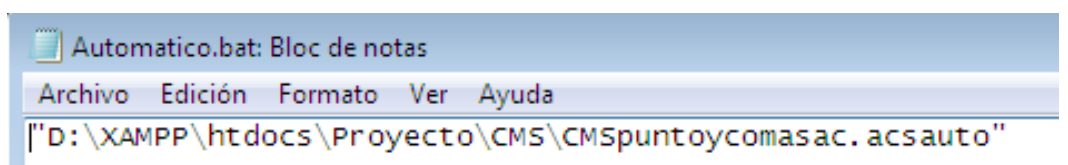

Figura 42. Archivo automatico.bat

Se ejecuta el archivo y al finalizar el procedimiento se cerraran las dos pantallas correspondientes al AVAYA CMS y al archivo .bat

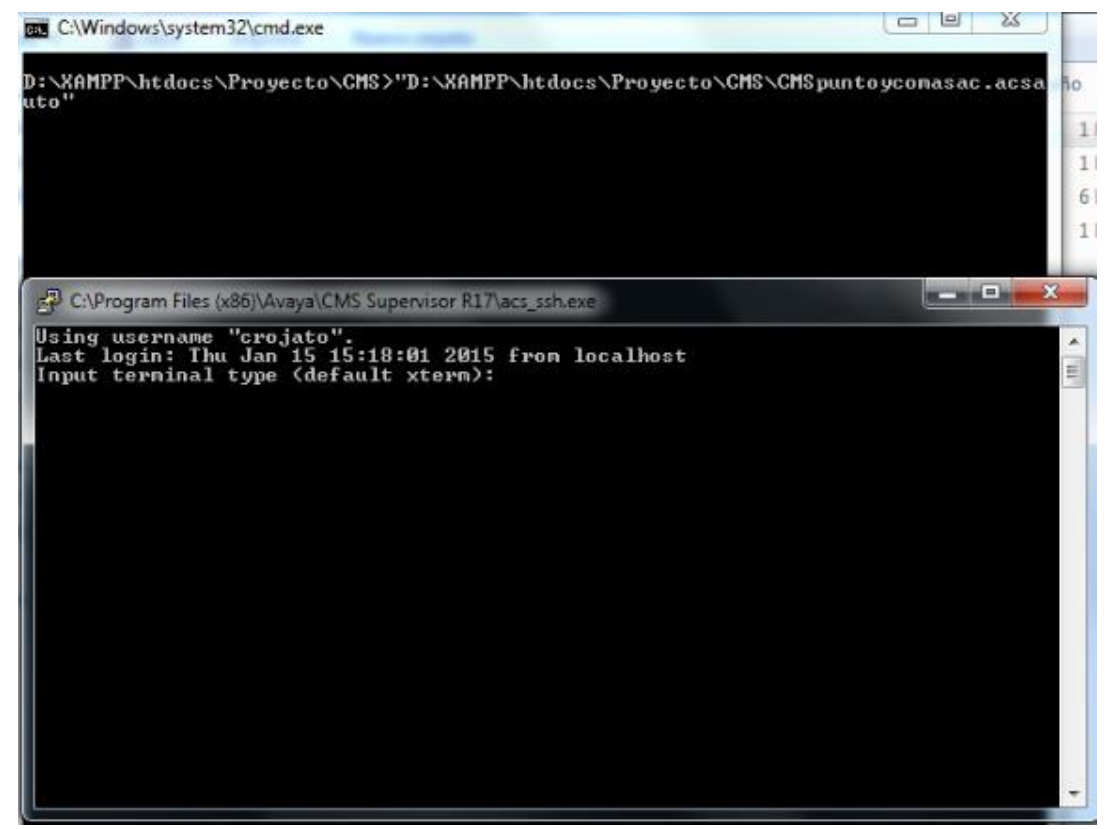

Figura $43 . \quad$ automatico.bat 
Ya con este archivo, se procede a crear la tarea automática con el programaor de tareas de Windows

Abrimos el programador de tareas

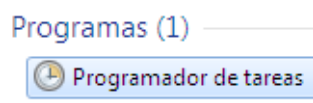

() Programador de tareas

\section{Figura 44. Programador de tareas}

Seleccionamos crear tarea

\begin{tabular}{|c|c|c|}
\hline \multicolumn{3}{|c|}{ Acciones } \\
\hline \multicolumn{2}{|c|}{ Programador de tareas (local) } & $\boldsymbol{\Delta}$ \\
\hline & Conectarse a otro equipo... & \\
\hline 강 & Crear tarea básica... & \\
\hline \multirow[t]{2}{*}{ b) } & Crear tarea... & \\
\hline & Importar tarea... & \\
\hline 挋成 & Mostrar todas las tareas en ejecuci... & \\
\hline \multirow[t]{3}{*}{ 圈 } & Habilitar el historial de todas las tar... & \\
\hline & Configuración de cuenta de servici... & \\
\hline & Ver & 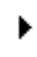 \\
\hline$Q$ & Actualizar & \\
\hline$?$ & Ayuda & \\
\hline
\end{tabular}

Figura 45. Programador de tareas

Se le da nombre a la tarea Bat, se selecciona que se ejecute con los privilegios más altos y click en aceptar 


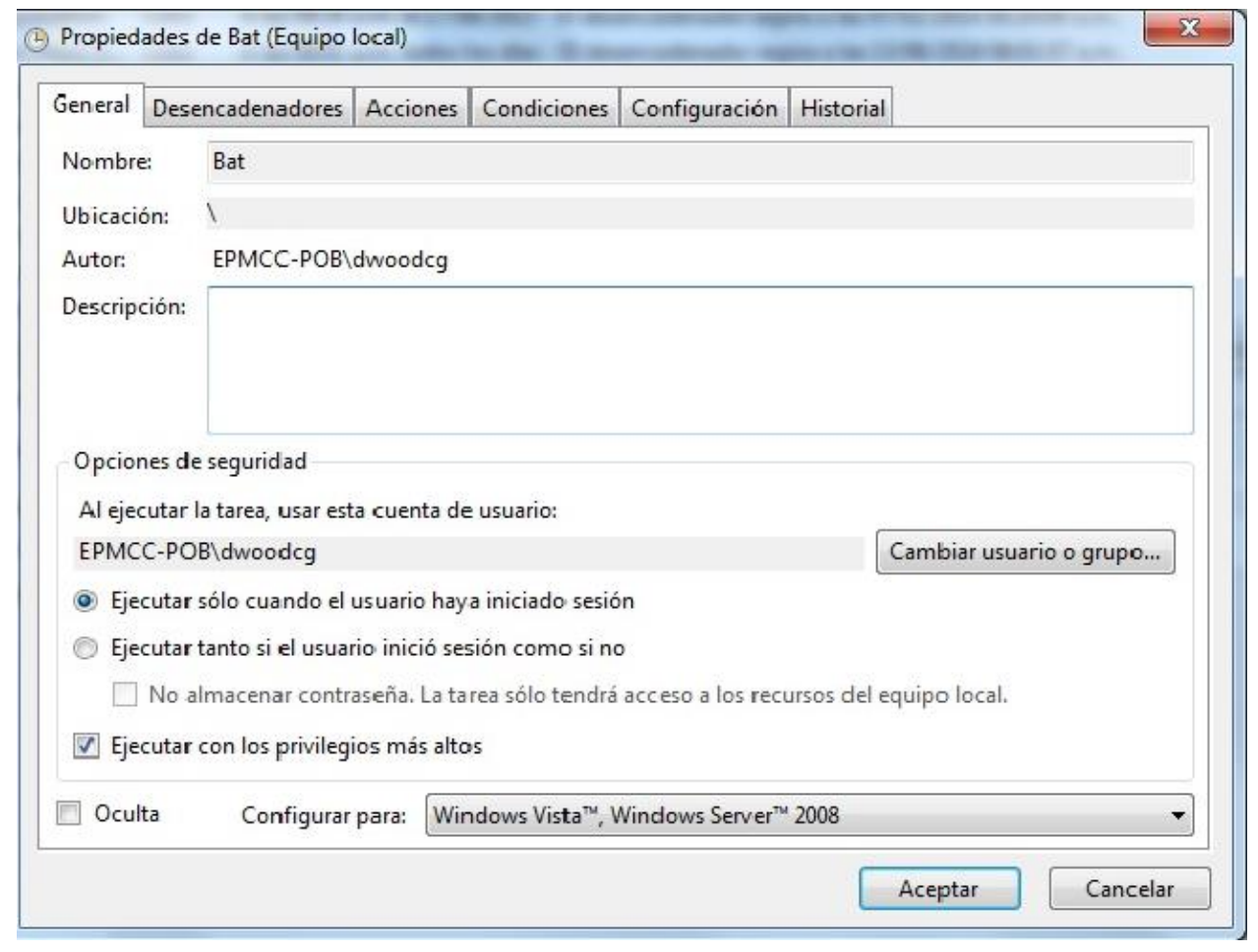

Figura 46. Programador de tareas

Seleccionamos la pestaña desencadenadores, y creamos uno nuevo. Seleccionamos le fecha de inicio de la tarea y la hora, dado que los indicaodores de gestión en el AVAYA CMS se actualizan cada 30 minutos, se elige repetir la tarea cada 30 minutos durante indefinidamente y clik en aceptar. 


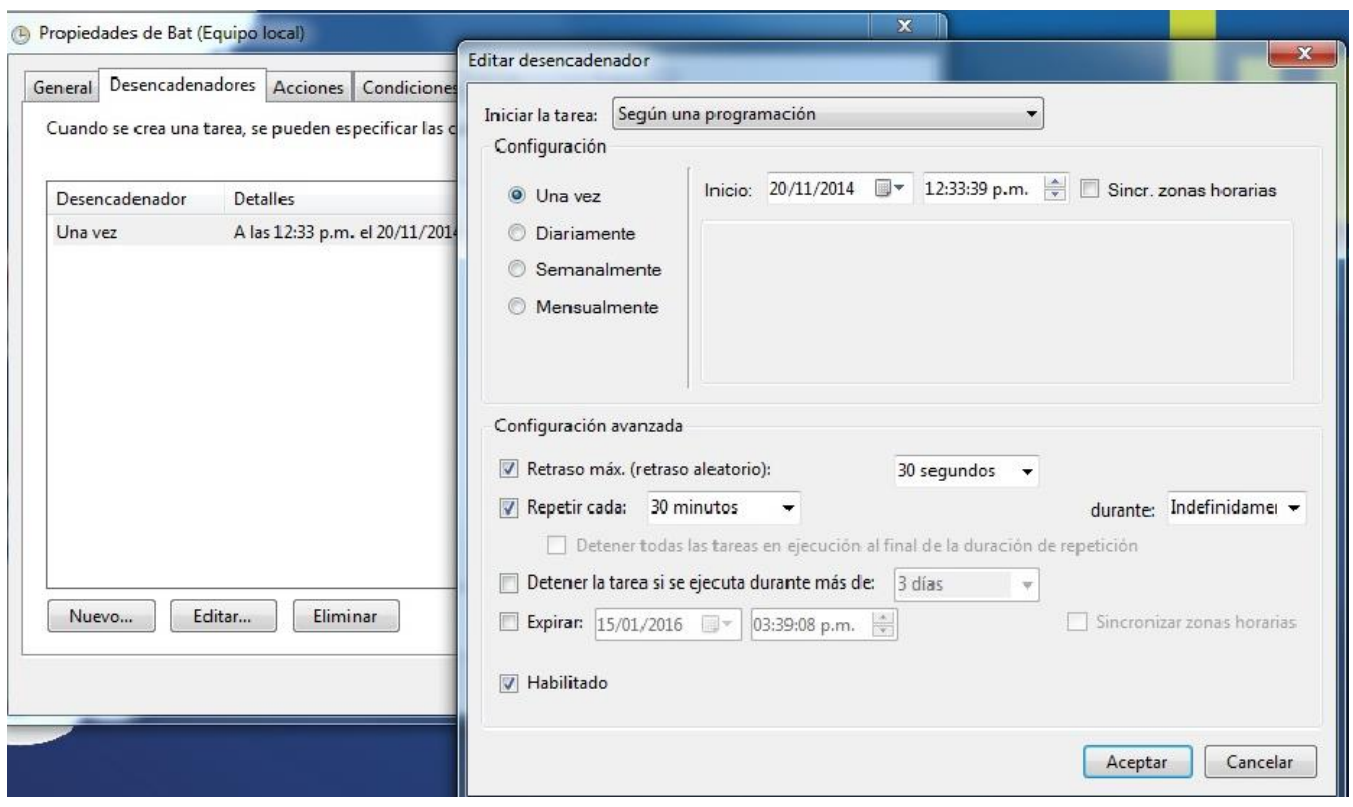

Figura 47. Programador de tareas

Seleccionamos la pestaña de acciones y creamos una nueva acción, elegimos iniciar un programa, escribimos la ubicación de donde se encuentra el archivo automatico.bat.

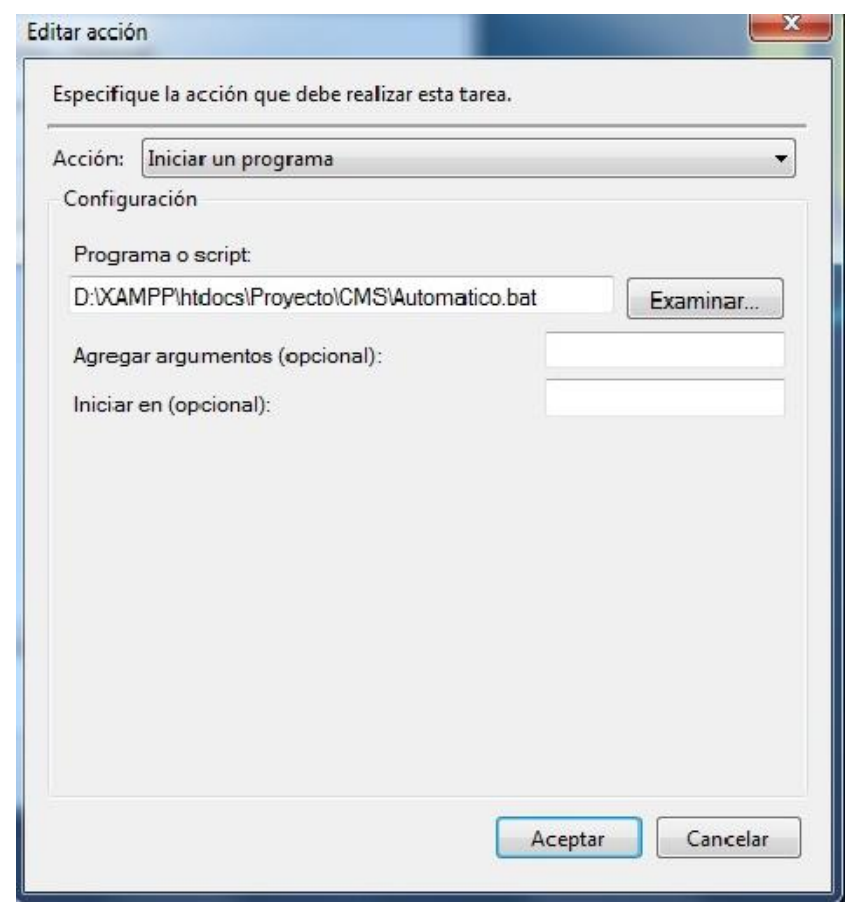

Figura 48. Programador de tareas 
Creamos una nueva acción, en la cual se ejecutara automáticamente el programa indext2.php

Se escribe la ruta donde se encuentra el ejecutable del navegador web y en Agregar argumentos se escribe la dirección: http://192.168.1.2/Proyecto/index2.php

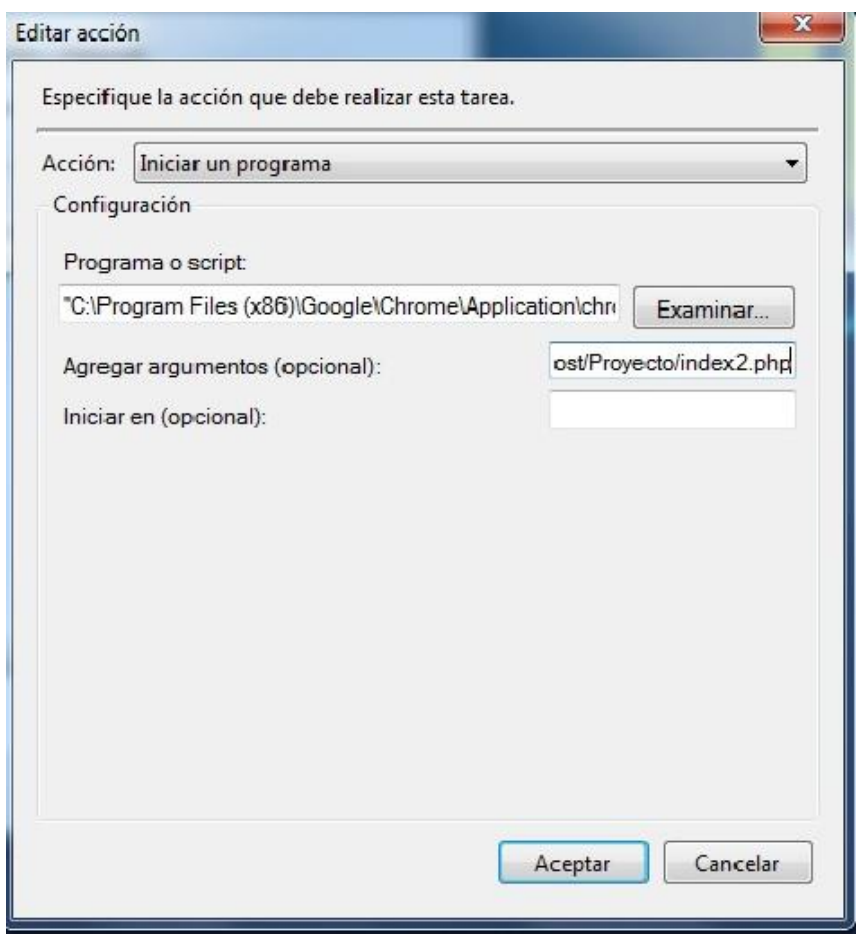

Figura 49. Programador de tareas 


\section{Verificamos si la tarea se creó correctamente.}

\begin{tabular}{|c|c|c|}
\hline Nombre & Estado & Desencadenadores \\
\hline (1) Adobe Acro... & En cola & Al iniciar la sesión un usuario - Tras desencadenarse, repetir cada 03:30:00 indefinidamente. El desen \\
\hline (1) Adobe Flash... & Listo & A las 07:44 p.m. todos los días - Tras desencadenarse, repetir cada 1 hora durante 1 día. \\
\hline (4) Bat & Listo & A las 12:33 p.m. el 20/11/2014 - Tras desencadenarse, repetir cada 30 minutos indefinidamente. \\
\hline (1) GoogleUpda... & Listo & Se definieron varios desencadenadores \\
\hline (1) GoogleUpda... & Listo & A las 08:55 a.m. todos los días - Tras desencadenarse, repetir cada 1 hora durante 1 día. \\
\hline (1) Index y carg... & Listo & A las 10:10 a.m. el 10/1.2/2014 - Tras desencadenarse, repetir cada 15 minutos indefinidamente. \\
\hline (4) Registration & Listo & A las 09:24 a.m. el 17/08/2013 - El desencadenador expira a las 07/02/2014 09:24:09 a.m.. \\
\hline (4) User_Feed_S... & Listo & A las 08:01 a.m. todos los días - El desencadenador expira a las 13/08/2024 08:01:57 a.m.. \\
\hline (1) User_Feed_S... & Listo & A las 05:10 p.m. todos los días - El desencadenador expira a las 22/01/2024 05:10:33 p.m.. \\
\hline () User_Feed_S... & Listo & A las 02:24 p.m. todos los días - El desencadenador expira a las 21/12/2023 02:24:39 p.m.. \\
\hline () User_Feed_S... & Listo & A las 03:31 p.m. todos los días - El desencadenador expira a las 21/12/2023 03:31:15 p.m.. \\
\hline (1) User_Feed_S... & Listo & A las 04:58 p.m. todos los días - El desencadenador expira a las 17/07/2024 04:58:37 p.m.. \\
\hline (1) User_Feed_S... & Listo & A las 10:15 p.m. todos los días - El desencadenador expira a las 18/08/2023 10:15:35 p.m.. \\
\hline (1) User_Feed_S... & Listo & A las 04:04 p.m. todos los días - El desencadenador expira a las 22/01/2024 04:04:58 p.m.. \\
\hline (4) User_Feed_S... & Listo & A las 12:16 p.m. todos los días - El desencadenador expira a las 24/07/2024 12:16:27 p.m.. \\
\hline 1 & & III \\
\hline
\end{tabular}

Figura 50. Programador de tareas 


\section{Diseño del aplicativo web}

El aplicativo web tendrá la siguiente forma:

\section{TITULO}

\section{Indicadores de gestión por intervalo de tiempo}

\section{Subtitulo}

Cuadro comparativo indicadores de gestión acumulados del día con la meta trazada con el cliente

Gráficas comparativas de los indicadores de gestión por intervalo de tiempo con la meta trazada con el cliente

Para proceder con el diseño deseado, primero se deben realizar las consultas a las tablas de la base de datos, para lo cual se crea una rutina de conexión son la base de datos, la cual será la llamada en cada consulta 


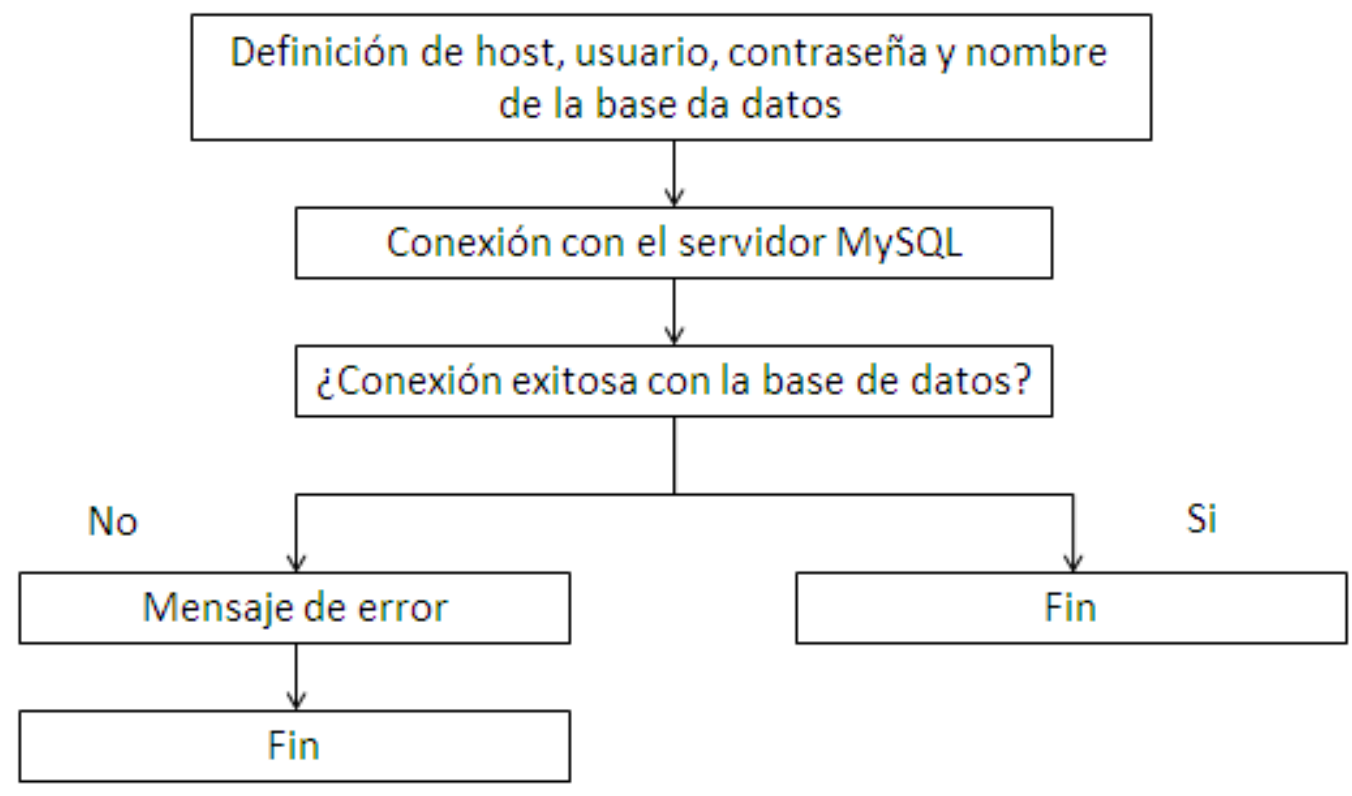

Figura 51. Conexión.php 
Se crea el título a la cabecera del aplicativo, de la misma manera, en el cuerpo se centra el título principal del aplicativo.

Se crea la primera tabla, donde se visualizarán los indicadores de gestión por intervalo de tiempo, a continuación se realiza la consulta a la tabla sac de la base de datos y se guarda en la variable resultado y se procede a organizar la información en la tabla anteriormente creada.

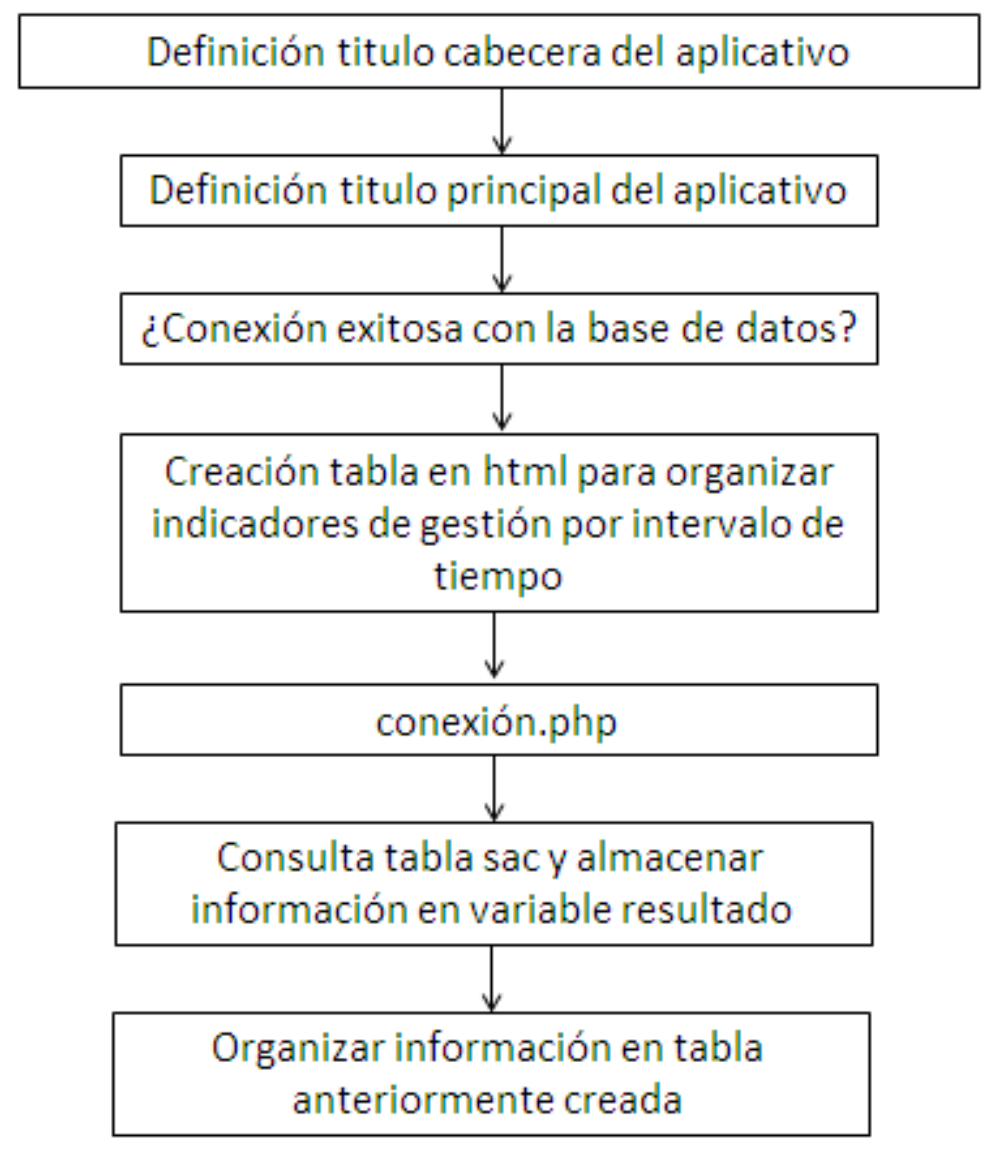

Figura 52. Consulta tabla sac 


\section{Indicadores de gestión por intervalo de tiempo}

\begin{tabular}{|c|c|c|c|c|c|c|c|c|c|c|c|c|c|}
\hline Hora & \begin{tabular}{|l} 
Llamadas \\
entrantes
\end{tabular} & \begin{tabular}{|l}
$\begin{array}{l}\text { Llamadas } \\
\text { contestadas }\end{array}$ \\
\end{tabular} & \begin{tabular}{|l}
$\begin{array}{l}\text { Llamadas } \\
\text { abandonadas }\end{array}$ \\
\end{tabular} & $\begin{array}{l}\% \\
\text { Abandono }\end{array}$ & \begin{tabular}{|l|}
$\%$ \\
Eficacia
\end{tabular} & \begin{tabular}{|l|l|}
$\%$ \\
NDS \\
\end{tabular} & AHT & $\mathrm{ACW}$ & \begin{tabular}{|l|} 
Promedio \\
Agentes
\end{tabular} & $\begin{array}{l}\text { Tiempo } \\
\text { ACD }\end{array}$ & \begin{tabular}{|l|}
$\%$ \\
Ocupacion
\end{tabular} & $\begin{array}{l}\text { Llamadas entrantes } \\
\text { totales }\end{array}$ & $\begin{array}{l}\text { Llamadas abandonadas } \\
\text { totales }\end{array}$ \\
\hline \begin{tabular}{|l|l|}
$07: 00: 00$ \\
\end{tabular} & 2 & 2 & 0 & 0 & 100 & 100 & 592.5 & 0 & 6 & 8873 & 19.902 & 2 & 0 \\
\hline $07: 30: 00$ & 3 & 3 & 0 & 0 & 100 & 100 & 335.667 & 0 & 10 & 17379 & 1.753 & 3 & 0 \\
\hline $08: 00: 00$ & 21 & 20 & 1 & 4.76 & 95.24 & 95.24 & 162.3 & 0 & 12 & 19475 & 19.788 & 21 & 1 \\
\hline $08: 30: 00$ & 20 & 20 & 0 & 0 & 100 & 100 & 223.3 & 0 & 16 & 29055 & 13.646 & 21 & 1 \\
\hline $09: 00: 00$ & 21 & 21 & 0 & 0 & 100 & 100 & 238.476 & 0 & 19 & 32235 & 16.94 & 21 & 0 \\
\hline \begin{tabular}{|l|}
$09: 30: 00$ \\
\end{tabular} & 38 & 38 & 0 & 0 & 100 & 100 & 249.5 & 0 & 18 & 31584 & 30.271 & 39 & 1 \\
\hline $10: 00: 00$ & 36 & 36 & 0 & 0 & 100 & 100 & 211.778 & 0 & 17 & 29051 & 27.765 & 36 & 0 \\
\hline$|10: 30: 00|$ & 60 & 60 & 0 & 0 & 100 & 100 & \begin{tabular}{|l|}
199.733 \\
\end{tabular} & 0 & 18 & 30882 & 39.034 & 61 & 1 \\
\hline $11: 00: 00$ & 44 & 44 & 0 & 0 & 100 & 100 & 222.909 & 0 & 18 & 31970 & 29.541 & 44 & 0 \\
\hline $11: 30: 00$ & 49 & 49 & 0 & 0 & 100 & 100 & 257.898 & 0 & 19 & 32977 & 38.416 & 49 & 0 \\
\hline $12: 00: 00$ & 34 & 34 & 0 & 0 & 100 & 100 & 257.912 & 0 & 15 & 25488 & 34.165 & 34 & 0 \\
\hline 12:30:00 & 28 & 28 & 0 & 0 & 100 & 100 & 264.214 & 0 & 12 & 20765 & 36.039 & 28 & 0 \\
\hline $13: 00: 00$ & 12 & 12 & 0 & 0 & 100 & 100 & 252.667 & 0 & 9 & 15425 & 16.873 & 12 & 0 \\
\hline $13: 30: 00$ & 29 & 29 & 0 & 0 & 100 & 100 & 225.31 & 0 & 13 & 23058 & 28.89 & 29 & 0 \\
\hline $14: 00: 00$ & 28 & 28 & 0 & 0 & 100 & 100 & 205.321 & & 19 & 33506 & 18.006 & 28 & 0 \\
\hline
\end{tabular}

Figura 53. Indicadores de gestión por intervalo de tiempo

Se realiza el mismo procedimiento para la consulta de la tabla "indicadores", la cual tiene la información sobre los indicadores de gestión acumulados del día.

\section{Acumulados del día}

\begin{tabular}{|c|c|c|c|c|c|c|c|c|c|c|c|c|}
\hline \begin{tabular}{|l} 
Llamadas \\
entrantes
\end{tabular} & $\begin{array}{l}\text { Llamadas } \\
\text { contestadas }\end{array}$ & $\begin{array}{l}\text { Llamadas } \\
\text { abandonadas }\end{array}$ & $\begin{array}{l}\text { \% } \\
\text { Abandono }\end{array}$ & $\begin{array}{l}\% \\
\text { Eficacia }\end{array}$ & $\begin{array}{l}\% \\
\text { NDS }\end{array}$ & AHT & ACW & $\begin{array}{l}\text { Promedio } \\
\text { Agentes }\end{array}$ & $\begin{array}{l}\text { Tiempo } \\
\text { ACD }\end{array}$ & $\begin{array}{l}\% \\
\text { Ocupacion }\end{array}$ & $\begin{array}{l}\text { Llamadas entrantes } \\
\text { totales }\end{array}$ & $\begin{array}{l}\text { Llamadas abandonadas } \\
\text { totales }\end{array}$ \\
\hline 425 & 424 & 1 & 0.24 & 99.76 & 99.76 & 230.962 & & 0 & 381723 & 25.873 & 428 & 4 \\
\hline
\end{tabular}

Figura 54. Indicadores de gestión acumulados del día

Para la consulta de la tabla meta, se realiza el mismo procedimiento, teniendo en cuenta que con el cliente, la campaña SIC, solo fija metas para porcentaje de abandono, porcentaje de eficacia, porcentaje de nivel de servicio y AHT.

\section{Meta}

\begin{tabular}{|l||l||l||}
\hline$\%$ Abandono & \% Eficacia & \% NDS \\
\hline 0.5 & 95 & 80 \\
\hline
\end{tabular}

Figura 55. Meta trazada con el cliente SIC 
Con la herramienta Google Chart ${ }^{23}$, se realizan gráficas comparativas de los indicadores de gestión por intervalo del tiempo y acumulados del día, con la meta trazada con el cliente.

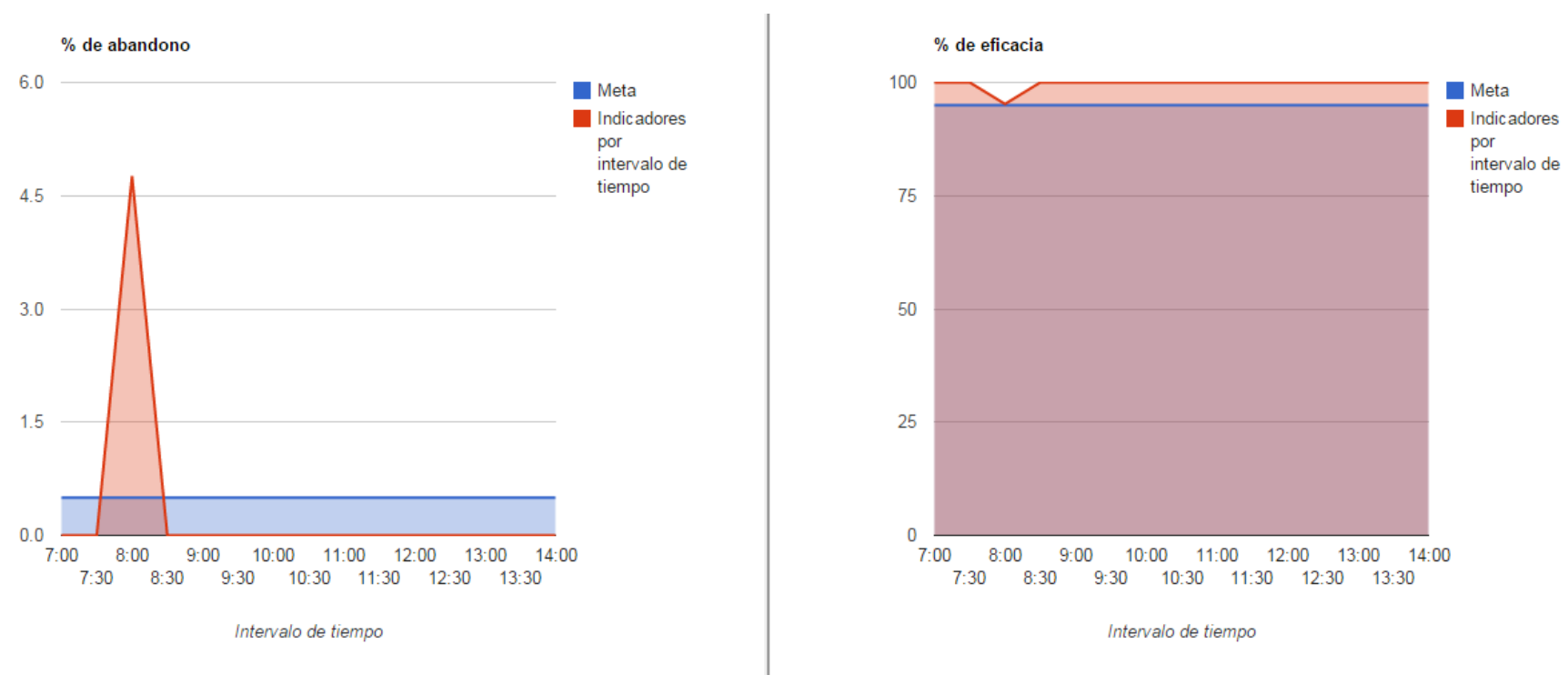

Figura 56. Gráficas comparativas por intervalo de tiempo
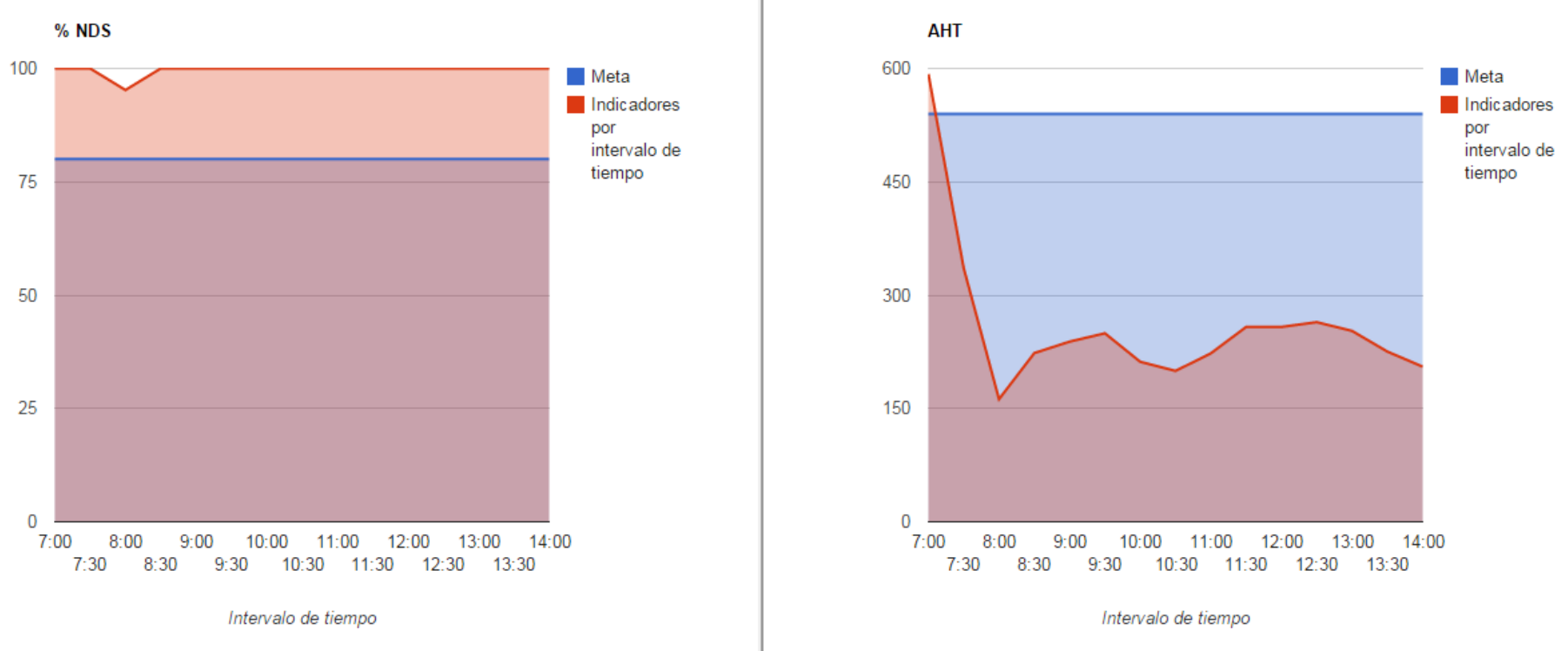

Figura 57. Gráficas comparativas por intervalo de tiempo

${ }^{23}$ Google Chart [en línea] <URL: https://developers.google.com/chart/interactive/docs/gallery> 

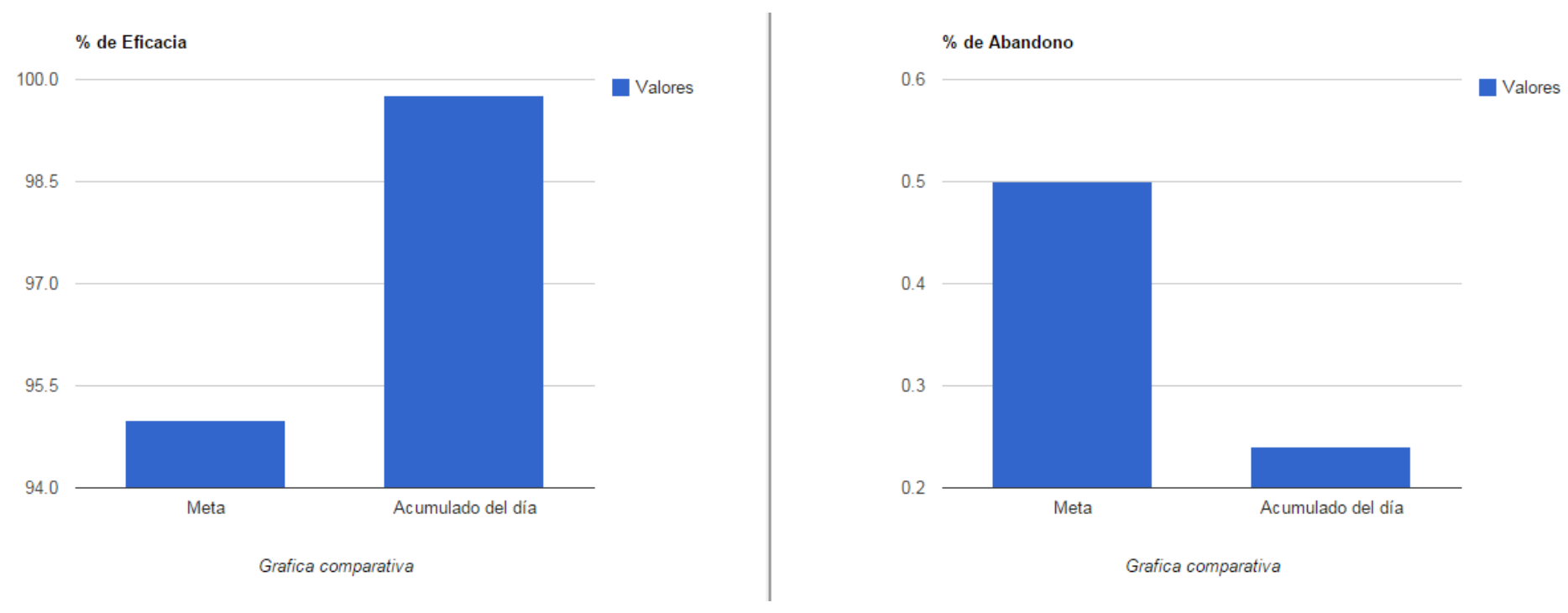

Figura 58. Gráficas comparativas acumulados del día
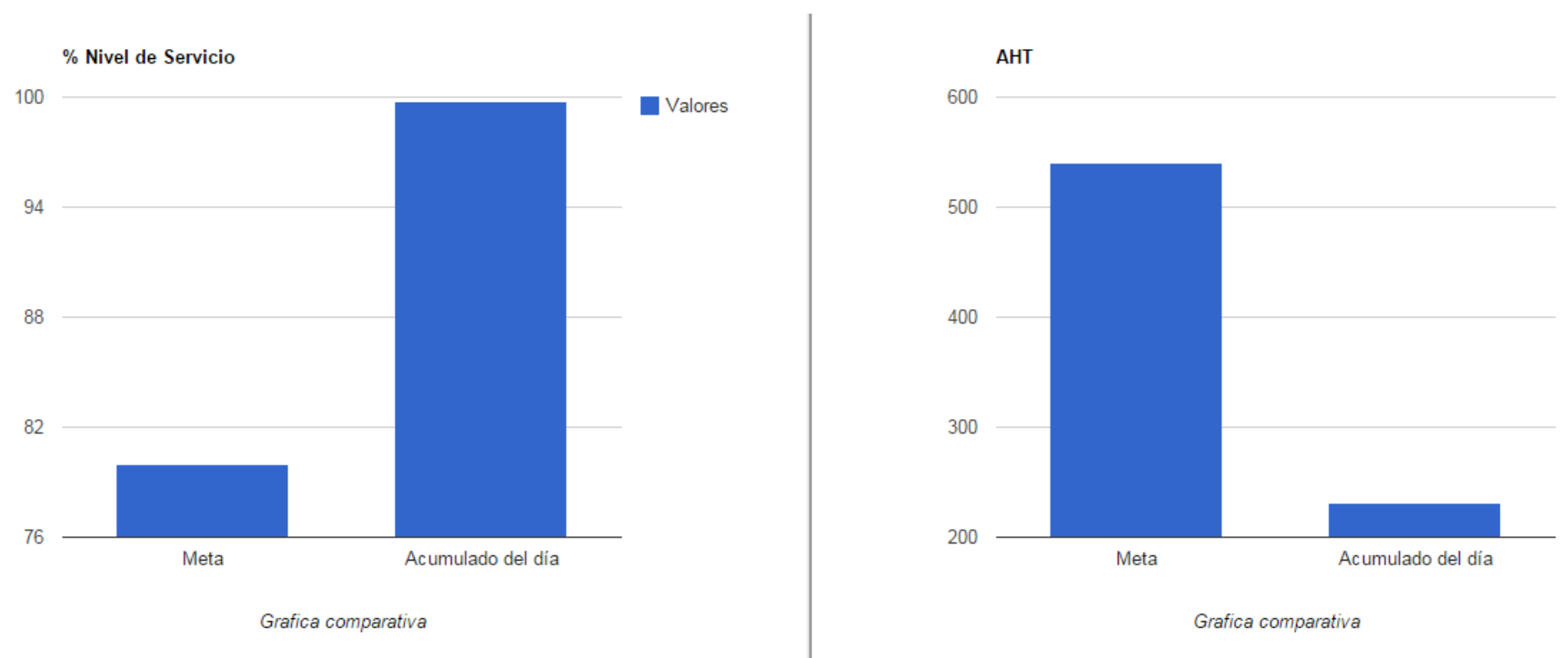

Figura 59. Gráficas comparativas acumulados del día

Finalmente, se crea un refresco automático del aplicativo cada 10 minutos, así cuando las tablas de la base de datos se actualicen, en el aplicativo se podrá visualizar la información actualizada sin necesidad de refrescar la página. 


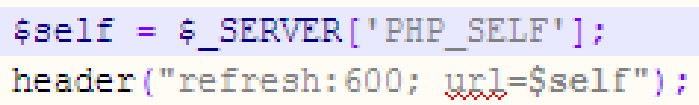

Figura 60. Refresco automático

El aplicativo web completo se puede observar en el Anexo 5 


\section{CONCLUSIONES}

1. Con el diseño del aplicativo web para dar a conocer los indicadores de gestión, se dio una solución innovadora que no acarrea ningún costo adicional a la empresa, en el cual se aprovecharon las tecnologías de la información, herramientas y equipos que la empresa posee.

2. El uso del aplicativo web es muy sencillo, solo es necesario escribir en el navegador web la dirección URL completa y de esa forma, se puede tener acceso al aplicativo, sin necesidad de actualizarla cada determinado para poder ver la información actualizada ya que el aplicativo se actualiza automáticamente cada 10 minutos.

3. El supervisor de la campaña, ya no necesita interrumpir sus actividades para poder generar los indicadores de gestión, y tampoco necesita compartir esta información en el tablero en el cual se escribía anteriormente los indicadores, todos los usuarios pueden acceder a la información desde su puesto de trabajo.

4. La formación recibida en la Universidad Santo Tomás, me permitió poder detectar la problemática que se presentaba en la campaña SIC y brindar una solución que permite que todos los miembros tengan acceso fácil y confiable a la información sobre el estado de la línea y así, tomar decisiones en conjunto bajo las órdenes del supervisor, que permitan brindarle un mejor servicio a los usuarios de la línea de atención al ciudadano de la Superintendencia de Industria y Comercio. 


\section{BIBLIOGRAFÍA}

Alegsa, Leandro. 2010. ALESGA. [En línea] 10 de 08 de 2010. [Citado el: 04 de 02 de 2015.] http://www.alegsa.com.ar/Dic/aplicacion\%20web.php.

Cáceres, Paloma y Marcos, Esperanza. 2001. Procesos ágiles para el desarrollo de aplicaciones Web. Madrid : s.n., 2001. 28933.

EMTELCO S.A. Emtelco.com.co. [En línea] [Citado el: 04 de 02 de 2015.] http://www.emtelco.com.co/index.php?option=com_k2\&view=item\&layout=item\&id $=37 \&$ ltemid $=31$ \&lang $=$ es .

Ing. Mora G., Luis Aníbal. 2014. Universidad Nacional Abierta y a Distancia. [En línea] 13 de 06 de 2014. [Citado el: 11 de 02 de 2015.]

http://datateca.unad.edu.co/contenidos/242005/Archivos_2014_2/unidad_tres/INDI CADORES_DE_GESTION_LOGISTICO.pdf.

Peña, Alejandro. Ministerio de Hacienda Costa Rica. [En línea] http://www.hacienda.go.cr/cifh/sidovih/spaw2/uploads/images/file/Tecnologias\%20 de\%20la\%20informacion.pdf>.

Perez, Gonzalo. 2004. degerencia.com. [En línea] 16 de 03 de 2004. [Citado el: 04 de 02 de 2015.]

http://www.degerencia.com/articulo/por_que_medir_y_para_que.

SILVA, Darío y MERCERAT, Bárbara. 2002. Universidad Autónoma de Bucaramanga. [En línea] 29 de 01 de 2002. [Citado el: 11 de 02 de 2015.] http://www.unab.edu.co/editorialunab/revistas/rcc/pdfs/r22_art5_c.pdf.

Stokford, Paul y Staples, Joe. 2013. Interactive Intelligence. [En línea] 2013. [Citado el: 04 de 02 de 2015.] http://www.inin.com/LatinAmericaes/Resources/Los-indicadores-del-Contact-Center-que-S\%C3\%AD-importan.pdf..

Universidad Santo Tomás. electronica.usta.edu.co. [En línea] [Citado el: 24 de 02 de 2015.] http://electronica.usta.edu.co/index.php/home-facultadelectronica/perfil-profesional.

TORRES, CRISTIAN ROJAS. 2014. INDICADORES DE GESTIÓN. 2014. 
13. ANEXOS

Anexo 1: Administración del proyecto

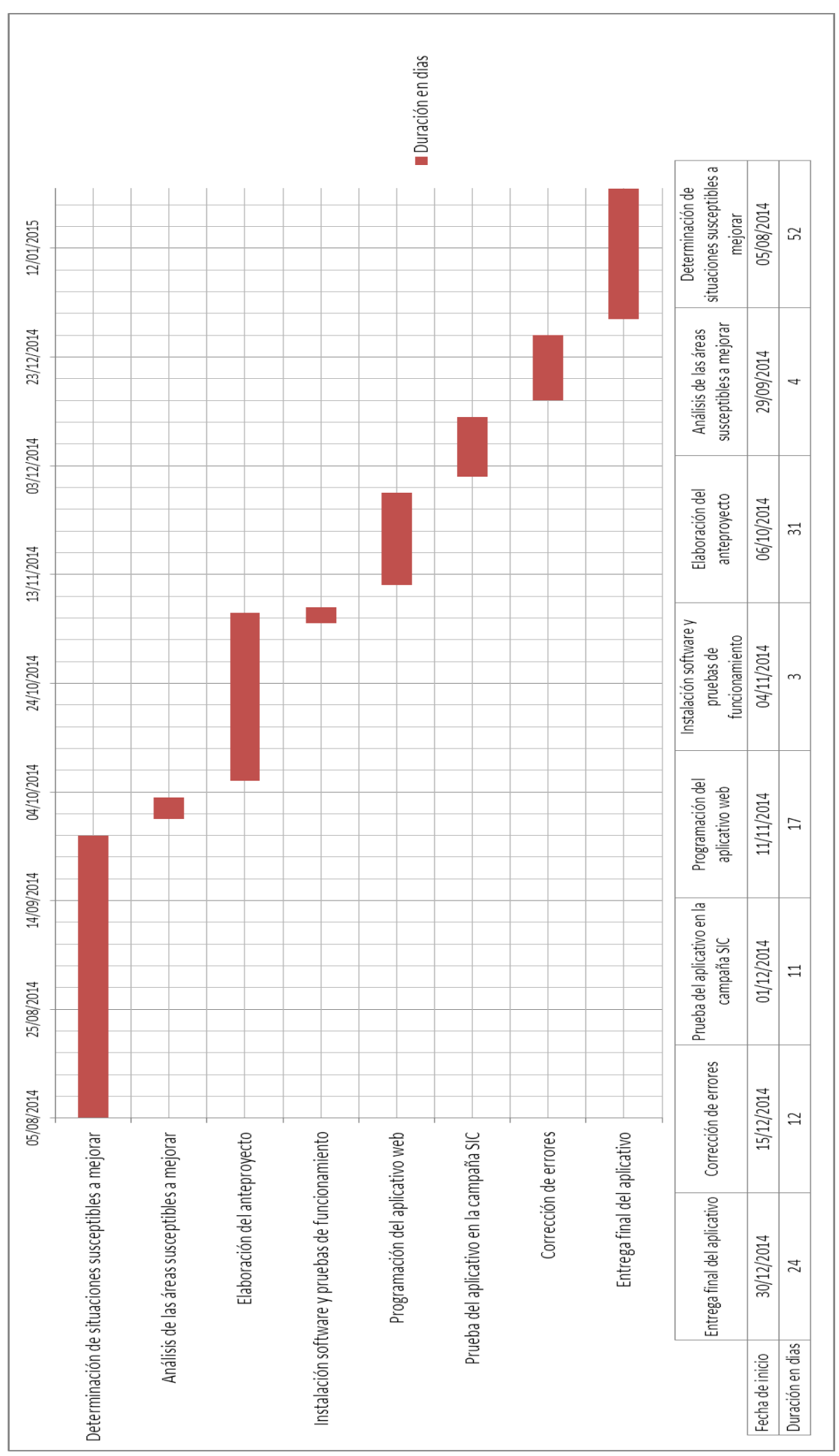




\section{Anexo 2: Instalación paquete XAMPP}

1. Se realizó la descarga del instalador del paquete XAMPP Windows, de la dirección: <URL: https://www.apachefriends.org/es/download.html>

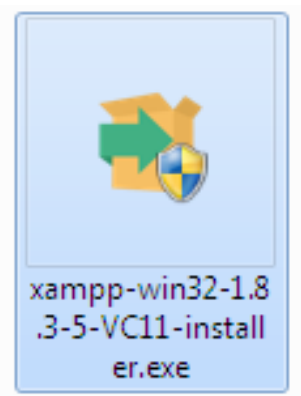

Figura 61. Instalador descargado

2. Una vez descargado el instalador, se procede con la instalación

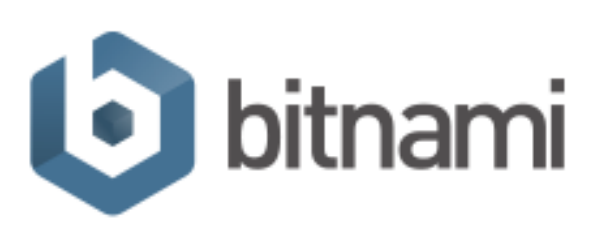

Figura 62. Proceso de instalación 


\section{Click en next}

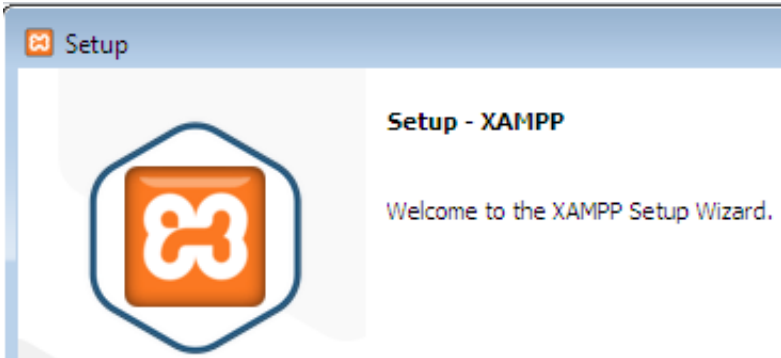

10 bitnami

Figura 63. Proceso de instalación

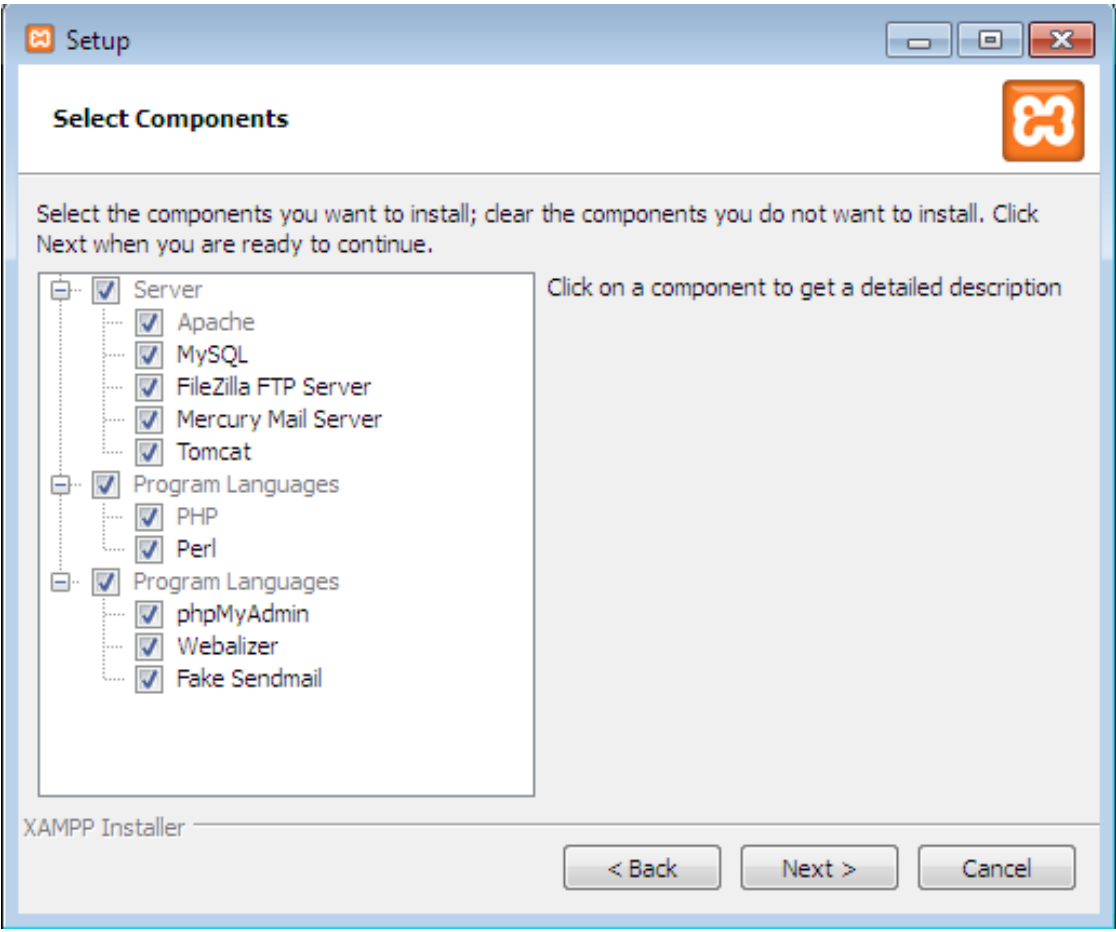


Figura 64. Proceso de instalación

Se selecciona la ubicación donde se instalará XAMPP y click en next

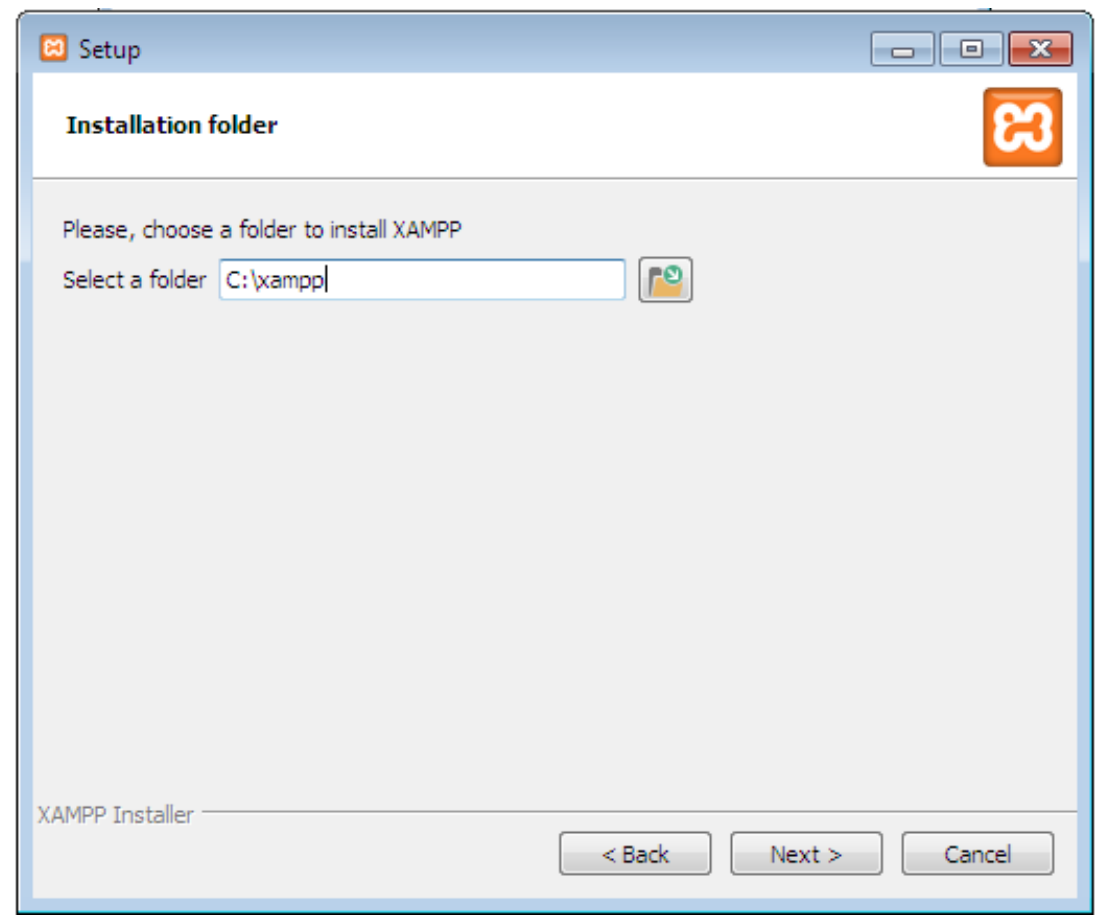

Figura 65. Proceso de instalación

Se selecciona si se desea o no acceder a la página web de Biitnami, y se da click en next. 


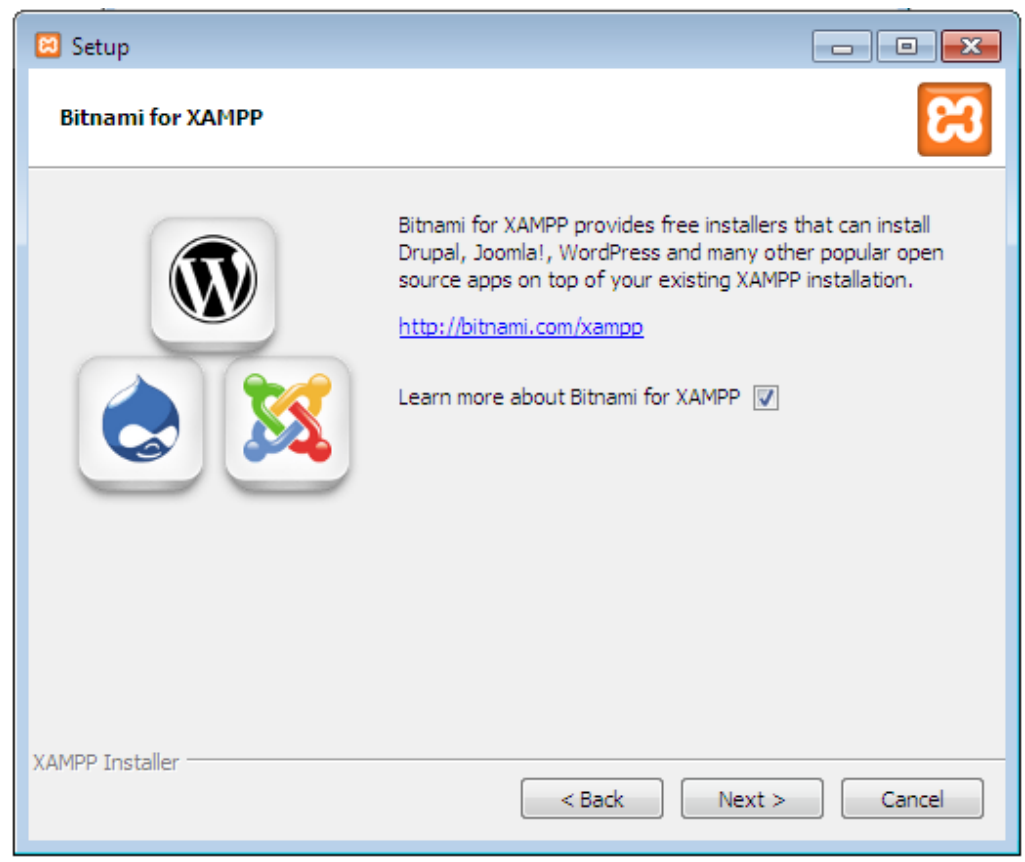

Figura 66. Proceso de instalación

Se da click en next e iniciara el proceso de instalación.

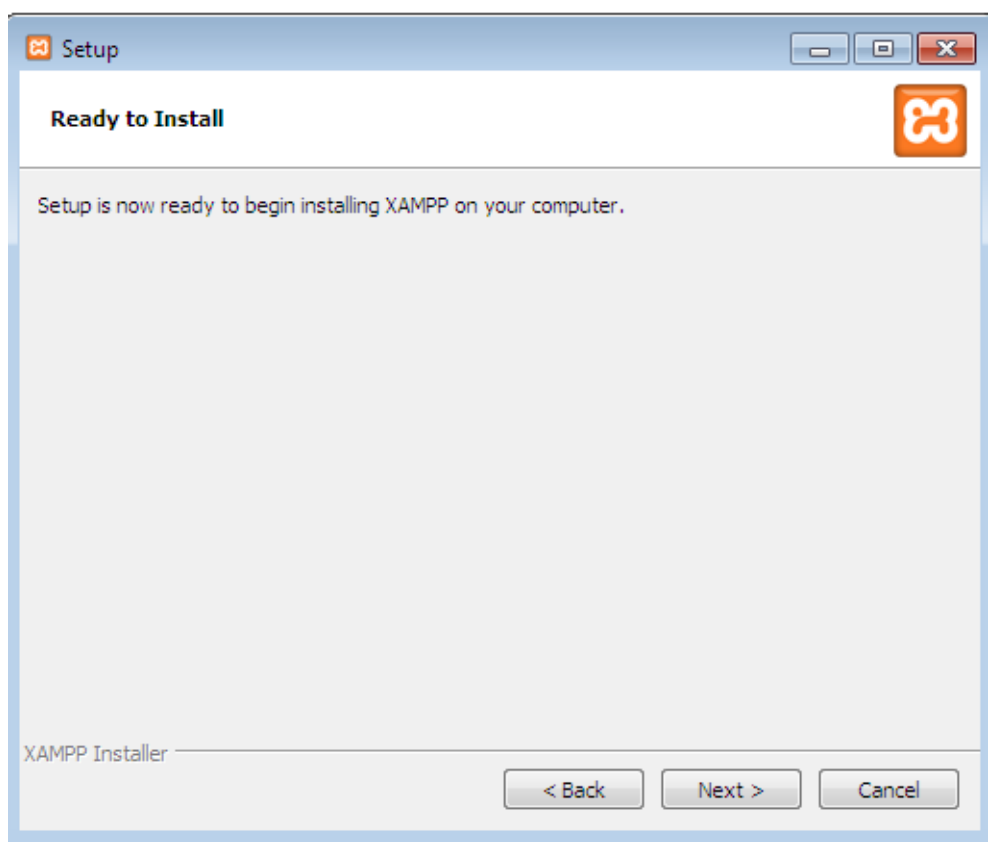

Figura 67. Proceso de instalación 
Al finalizar la instalación se crea un acceso directo en el escritorio, con el cual se puede acceder al panel de control de paquete XAMPP

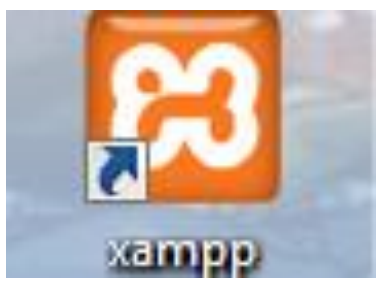

Figura 68. Acceso directo paquete XAMPP 


\section{Anexo 3: Instalación Notepad++}

1. Se realiza la descarga del instalador del software en la dirección <URL: http://notepad-plus-plus.org/download/v6.7.4.html>

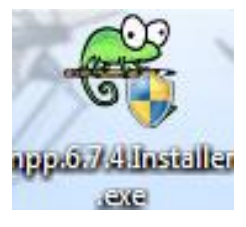

Figura 69. Instalador del software

2. Se ejecuta el instalador del programa

Se elige el idioma de preferencia y click en OK

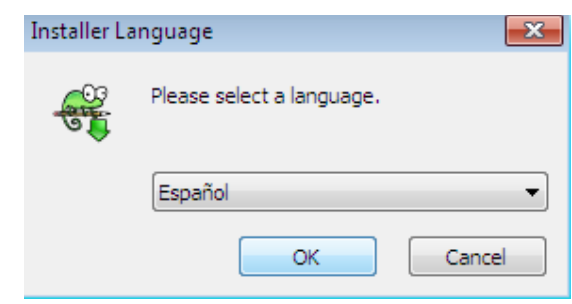

Figura 70. Proceso de instalación

Click en siguiente

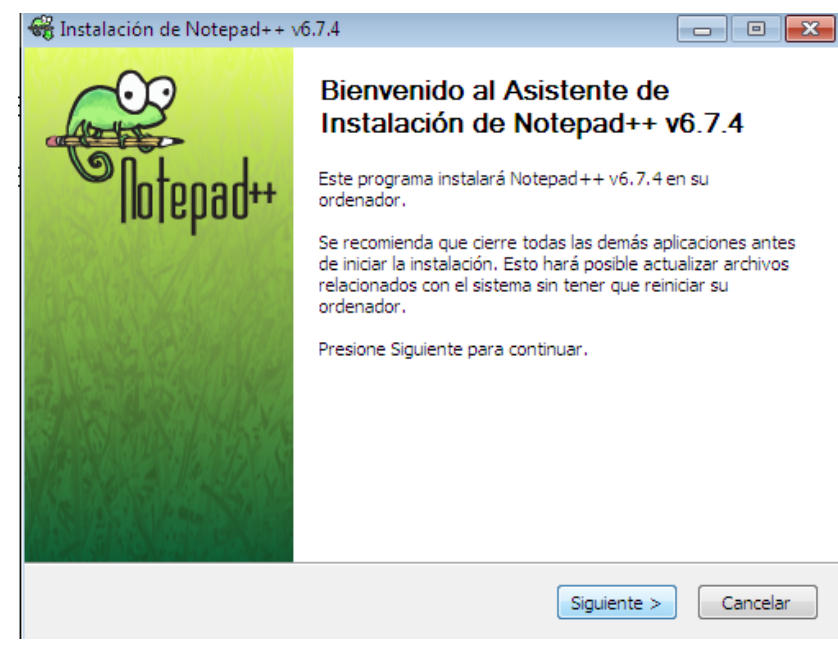

Figura 71. Proceso de instalación 


\section{Aceptamos los términos de licencia}

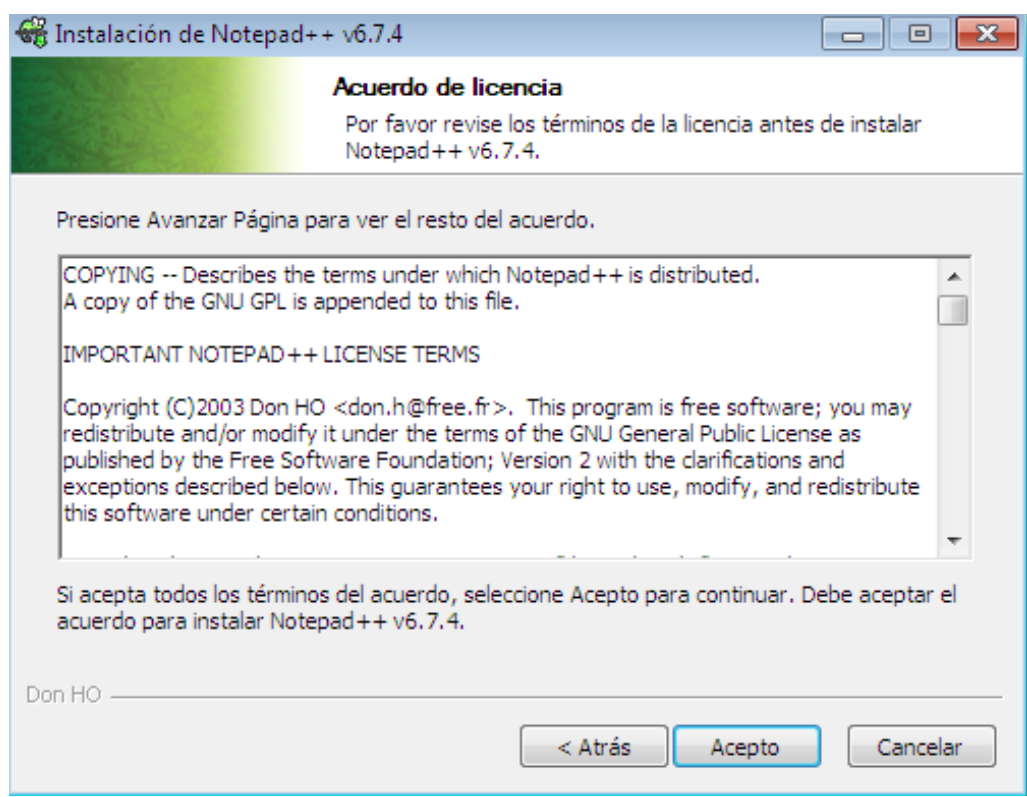

Figura 72. Proceso de instalación

\section{Seleccionamos la ruta donde se desea instalar el software}

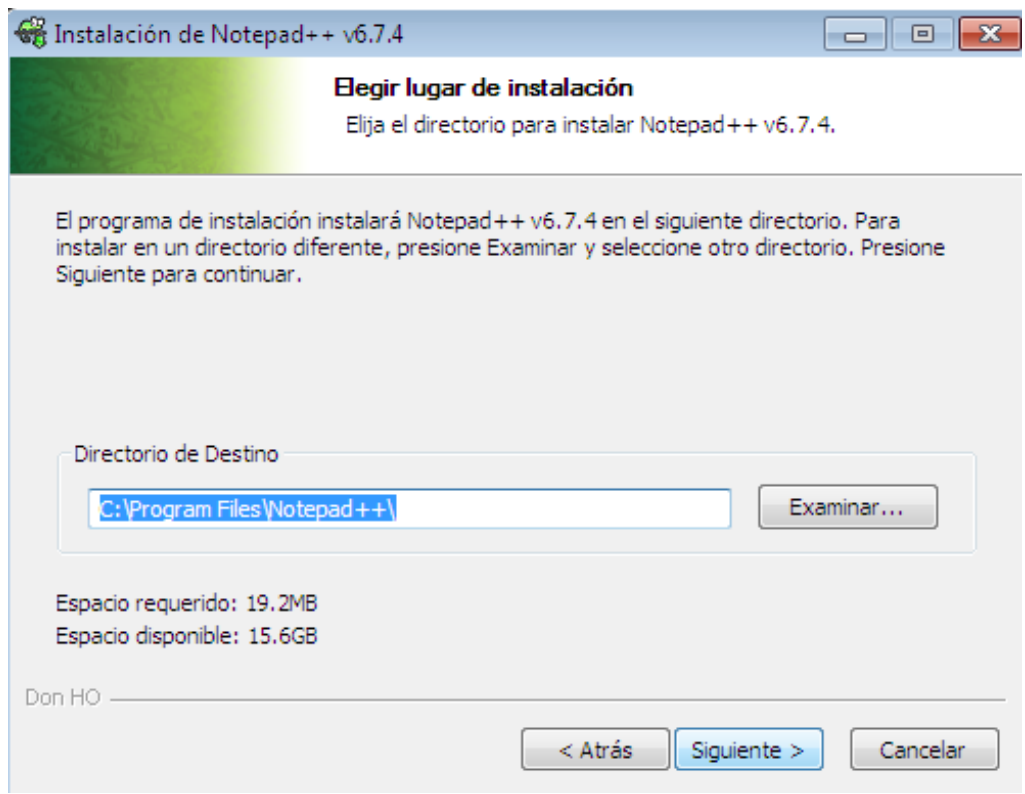

Figura 73. Proceso de instalación 
A continuación, inicia el proceso de instalación

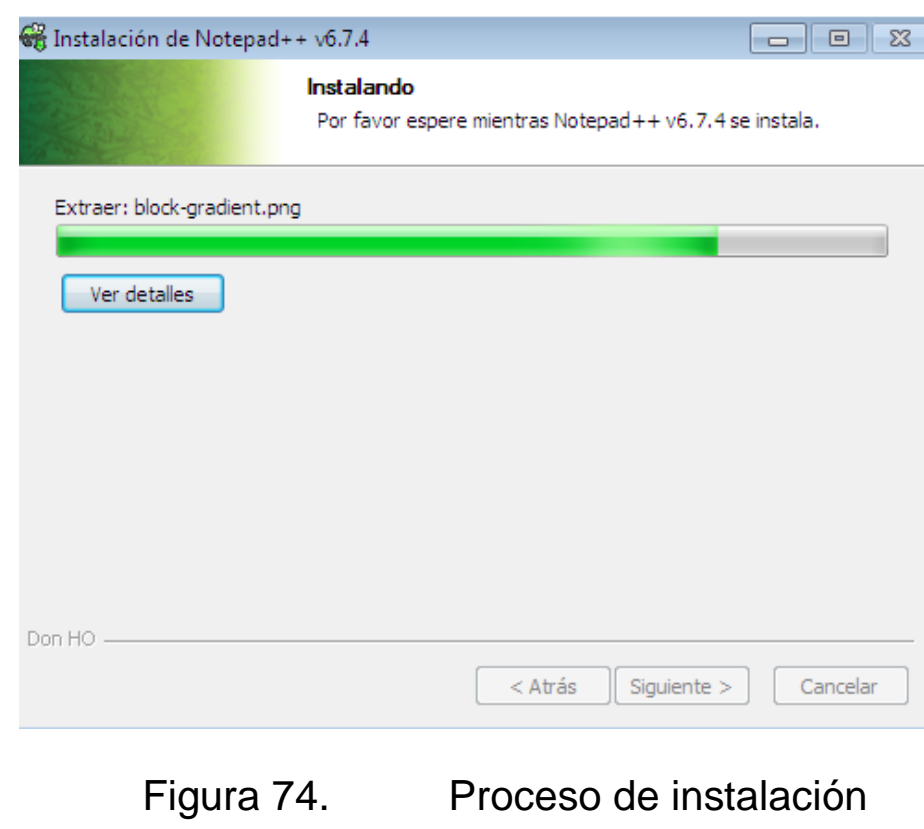

Una vez terminado el proceso, seleccionamos si se quiere que se ejecute el programa y click en terminar.

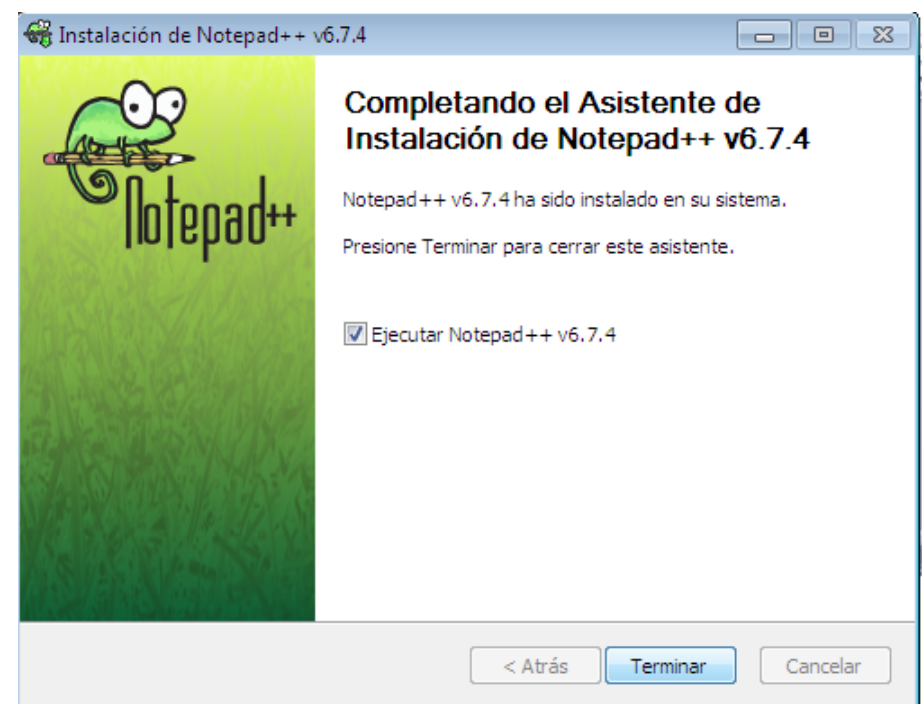

Figura 75. Finalización del proceso de instalación 


\section{Anexo 4: Generación manual de los indicadores de gestión}

Para poder generar los indicadores de gestión de forma manual, se debe realizar el siguiente procedimiento.

1. Ingresar al aplicativo AVAYA CMS

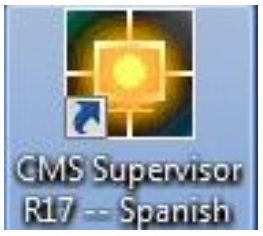

Figura 76. Acceso directo al aplicativo

2. Ingresar las credenciales de acceso al aplicativo y esperar que la conexión con el servidor sea exitosa

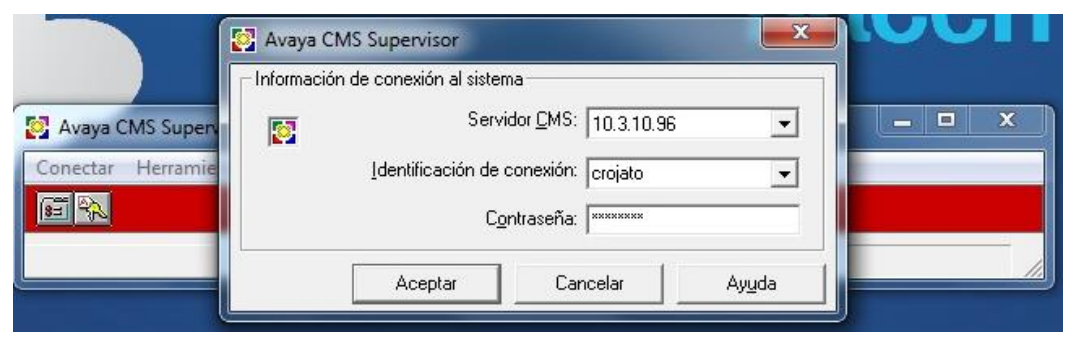

Figura 77. Acceso al aplicativo

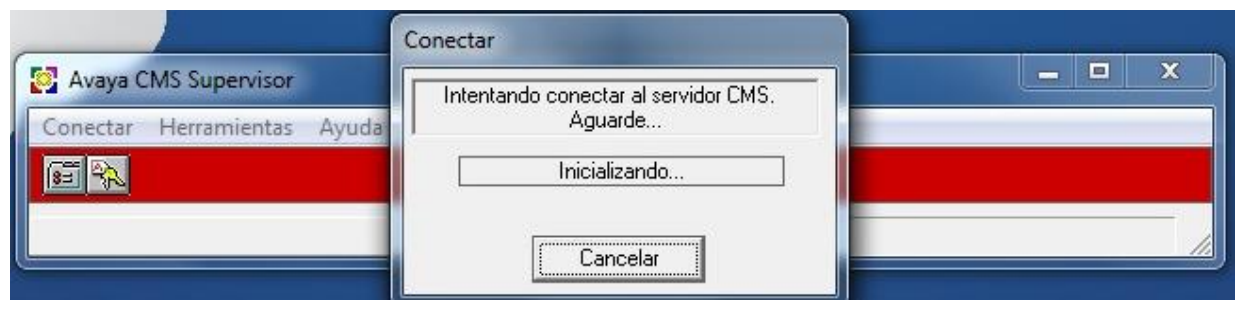

Figura 78. Conexión con el servidor CMS 
3. Una vez en el sistema, seleccionar la pestaña de comandos e ingresar en la opción de reportes.

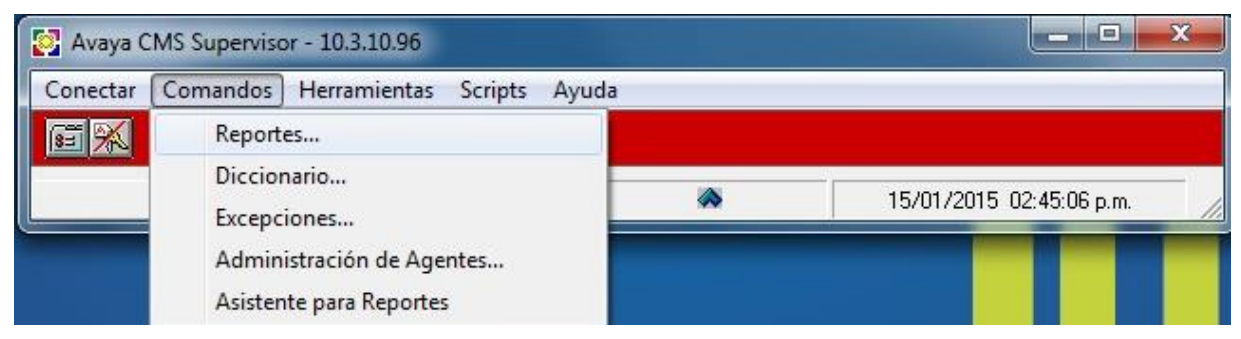

Figura 79. Ingreso a la creación de reportes

4. Se debe seleccionar que tipo de reporte se desea generar, para lo cual se selecciona la pestaña de histórico, la categoría diseñador y se selecciona el reporte indicadores de gestión - total entrantes.

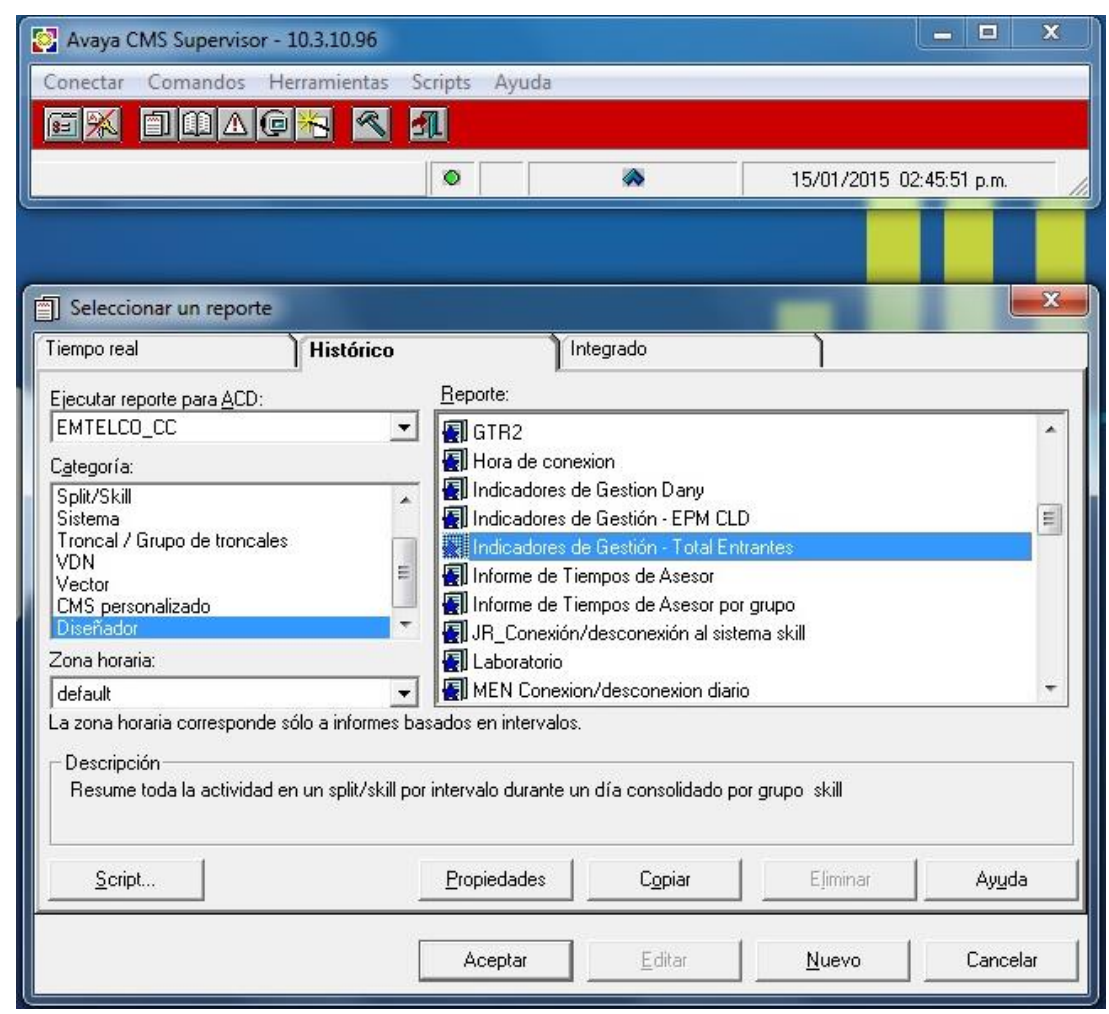

Figura 80. Selección del reporte a generar 
5. Al seleccionar el reporte a generar se debe seleccionar el skill, que en caso de la campaña SIC es 641 , la fecha en la que se desea crear el reporte y el intervalo de hora.

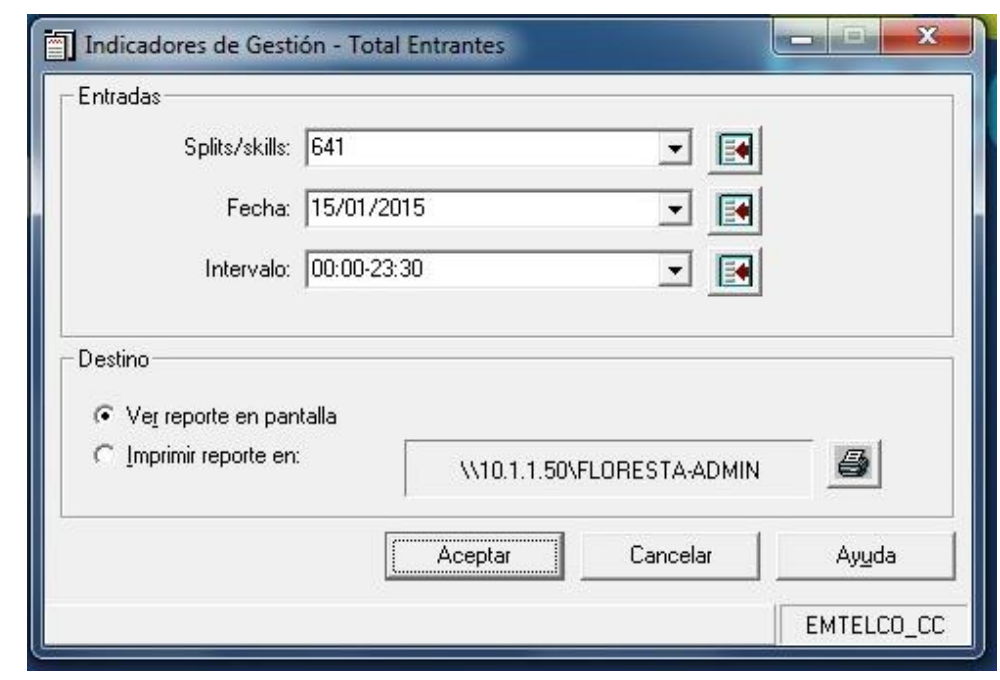

Figura 81. Selección de entradas

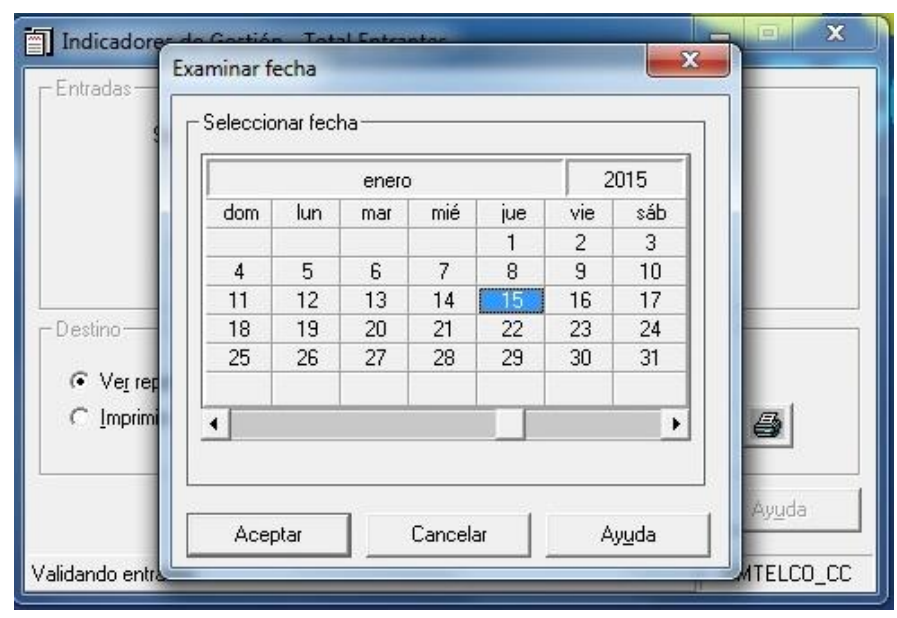

Figura 82. Selección de fecha a generar el reporte

6. Al realizar el anterior procedimiento, se obtendrá el reporte de los indicadores de gestión en pantalla de la fecha e intervalo de hora seleccionados. 
EMTELCO S.A.

Indicadores de Gestión Consolidado por Intervalo

Fecha: 15/01/2015

Split/Skill: SIG SAC

\begin{tabular}{|c|c|c|c|c|c|c|c|c|c|c|c|c|c|}
\hline Hora & $\begin{array}{l}\text { Llamadas } \\
\text { Entrantes }\end{array}$ & $\begin{array}{c}\text { Llamadas } \\
\text { Contestadas }\end{array}$ & $\begin{array}{c}\text { Llamadas } \\
\text { Abandonadas }\end{array}$ & $\begin{array}{c}\% \\
\text { Abandono }\end{array}$ & $\begin{array}{c}\% \\
\text { Eficacia }\end{array}$ & $\%$ NS & $\begin{array}{c}\text { Tiempo } \\
\text { prom. de ACD }\end{array}$ & $\begin{array}{c}\text { Tiempo } \\
\text { Prom } \\
\text { ACW } \\
\text { Seg } \\
\end{array}$ & $\begin{array}{c}\text { Promedio } \\
\text { Agentes }\end{array}$ & \begin{tabular}{|c|} 
Tiempo \\
Total ACD \\
Seg
\end{tabular} & \begin{tabular}{c|}
$\%$ \\
Ocupacion
\end{tabular} & $\begin{array}{c}\text { Llamadas } \\
\text { Entrantes } \\
\text { Totales }\end{array}$ & $\begin{array}{c}\text { Llamadas } \\
\text { Abandonadas } \\
\text { Totales }\end{array}$ \\
\hline 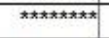 & 899 & 897 & 2 & ,22 & 99,78 & 96,00 & 242 & 0 & & 398221 & 54,991 & 902 & 5 \\
\hline $6: 30$ a.m. & 0 & 0 & 0 & & & & & 0 & 1 & 0 & & 0 & 0 \\
\hline 7:00 a.m. & 2 & 2 & 0 &, 00 & 100,00 & 100,00 & 185 & 0 & 8 & 14239 & 2,598 & 2 & 0 \\
\hline 7:30 a.m. & 11 & 11 & 0 &, 00 & 100,00 & 90,91 & 246 & 0 & 10 & 16688 & 20,338 & 11 & 0 \\
\hline 8:00 a.m. & 38 & 38 & 0 &, 00 & 100,00 & 100,00 & 224 & 0 & 13 & 20489 & 45,846 & 38 & 0 \\
\hline 9:00 a.m. & 96 & 94 & 2 & 2,08 & 97,92 & 85,42 & 233 & 0 & 16 & 27019 & 81,405 & 96 & 2 \\
\hline 9:30 a.m. & 85 & 85 & 0 &, 00 & 100,00 & 95,29 & 244 & 0 & 17 & 27518 & 76,642 & 85 & 0 \\
\hline 10:00 a.m. & 101 & 101 & 0 &, 00 & 100,00 & 88,12 & 228 & 0 & 19 & 34463 & 65,509 & 102 & 1 \\
\hline $10: 30$ a.m. & 93 & 93 & 0 &, 00 & 100,00 & 97,85 & 268 & 0 & 19 & 32424 & 77,993 & 94 & 1 \\
\hline 11:00 a.m. & 82 & 82 & 0 &, 00 & 100,00 & 100,00 & 232 & 0 & 20 & 32416 & 61,318 & 82 & 0 \\
\hline $11: 30$ a.m. & 74 & 74 & 0 & .00 & 100,00 & 100,00 & 255 & 0 & 21 & 35755 & 53,190 & 74 & 0 \\
\hline $12: 00$ p.m. & 61 & 61 & 0 &, 00 & 100,00 & 100,00 & 298 & 0 & 17 & 33560 & 47,386 & 62 & 1 \\
\hline $12: 30$ p.m. & 41 & 41 & 0 &, 00 & 100,00 & 100,00 & 220 & 0 & 12 & 20903 & 44,126 & 41 & 0 \\
\hline $1: 30$ p.m. & 39 & 39 & 0 &, 00 & 100,00 & 100,00 & 236 & 0 & 15 & 24483 & 40,873 & 39 & 0 \\
\hline $2: 00$ p.m. & 50 & 50 & 0 &, 00 & 100,00 & 100,00 & 257 & 0 & 19 & 32963 & 38,231 & 50 & 0 \\
\hline
\end{tabular}

Figura 83. Reporte en pantalla 
Anexo 5: Aplicativo web completo
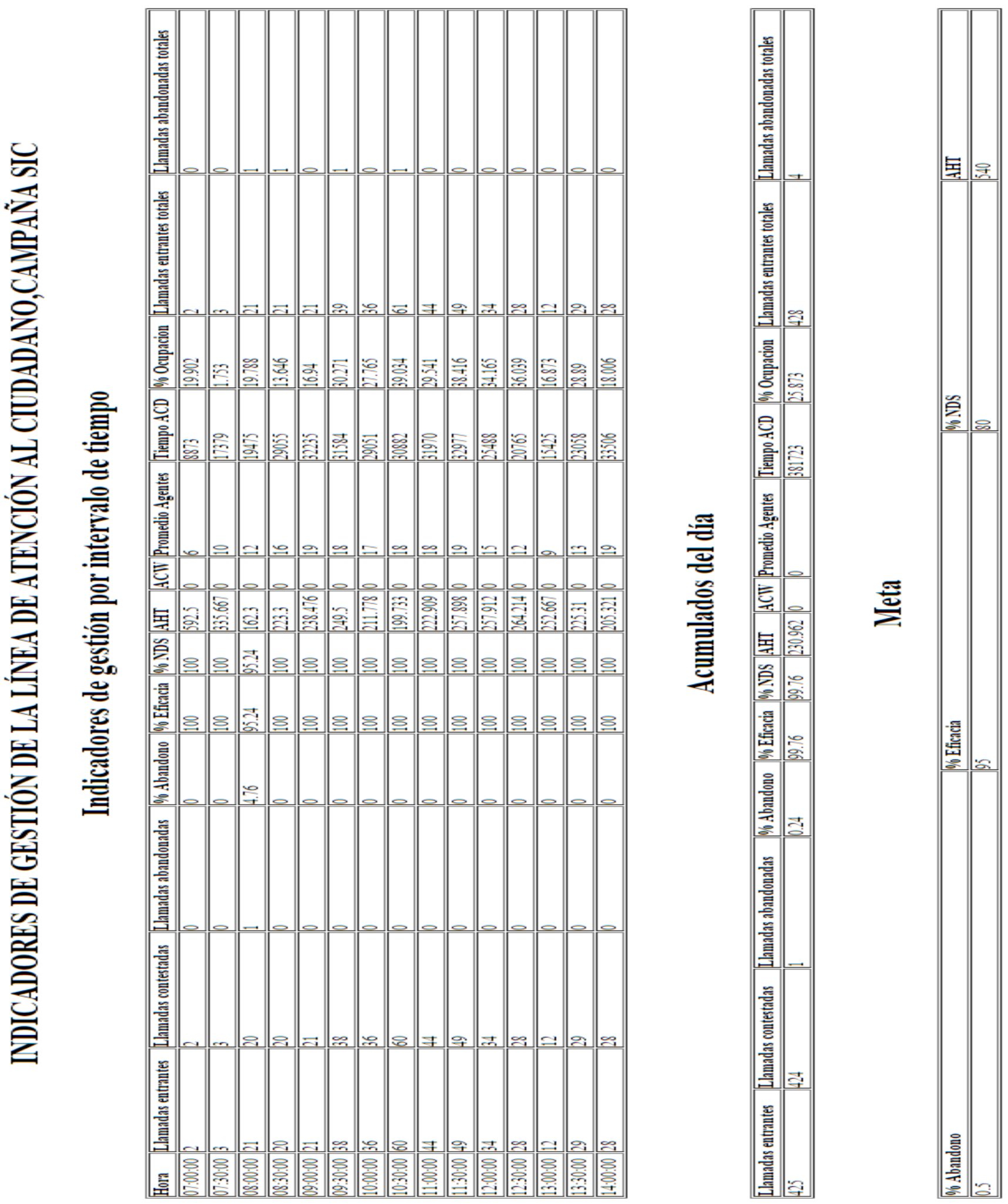


\section{Gráficas comparativas por intervalo de tiempo}

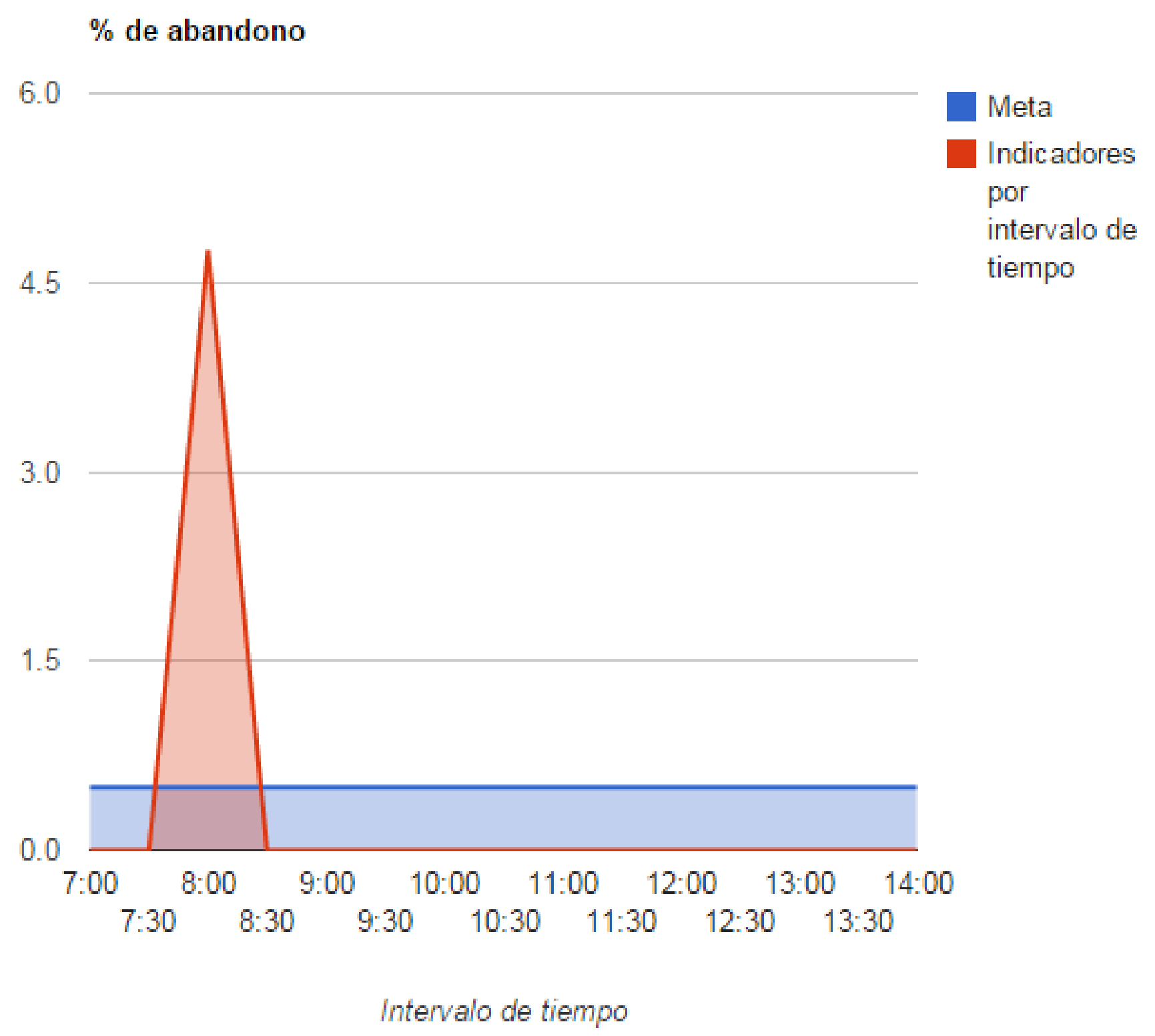


$\%$ de eficacia

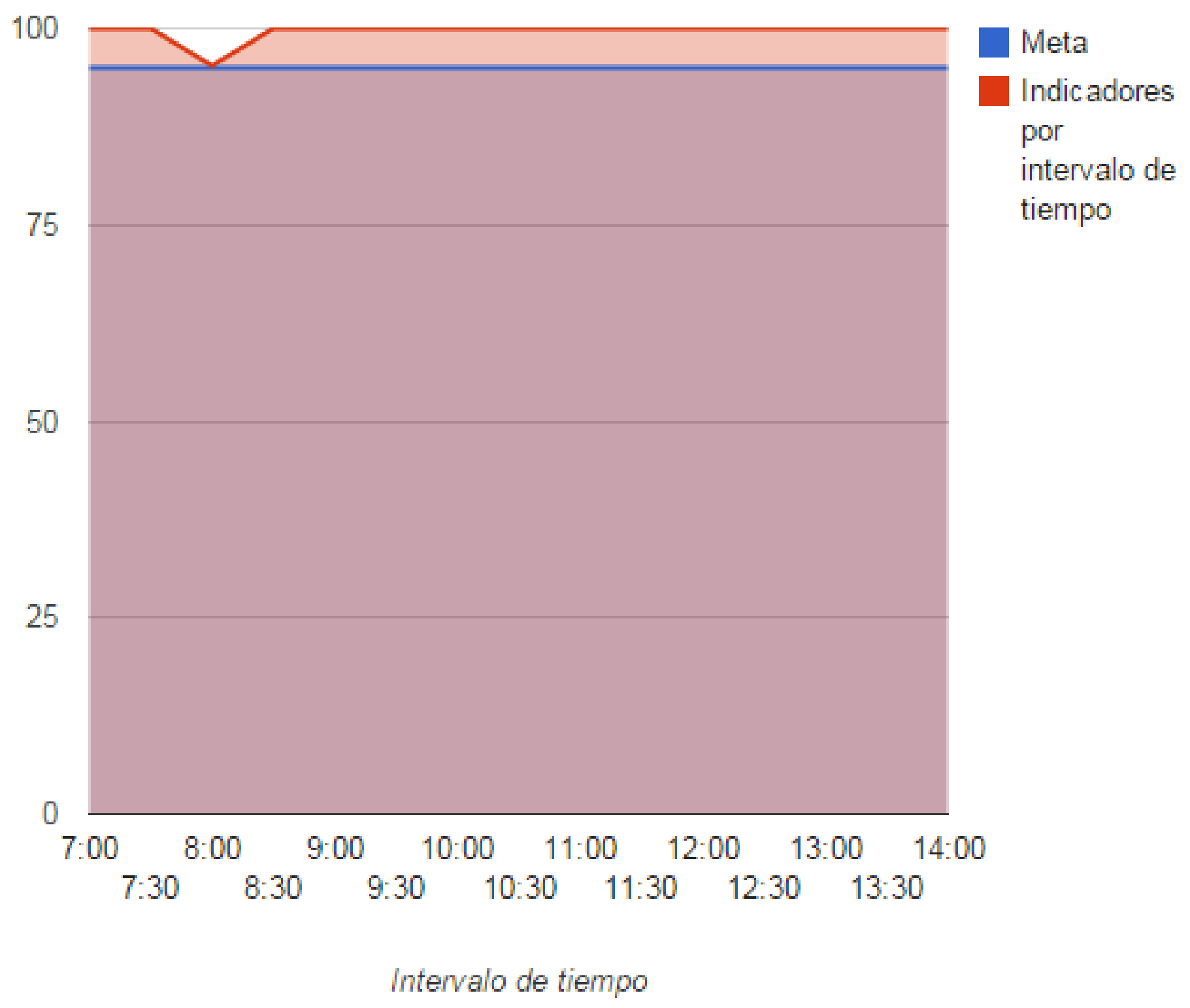




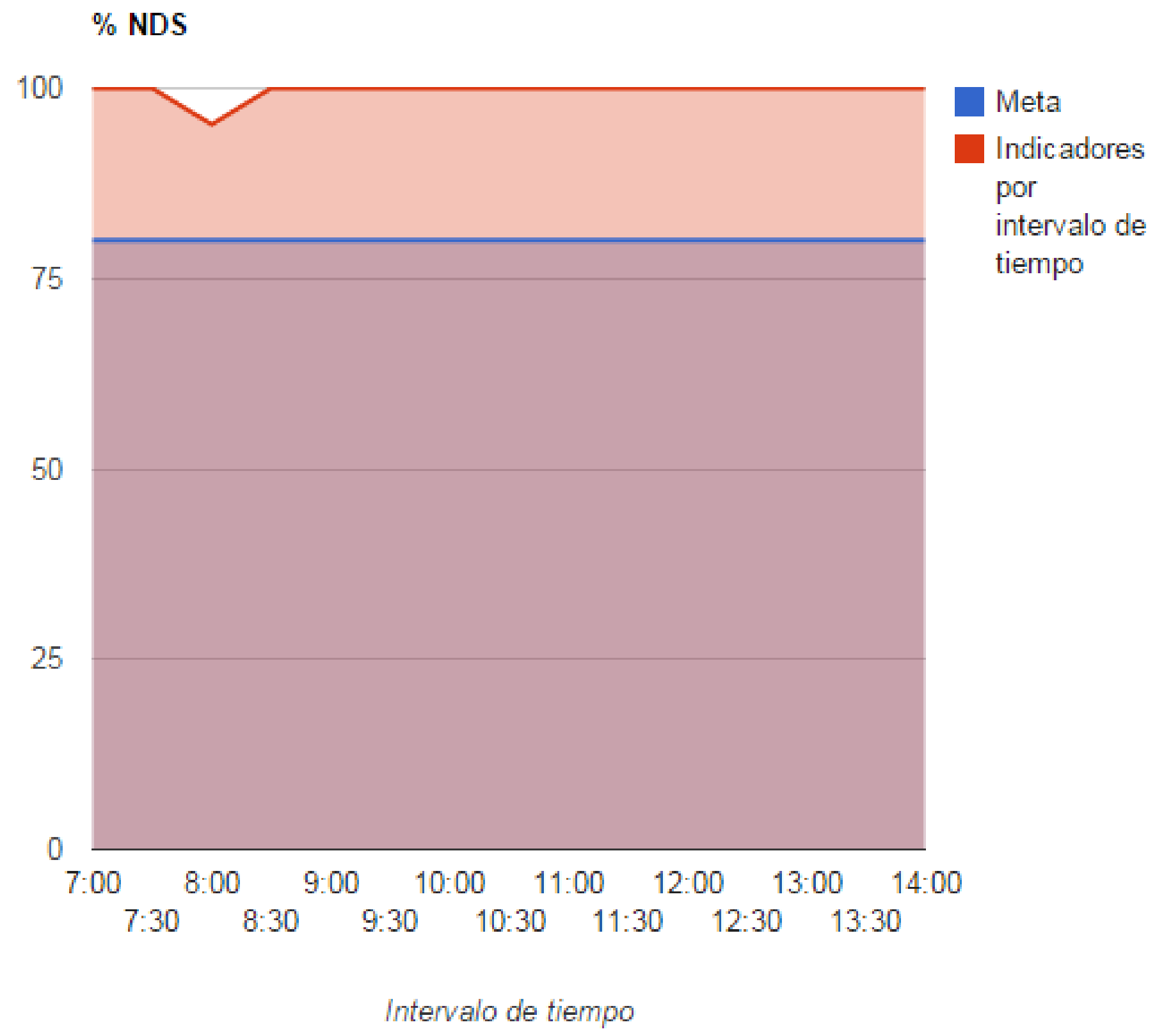




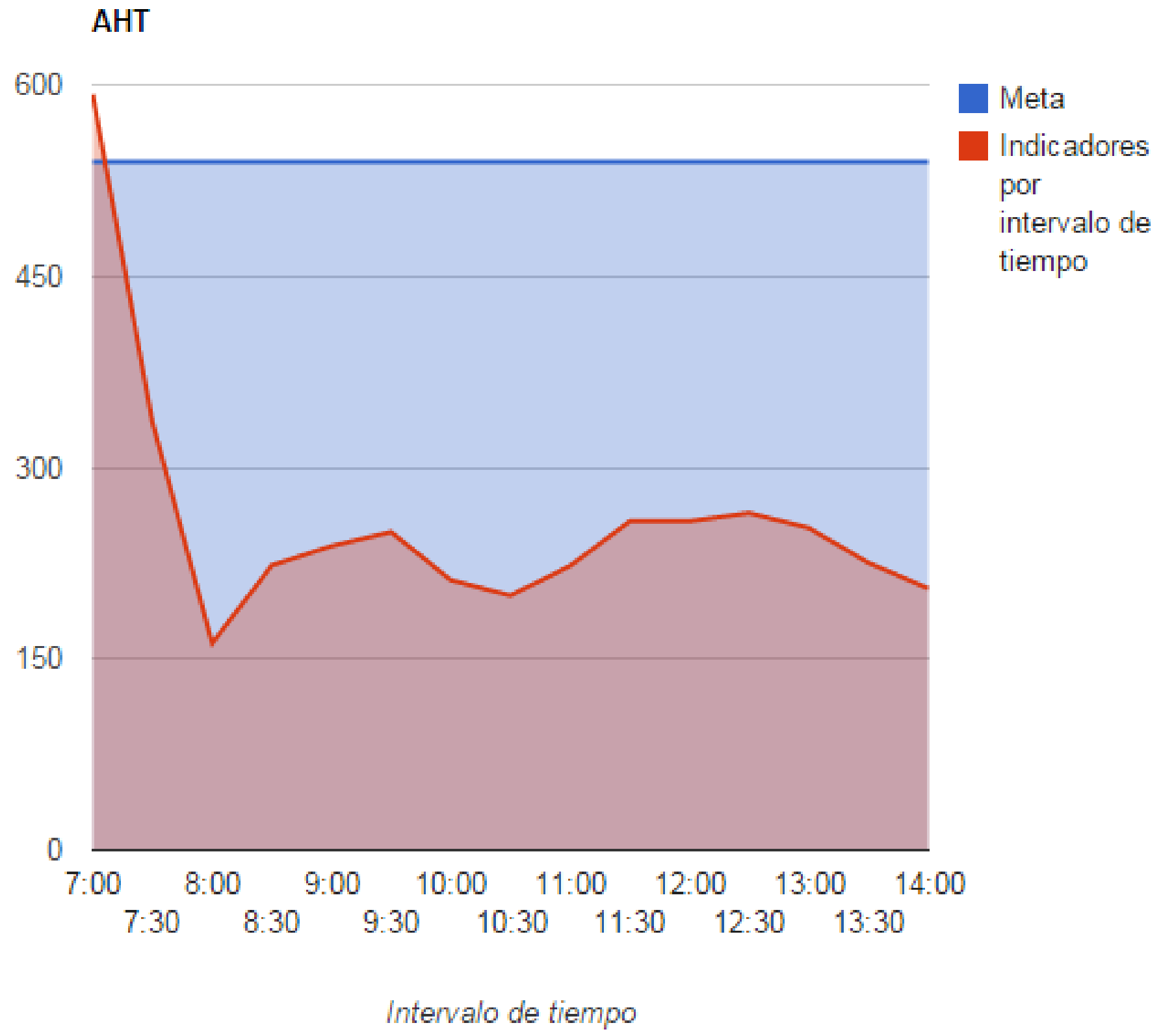




\section{Gráficas comparativas acumulados del día}

$\%$ de Eficacia

100.0

100.0

98.5

97.0

95.5

94.0

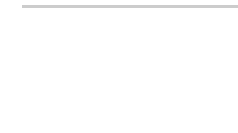

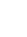


$\%$ de Abandono

0.6

Valores

0.5

0.4

0.3

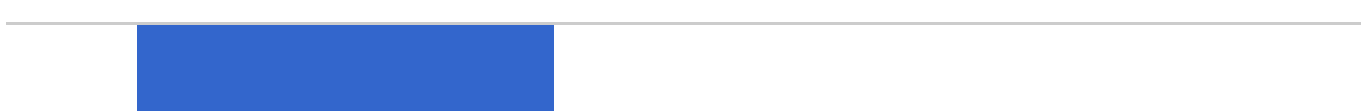

0.4

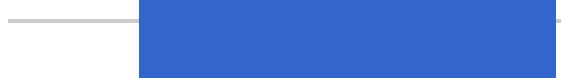

0.2

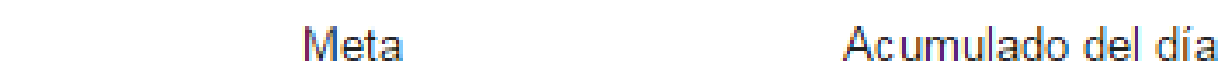

Gráfica comparativa 
$\%$ Nivel de Servicio

100

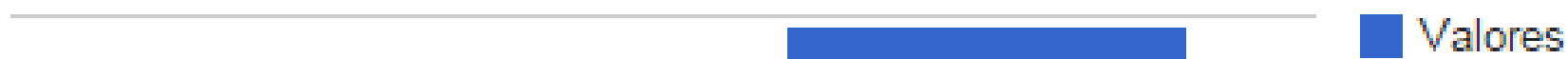

94

88

82

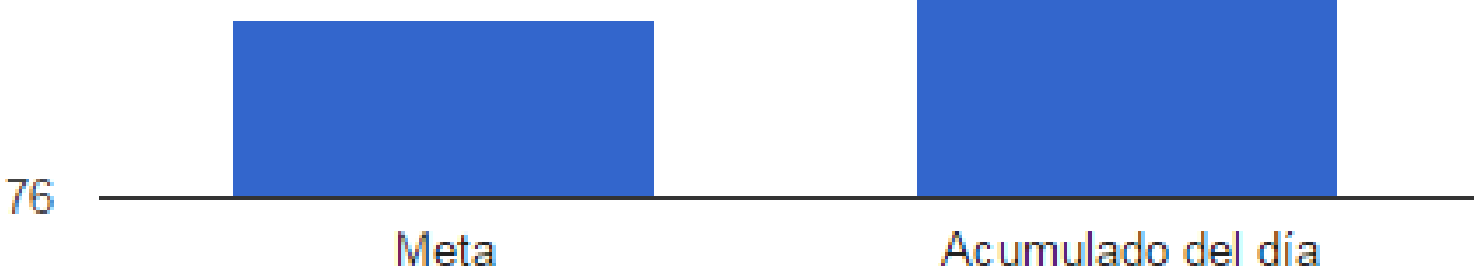

Gráfica comparativa 


\section{AHT}

600

Valores

500

400

300
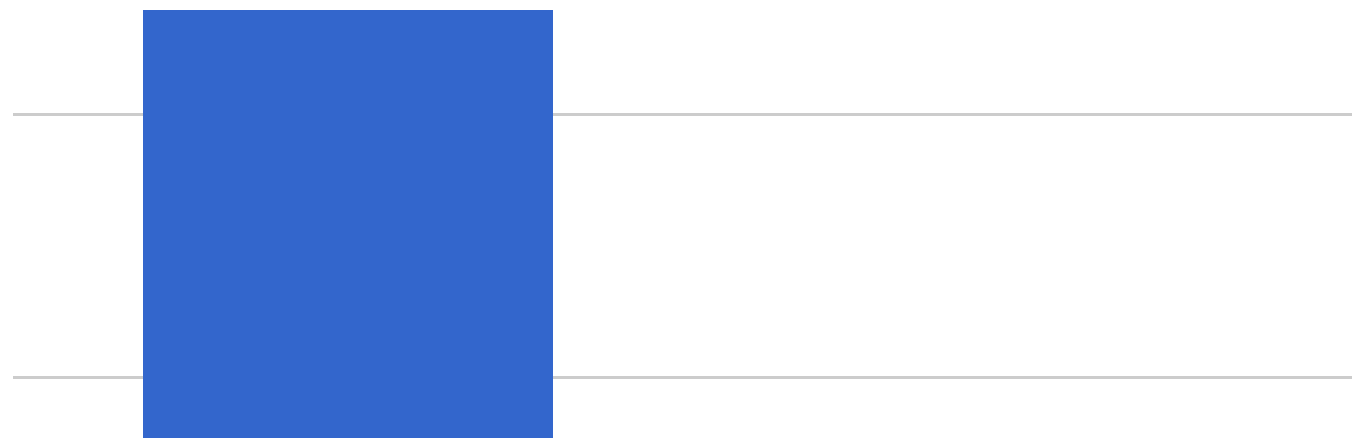

200

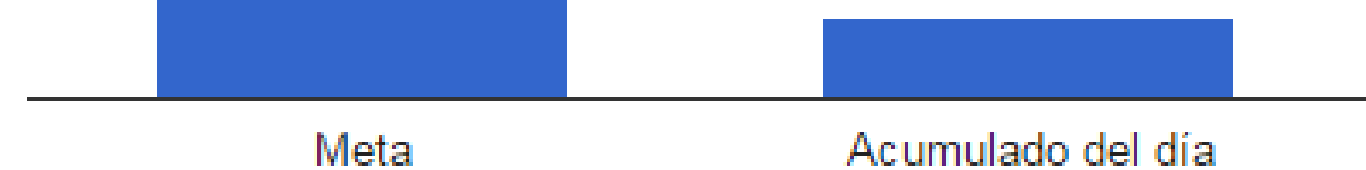

Gráfica comparativa 